\title{
Correlations between haemostasis parameters and several cardiovascular risk factors in man
}

Citation for published version (APA):

Donders, S. H. J. (1992). Correlations between haemostasis parameters and several cardiovascular risk factors in man. [Doctoral Thesis, Maastricht University]. Rijksuniversiteit Limburg. https://doi.org/10.26481/dis.19920605sd

Document status and date:

Published: 01/01/1992

DOI:

10.26481/dis.19920605sd

Document Version:

Publisher's PDF, also known as Version of record

\section{Please check the document version of this publication:}

- A submitted manuscript is the version of the article upon submission and before peer-review. There can be important differences between the submitted version and the official published version of record.

People interested in the research are advised to contact the author for the final version of the publication, or visit the DOI to the publisher's website.

- The final author version and the galley proof are versions of the publication after peer review.

- The final published version features the final layout of the paper including the volume, issue and page numbers.

Link to publication

\footnotetext{
General rights rights.

- You may freely distribute the URL identifying the publication in the public portal. please follow below link for the End User Agreement:

www.umlib.nl/taverne-license

Take down policy

If you believe that this document breaches copyright please contact us at:

repository@maastrichtuniversity.nl

providing details and we will investigate your claim.
}

Copyright and moral rights for the publications made accessible in the public portal are retained by the authors and/or other copyright owners and it is a condition of accessing publications that users recognise and abide by the legal requirements associated with these

- Users may download and print one copy of any publication from the public portal for the purpose of private study or research.

- You may not further distribute the material or use it for any profit-making activity or commercial gain

If the publication is distributed under the terms of Article $25 \mathrm{fa}$ of the Dutch Copyright Act, indicated by the "Taverne" license above, 


\title{
Correlations between haemostasis parameters and several cardiovascular risk factors in man
}

\section{Proefschrift}

\author{
ter verkrijging van de graad van doctor \\ aan de Rijksuniversiteit Limburg te Maastricht, \\ op gezag van de Rector Magnificus, Prof. mr. M.J. Cohen, \\ volgens het besluit van het College van Dekanen, \\ in het openbaar te verdedigen op \\ vrijdag 5 juni 1992 om 14.00 uur
}

door

Servaes Hubert Joan Donders 


\section{Promotores}

Prof. dr. P.J. Brombacher

Prof. dr. J.A. Flendrig

\section{Copromotor}

Dr. J.W.J. van Wersch

\section{Beoordelingscommissie}

prof. dr. H.C. Hemker (voorzitter)

prof. dr. J.P.M. Geraedts

prof. dr. H. Greiling (RWTH, Aken)

prof. dr. P.G. Knipschild

prof. dr. A.C. Nieuwenhuijzen Kruseman

Het in dit proefschrift beschreven onderzoek is mogelijk gemaakt door een royale subsidie van de Dr. Ir. J.H.J. van de Laar Stichting, Heerlen.

Het verschijnen van dit proefschrift werd mede mogelijk gemaakt door steun van de Nederlandse Hartstichting en van het De Wever-Ziekenhuis. Een financiële bijdrage in de publicatiekosten is ook geleverd door BYK Nederland BV, Sandoz BV, Novo Nordisk Farma BV en Zyma Nederland BV. 
Voor Ruth en de kinderen

Voor mijn ouders 



\section{Contents}

Introduction

\section{Chapter 1}

Lipoprotein(a): a hereditary risk factor for atherosclerotic disease

\section{Chapter 2}

On lipoprotein(a) and the coagulation/fibrinolysis balance in the acute phase of deep venous thrombosis

\section{Chapter 3}

Low order correlations of lipoprotein(a) with other blood lipids and with coagulation and fibrinolysis parameters in hypertensive and diabetic patients

\section{Chapter 4}

Haemostasis parameters and lipid composition of the blood in treated and untreated hypertensive patients

\section{Chapter 5}

Prothrombin fragment 1.2 in both treated and untreated hypertensive patients

\section{Chapter 6}

Interrelations of glycometabolic control, lipids, coagulation parameters and microalbuminuria in non-insulin-dependent diabetes mellitus

\section{Chapter 7}

Microalbuminuria in insulin-regulated diabetic patients: relationship to lipid, glycometabolic, coagulation and fibrinolysis parameters 
Chapter 8

113

Summary and conclusions

Chapter 9

119

Samenvatting en conclusies

Dankwoord

125

Curriculum vitae 


\section{Introduction}

Hypertension, diabetes mellitus and lipid disorders are important modifiable risk factors for the development of atherosclerotic vascular disease and its sequelae. The combined presence of these factors greatly enhances the risk for cardiovascular complications. In the Framingham Study, for instance, persons with a systolic blood pressure of $195 \mathrm{mmHg}$ and normocholesterolaemia, compared with normotensive individuals, showed a doubled risk for cardiovascular disease, whereas the same systolic hypertension was associated with a six-fold increment in cardiovascular risk for hypercholesterolaemic patients (1). Diabetes mellitus has been reported to aggravate the risk for cardiovascular disease in hypertensive persons $(2)$ and in patients with hypercholesterolaemia $(3,4)$. The cardiovascular risk factors mentioned above have been associated with perturbations in haemostasis which themselves may play a role in atheroscierosis and its thrombotic complications.

In 1841 von Rokitansky suggested that thrombosis could contribute to the pathogenesis of plaque formation by intimal deposition of fibrin and other blood components. Nowadays numerous studies indicate that plaque formation depends to a certain extent on the organization and incorporation of mural thrombi $(5-8)$. Although there is little evidence that a thrombotic event initiates plaque formation, the layers of fibrin seen at many levels within atherosclerotic lesions suggest this mechanism to be involved in the further growth and progression of atherosclerotic plaques (8). This hypothesis is supported by the observation that in immunohistochemical studies platelet antigens were detected in advanced atherosclerotic plaques, but not in fatty streaks (7). Atherosclerotic lesions predispose to the formation of occlusive thrombi and hereby clinically overt cardiovascular complications. When fibrin formation does facilitate the development of atherosclerosis and its related complications, the balance between the activity of the coagulation and fibrinolysis systems might be of importance in this respect. And indeed, in studies concerning predominantly middle-aged white men procoagulant and hypofibrinolytic states have been associated with coronary heart disease.

In the Northwick Park Heart Study $(9,10)$ high levels of factor VII clotting activity and fibrinogen were associated with increased risk for coronary heart disease. The independent association between $F$ Vil and cardiovascular deaths was at least as strong as the association of serum cholesterol with such deaths (9). 
Dalaker et all. $(11,12)$ discovered that men at risk for coronary heart disease showed increased levels of F VII clotting activity due to a factor VII-phospholipid complex in their plasma. Factor Vilc and fibrinogen levels appeared to be related to the degree of atheroma in patients who survived myocardial infarction (13-16). Spontaneous platelet aggregation in vitro and an increased mean platelet volume (MPV) were reported to be related to reinfarction and mortality in patients with sustained myocardial infarction (17-19). Recently, numerous studies have shown a decreased fibrinolytic activity in patients with angina pectoris or myocardial infarction compared with healthy controls (20-25). The major mechanism for impaired fibrinolysis in patients with coronary heart disease is elevated plasminogen activator inhibitor-1 (PAl-1) activity in plasma, whereas a minor proportion of these patients demonstrate fibrinolytic impairment due to decreased release of tissue plasminogen activator ( $t-P A)$ after venous occlusion (21).

As stated above, in hypertension, diabetes mellitus and hyperlipidaemia various abnormalities in haemostasis have been described. However "the studies available are not unanimous in their conclusions and in some respects rather scanty.

In hypertensive patients, elevated levels of coagulation factors XII, XI, VIIIC, fibrinogen, fibrin monomers and thrombin-antithrombin III have been described (26-31), as have correlations between blood pressure and factors $X I I, X I$ and VIIIc $(27,29)$. Signs of increased platellet activation were indicated by elevated concentrations of beta-thromboglobulin and platelet factor $4(28,30)$ and by increased in vitro ADP-induced platelet aggregation (31). Impaired fibrinolysis in hypertension due to decreased tissue plasminogen activator activity and elevated plasminogen activator inhibitor-1 concentrations has also been reported (31-34).

In diabetic patients, elevated levels of fibrinogen, prothrombin and factor $\mathrm{V}$, VII, VIIII and $X(35$, review), increased platelet activation and aggregation $(35,36)$, malfunctioning tissue plasminogen activator (t-PA) (37), impaired plasminogen activation (38), increased PAI-1 concentrations (39) and poorly degradable fibrin (40) have all been described.

Hypertriglyceridaemia has been reported to be associated with elevated levels of prothrombin, fibrinogen, factors VII, VIIIC, IX, X, platelet hyperreactivity and with increased PAl-1 concentrations $(41-47)$, whereas hypercholesterolaemia has been associated with elevated levels of prothrombin and factor $X(41)$.

Diabetes mellitus, hypertension and hyperlipidaemia induce progressive impairment of the vascular endothelium that can activate the coagulation system by exposing negatively charged substances such as collagen, elastin and basement membrane. Subsequently, factor XII triggers the intrinsic coagulation pathway and hereby the formation of thrombin and fibrin. We have to consider that the alterations in haemostasis described in the disease states mentioned above might be secondary to atherosclerotic changes in the blood vessels. For instance, thrombin can be generated also by activation of the extrinsic pathway through tissue 
factor release after plaque rupture. However, beyond doubt abnormalities in haemostasis are associated with cardiovascular complications and, whether these abnormalities are primary or secondary phenomena, they might contribute to a further progression of atherosclerosis.

Recently developed assays for laboratory determinations of plasma concentrations of haemostasis parameters such as prothrombin fragment 1.2, fibrin monomers, thrombin-antithrombin III complex, tissue plasminogen activator (t-PA) antigen and activity, plasminogen activator inhibitor-1 (PAl-1) and D-dimers have delivered sensitive tools for monitoring the activity of the coagulation and fibrinolysis systems. For a good positioning of these haemostasis factors the normal coagulation and fibrinolysis mechanisms will be summarized.

Haemostasis is initiated by adherence of platelets to vascular or foreign surfaces and subsequent aggregation with one another. Furthermore, by release and exposure of their constituents they contribute to the fluid phase of coagulation. Although platelets appear to be involved in the development of atherosclerosis in hypertension, diabetes mellitus and hyperlipidaemia as has been briefly reviewed above, this thesis will, for practical reasons, be restricted to studies on the fluid phase of the coagulation system and fibrinolysis.

The coagulation proces is a complex cascade of enzymatic reactions between the coagulation factors and cofactors. The coagulation factors participate via the intrinsic and/or the extrinsic pathways to the formation of thrombin and subsequently cross-linked fibrin. These pathways seem closely interrelated in vivo and apparently function simultaneously (48, review). The coagulation system appears to be initiated by activation of factor XII (Hageman factor) in the presence of prekallikrein, high-molecular-weight kininogen and negatively charged surfaces which are exposed in the blood vessels after loss of endothelial integrity (intrinsic pathway) or by activation of factor VII in the presence of tissue factor and ionized calcium (extrinsic pathway). The intermediate reactions which lead to the formation of thrombin, fibrin monomers and insoluble fibrin are schematically represented in figure 1. By the prothrombinase complex (factors Xa, Va, calcium and phospholipid) prothrombin is cleaved into the active thrombin and a peptide designated prothrombin fragment 1.2. Antithrombin III is an important inhibitor of thrombin through the formation of thrombin-antithrombin III complex ( 48,49 reviews). Plasmin, the key-enzyme of fibrinolysis, is capable of cleaving a series of bonds in the fibrin molecules and thereby releasing fibrin degradation products. Several mechanisms lead to the formation of the active serine protease plasmin. Activation of the intrinsic coagulation pathway by factor XII, prekallikrein and high-molecular-weight kininogen is associated with the proteolytic cleavage of the zymogen plasminogen to the active enzyme plasmin (50). Tissue plasminogen activator ( $t-P A)$ released from the endothelial cells as a result of local or systemic stimuli seems to be the predominant activator of plasminogen in the vasculature. Regulation of t-PA activity provides a sensitive mechanism for the control of fibrinolysis. Whereas t-PA binding to fibrin greatly enhances its activity, plasminogen activator inhibitor-1 or PAll-1 (which is released by endothelial cells, vascular smooth muscle cells, platelets and hepatocytes) is 
Intrinsic pathway

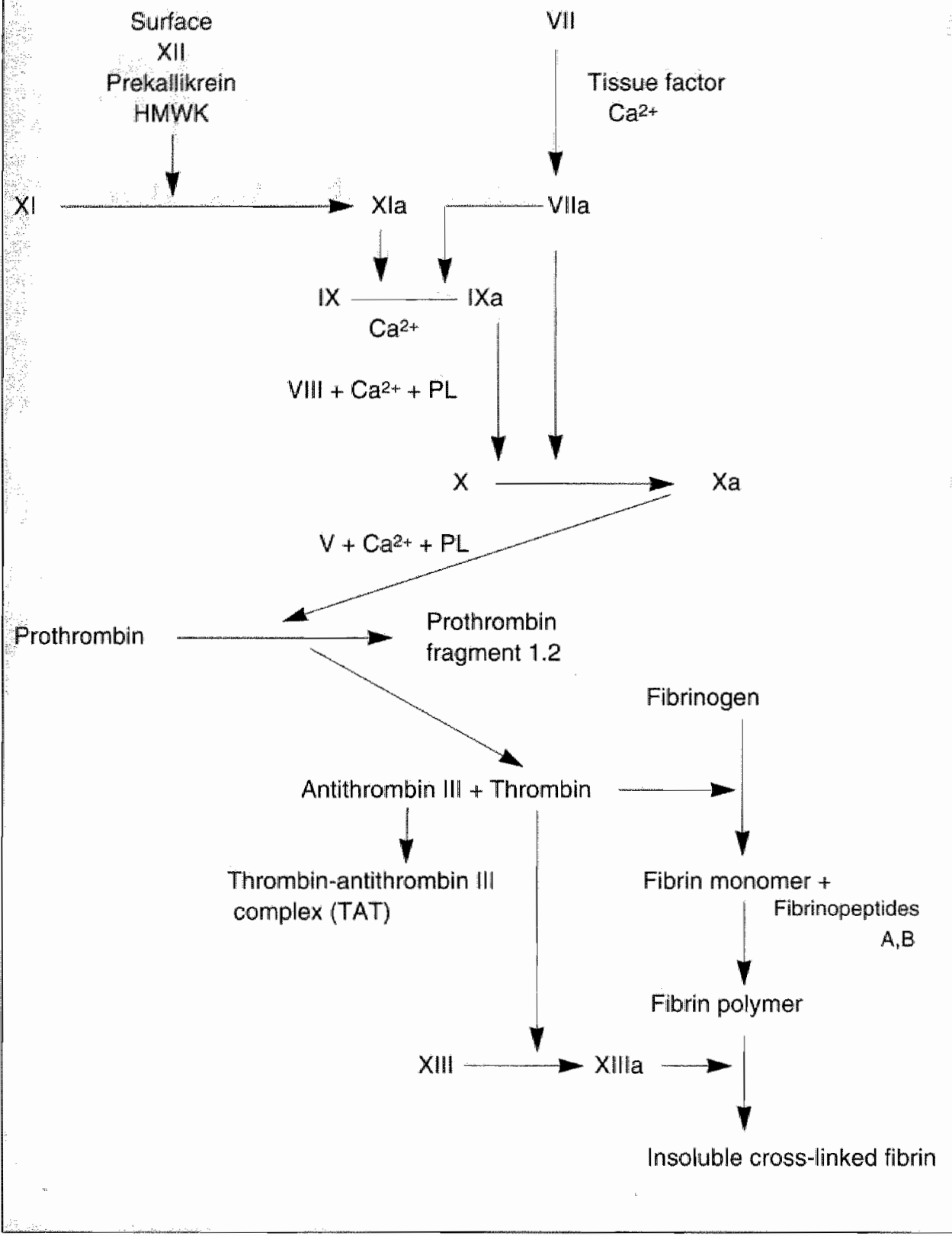

Figure 1. A simplefied scheme of blood coagulation.

PL, platelet factor 3 or phospholipid; HMWK, high-molecular-weight kininogen. 
the main inhibitor of t-PA in plasma (49, review). Urokinase, an activator produced by the kidney and excreted into the urine, has also been isolated in plasma (51). The physiological role of urokinase in blood has not yet been established. Once formed, plasmin is capable not only of degrading fibrin clots but also of degrading native fibrinogen. When a cross-linked fibrin clot is dissolved by plasmin a variety of fibrin split products are found and the most characteristic one, called D-dimer, is composed of one $E$ and two $D$ moieties (D2E fragment). The primary inactivator of plasmin is $\alpha_{2}$-antiplasmin by the formation of a $1: 1$ complex with plasmin ( 48,49 reviews). The fibrinolysis factors discussed here are schematically represented in figure 2.

The cardiovascular risk factors mentioned above seem to be related with each other in several ways. Hypertensive patients are more likely to have hyperlipidaemia and low HDL-cholesterol levels (52), whereas a hypercoagulable state with signs of an activated coagulation system and impaired fibrinolysis has been reported to occur in patients with hypertension, diabetes mellitus or hyperlipidaemia. The presence of insulin resistance is well known in diabetes mellitus but has recently also been implicated in the pathogenesis of essential hypertension (53-56). The precise role of insulin resistance in hypertension is still unclear but can be sought in at least four general types of mechanisms: increased tubular

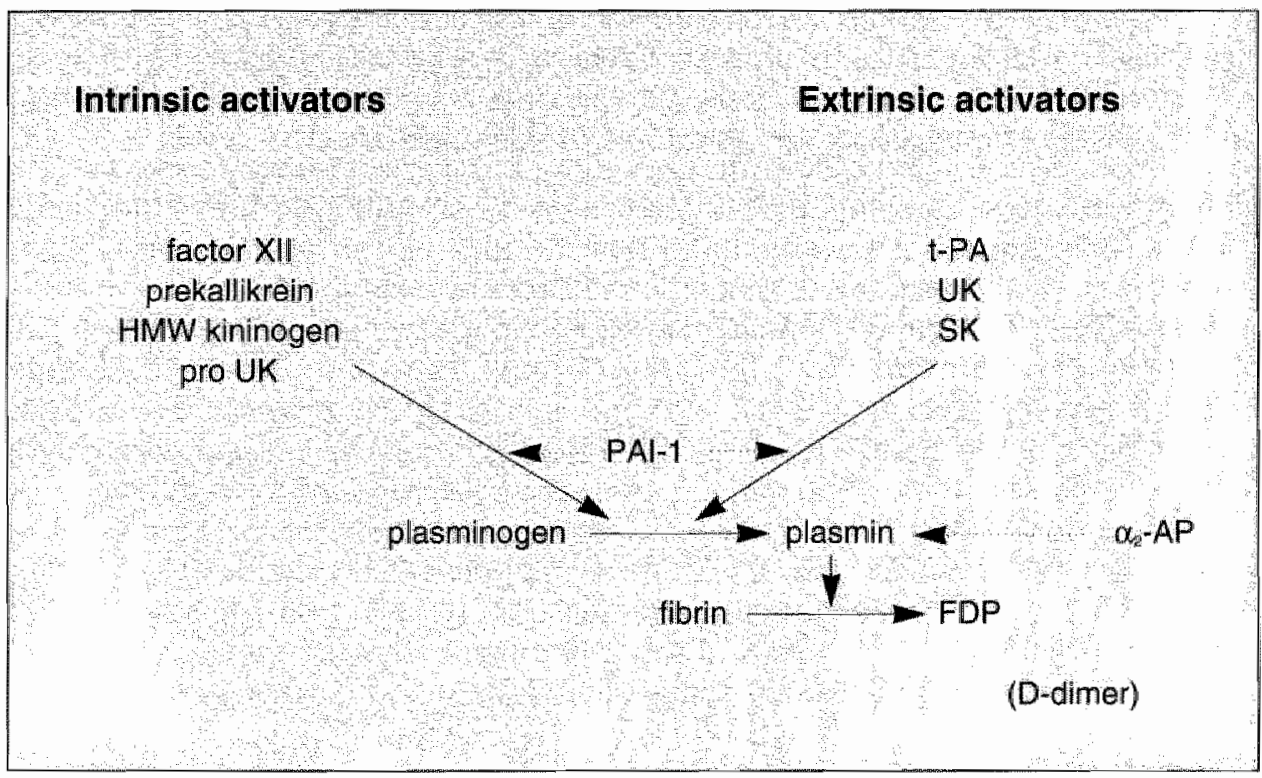

Figure 2 Scheme of fibrinolysis.

HMW kinogen, high-molecular-weight kininogen; $t-P A$, tissue plasminogen activator; UK, urokinase; SK, streptokinase; PAl-1, plasminogen activator inhibitor- $1 ; \alpha_{2}-A P, \alpha_{2}$ antiplasmin; FDP, fibrin degradation products. The dotted line indicates inhibition. 
sodium reabsorption in the kidney, sympathetic nervous system overactivity. disturbed membrane ion transport and proliferation of vascular smooth muscles (57, review). After the demonstration of a correlation between insulin, triglyceride and PAl-1 concentrations by Juhan Vague et al. $(58,59)$ the term 'syndrome $X$ ' has been applied to the clinical association of insulin resistance (as an underlying common pathway); hypertension, overweight, hypertriglyceridaemia and low HDL-cholesterol $(55,60)$, whereas Kluft (61) proposed adding elevated factor Vil, fibrinogen and plasminogen activator inhibitor-1 (PAl-1) concentrations to syndrome $X$ and calling it 'syndrome $X+$ '.

Another sign pointing to a connection between two cardiovascular risk factors is the existence of lipoprotein(a) or $L p(a)$. Because $L p(a)$ contains constituents of both systems it symbolizes the interrelations between lipid metabolism and the haemostasis system. LP(a), discovered as a distinct lipid fraction by $K$. Berg in 1963 (62), consists of an LDL-like particle with an additional apolipoprotein called apolipoprotein(a) or apo(a). Apo(a) turned out to be highly homologous to plasminogen, the fibrinolytic pro-enzyme $(63,64)$. Elevated $L p(a)$ concentrations appeared to be an important independent cardiovascular risk factor and as such comparable in magnitude to LDL-cholesterol $(65,66$, reviews). The mechanism of $L p(a)$-induced atherogenicity is still unknown. Conflicting data on the involvement of the LDL-receptor in $L p(a)$ catabolism have been reported, whereas the striking homology of apo(a) with plasminogen, together with its lack of fibrinolytic activity, has given rise to the suggestion that $\operatorname{Lp}(\mathrm{a})$ could promote the development of atheroscierosis by interference with fibrinolysis $(63,64,67)$. Recently numerous in vitro studies have shown $L p(a)$ to impair fibrinolysis substantially $(68,69$, reviews). However, few data concerning the effect of $L p(a)$ on the plasma fibrinolytic system in vivo have been published.

In this thesis the correlations between several coagulation and fibrinolysis parameters and the cardiovascular risk factors lipoprotein(a), other lipid parameters, hypertension and diabetes mellitus are described. Chapter 1 gives a review of $L p(a)$. A grossly activated coagulation system and increased reactive fibrinolysis are characteristic features of patients with acute deep venous thrombosis. To assess whether or not $L p(a)$ is related to haemostasis in vivo the correlations between $L p(a)$ and several coagulation and fibrinolysis parameters in 31 patients with acute deep venous thrombosis are reported in chapter 2.

Chapter 3 describes the correlations of $L p(a)$ with other lipid parameters and with several haemostasis factors in patients with essential hypertension $(n=54)$, non-insulin-dependent diabetes mellitus (NIDDM) $(n=65)$ and insulin-regulated diabetes mellitus $(n=116)$, being three atherogenic disease states associated with varying signs of an activated coagulation system and reactive fibrinolysis.

In chapter 4 the correlations between blood pressure, lipid parameters and several coagulation and fibrinolysis parameters are reported in a group of treated or untreated patients $(n=54)$ with essential hypertension, whereas chapter 5 describes the correlations between blood pressure, F VII, fibrin monomers and thrombin-antithrombin III with plasma prothrombin fragment 1.2 concentrations, 
determined by a recently developed ELISA method "in the same patient group. Chapter 6 describes the interrelations between glycometabolic control, lipid and coagulation parameters and microalbuminuria in 65 NIDOM patients. In chapter 7 the correlations of microalbuminuria with glycometabolic control, lipid, coagulation and fibrinolysis parameters in 116 insulin-regulated diabetic patients are reported.

Because this thesis comprises eight separate self-contained papers some repetition is inevitable.

\section{References}

1. Castellii WP.

Epidemiology of coronary heart disease: the Framingham Study.

Am J Med 1984; 76: 4-12.

2. Kannell WB, McGee DL.

Diabetes and cardiovascular disease: the Framinginam Sturdy.

J Am Med Assn 1979; 241: 2035-8.

3. Assman G, Schulte $H$.

Diabeles mellitus and hypertension in the elderly: concomitant hyperlipidaemia and coronary heart disease risk.

Am ل Cardiol 1989; 63: 33H-37H.

4. Rosengren $A$, Welin $L$, Tsipogianni $A$, Wilhelmsen $L$.

Impact of cardiovascular risk factors as coronary heart disease and mortality among middle-aged diabetic men: a general population study.

Br Med J 1989; 299: 1127-31.

5. Duguid JB.

Thrombosis as a factor in the pathogenesis of coronary atherosclerosis.

J. Pathol Bacteriol 1946; $58: 207-12$.

6. Haust MD, Movat $\mathrm{HZ}$, Moore $\mathrm{RH}$.

The role of fibrin thrombi in the genesis of the common white plaque in arteriosclerosis.

Circulation 1956; 14:483.

7. Woolf $N$, Carstains KC.

Infiltration and thrombosis in atherogenesis. A study using immunofluorescent

techniques.

Am J Pathol 1967; 51: 373-86.

8. Chandler $A B$, Pope JT.

Arterial thrombosis in atherogenesis. A survey of the frequency of incorporation of thrombi into atherosclerotic plaque.

In: Haustvast JGAJ, Hermus RJJ, Van der Haan F Eds: Blood and arterial wall in atherogenesis and arterial thrombosis EJ Brill, Leiden 1975: pp 110-B.

9. Meade TW, North WRS, Chakrabarti R, Stirling Y, Haines AP, Thompson SG,Brozovic M. Haemostatic function and cardiovascular death: early results of a prospective study.

Lancet 1980; i: 1050-4. 
10. Meade TW, Mellows S, Brozovic M. Miller Gu, Chakrabarti RR, North WRS,Haines AP, Stirling $Y$, Imeson JD. Thompson SG.

Haemostatic function and ischaemic heart disease: principal results of the Northwick Park Heart Study

Lancet 1986; it: 533-7.

11. Dalaker $K$, Hjermann I, Prydz $H$.

A novel form of factor VII in plasma from men at risk for cardiovascular disease.

Br J Haematol 1985, 61: 315-22.

12. Dalaker $K_{1}$ Smith $P_{0}$ Arnesen $H_{8}$ Prydz $H$.

Factor V/l-phospholipid complex in male survivors of acute myocardial infarction.

Acta Med Scand 1987; 222: 111-6.

13. Broadhurst $P$, Kelleher $C$, Hughes $L$, Imeson JD, Raftery EB.

Fibrinogen, factor Vil clotting activity and coronary antery disease severity.

Atherosiclerosis 1990; 85: 169-73.

14. Lowe GDO, Drummond MM, Lorimer AR, Hutton I, Forbes CD, Prentice CRM, Barbenel JC. Relation between extent of coronary artery disease and blood viscosity.

Br Med J 1980" 280: 673-4.

15. Handa K, Kono S, Saku K, Sasaki J, Kawano T, Sasaki Y, Hiroki T, Arawaka K. Plasma fibrinogen levels as an independent indicator of severity of coronary athersclerosis.

Atherosclerosis 1989; $77: 209-13$.

16. Small M, Lowe GDO, Beattie JM, Hutton I, Lorimer AR, Forbes CD.

Severity of coronary artery disease and basal fibrinolysis.

Haemostasis 1987; 17: 305-11.

17. Trip MD, Cats VM, van Capelle FJL, Vreeken J.

Platelet hyperreactivity and prognosis in survivors of myocardial infarction.

N Engl I Med 1990; 322: 1549-54.

18. Tofler GM, Brezinski D, Schafer Al.

Concurrent morning increase in platelet aggregability and the risk of myocardial infarction and sudiden cardiac death.

N Engl J Med 1987; 316: 1514-51.

19. Martin JF, Bath PMW, Bun ML.

Influence of platelet size on outcome after myocardial infarction.

Lancet 1991; 338: 1409-11.

20. Chakrabarti R, Hocking ED, Faarnley GR, Marn RD, Attwell TN, Jackson D.

Fibrinolytic activity and coronary artery disease.

Lancet 1968; i: $987-90$.

21. Hamsten $A$, Wiman $B$, de Faire $U$, Blomback $M$.

Increased plasma levels of a rapid inhibitor of tissue plasminogen activator in young survivors of myocardial infarction.

N. Engl. J. Med. 1985; 313: 1557-63.

22. Hamsten $A$, de Faire U, Walldius $G$, Dahlen $G$, Szamosi A, Landou $C$, BlömbackM, Wiman $B$.

Plasminogen activator inhibitor in plasma: risk factor for recurrent myocardial infarction. Lancet 1987; ii: $3-9$.

23. Mehta J, Mehta P, Lawson D, Saldeen T.

Plasma tissue plasminogen activator inhibitor levels in coronary artery disease: correlation with age and serum triglyceride concentraticns.

J Am Coll Cardiol 1987; 9: 263-8. 
24. Juhan-Vague I, Alessi MC, Joly $P$, Thirion $X$, Vague $P$, Declerck PJ, Serradimigni $A$, Collen D.

Plasma plasminogen activator inhibitor-1 in angina pectoris. Influence of plasma insulin and acute-phase response.

Arteriosclierosis 1989; 9: 362-7.

25. Zalewski $A$, Shi $Y$, Nardone D, Bravette $B$, Weinstock $P$, Fuchman D, Wilson $P$, Goldberg $S$, Levin DC, Bjornsson TD.

Evidence for reduced fibrinolytic activity in unstable angina at rest. Clinical, biochemical " and angiographic correlates.

Circulation 1991; 83: 1685-91.

26. Patrassi GM Fallo $F_{\text {, Santarossa }}$, Sartori MT, Casonato A, Girolami A.

Clotting changes in borderline hypertension.

$\mathrm{J}$ Hum Hyperten 1987 ; i: 101-3.

27. Boneu B, Durand D, Counillon F, Charlet JP, Bierme R, Sue JM.

Increased level of factor VII complex in severe arterial hypertension.

Haemostasis $1978 ; 7: 332-8$.

28. Isles C, Lowe GDO, Rankin BM, Forbes CD, Lucie N, Lever AF, Kennedy AC.

Abnormal haemostasis and blood viscosity in malignant hypertension.

Thromb Haemost 1984; 52: 253-5.

29. Patrassi GM, Fallo F, Martinelli S, Mantero F, Boeri G, Girolami A.

The contact phase of blood coagulation and renin activation in essential hypertension before and after captopril.

Eur Heart J 1984; 5: 561-7.

30. Yamanishi J, Sano H, Saito K, Furuta $Y$, Fukuzaki $H$.

Plasma concentrations of platelet-specific proteins in different stages of hypertension:

interaction between platelet aggregation, blood lipids and age.

Thromb Haemost 1985; 54: 539-43.

31. van Wersch JWJ, Rompelberg-Lahaye J, Lustermans FAT.

Plasma concentration of coagulation and fibrinolysis factors and the level of platelet function in hypertension.

Eur J Clin Chem Clin Biochem 1991; 29: 375-9.

32. Ettenger MM, MacCarthy EP, Glas-Greenwalt P, Clyne DH, Polliak VE.

Abnormalities of fibrinolysis in essential hypertension.

J Hypertens Suppl 1984; 2 : S175-8.

33. Palermo A, Bertalero P, Pizza N, Amelatti R, Libretti A.

Decreased fibrinolytic response to adrenergic stimulation in hypertensive patients.

J Hypertens Suppli 1989; 7: S162-3.

34. Landin K, Tengborn L., Smith U.

Elevated fibrinogen and plasminogen activator inhibitor (PAI-1) in hypertension are related to metabolic risk factors for cardiovascular disease.

J Intern Med 1990; 227: 273-8.

35. Ostermann H., van de Loo J.

Factors of the hemostatic system in diabetic patients.

Haemostasis 1986; 16: 386-416.

36. Tschaepe D., Ostermann H., Huebinger A., Ziegler D., Wiefels K., Gries F.A.

Elevated platelet activation in type I diabetics with chronic complications under longterm near-normoglycemic control.

Haemostasis 1990; 20: 93-8.

37. Geiger M., Binder B.R.

Plasminogen activation in diabetes mellitus.

J. Biol. Chem. 1984; 259: 2976-81. 
38. Gelger M., Binder B.R.

Nonenzymatic glucosylation as a contributing factor to defective fibrinolysis in diabetes mellitus.

Haemostasis $1986 ; 16: 439-46$.

39. Small M., Kluft C. Mac Cuish A.C., Lowe G.D.O.

Tissue plasminogen activator inhibitor in diabetes mellitus.

Diabetes Care 1989; 12: 655-8.

40. Mirshahi M., Soria J., Soria $C_{\text {. }}$ Bertrand D., Mirshahi M., Basdevant A.

Glycosylation of human fibrinogen and fibrin in vitro, its consequences on the properties of fibrin(ogen).

Thromb. Res. 1987; 48: 279-89.

41. Constantino $M$, Merskey $C$, Kudzma D $d$, Zucker MB.

Increased activity of vitamin K-dependent clotting factors in human

hyperlipoproteinaemia-association with cholesterol and triglyceride levels.

Thromb Haemost 1977; 38: 465-75.

42. Elkeles RS, Chakrabarti $R$, Vickers $M_{*}$ Stirling $Y$, Meade TW.

Effect of trealtment of hyperlipidaemia on haemostatic variables.

Br Med J 1980; 281: 973-4.

43. Simpson HCR, Mann Jl, Meade TW, Chakrabarti R: Stirling $Y$, Woolf L.

Hypertriglyceridaemia and hypercoagulability.

Lancet 1983; i: 786-90.

44. Nordoy A, Illingworth DR, Connor WE, Goodnight S Jr.

Increased activity of factor VII and factor VII-phospholipid complex measured using a

Normotest system in subjects with hyperlipidemia.

Haemostasis 1990; 20: 65-72.

45. Carvalho de Sousa J, Bruckert E, Giral P, Sonia C, Chapman J, Truffert J,Dairou $F_{1}$ De Gennes JC, Caen JP.

Coagulation factor VII and plasma triglycerides: decreased catabolism as a possible mechanism of factor VII hyperactivity.

Haemostasis 1989; 19: 125-30.

46. Nordoy A, Rodset JM.

Platelet function and platelet phospholipids in patients with hyperbetalipoproteinemia.

Acta Med Scand 1971; 189: 385-9.

47. Zahavi J. Betteridge JD, Jones NAG, Gallton DJ, Kakkar VV.

Enhanced in vivo platelet release reaction and malondialdehyde formation in patients with hyperlipidaemia.

Am J Med 1981: 70: 59-64.

48. Saito $H$.

Normal hemostatic mechanisms

In: Ratnoff $O D$, Forbes CD Eds. Disorders of hemostasis 2nd ed. Philadelphia

WB Saunders Company 1991: $118-47$.

49. Edelberg JM, Reilly CF, Pizzo SV

The inhibition of tissue type plasminogen activator by plasminogen activator inhibitor- 1 .

The effects of fibrinogen, heparin, vitronectin and lipoprotein(a).

J Bioll Chem 1991; 266: 7488-93.

50. Kluft C, Dooijeweard G, Emeis JJ.

Role of the contact system in fibrinalysis.

Semin Thromb Hemost 1987; 13: 50-68.

51. Wun TC, Schlenning WD, Reich E.

Isolation and characterization of urokinase from human plasma.

J Biol Chem 1982; 257: 3276-83. 
52. Castelli WP, Anderson $K$.

A population at risk: prevalence of high cholesterol levels in hypertensive patients in the Framinghan study.

Am J Med 1986; 80 (suppl 2a): 23-32.

53. Ferranini E, Buzzigoli G, Bonadonna R, Giorico MA, Oleggini M, Graziadei L, Pedrinelli R. Brandi L, Bevilacqua $S$.

Insulin resistance in essential hypertension.

N Eng J Med 1987:317: 350-7.

54. Shen DC, Shieh SH, Fuh MT, Wu DA, Chen Y Do, Reaven GM.

Resistance to insulin stimulated glucose uptake in patients with hypertension.

J Clin Endocrinol Metab 1988; 66: 580-3.

55. Reaven GM

Banting lecture 1988: Role of insulin resistance in human disease.

Diabetes 1988; 37: 1595-1607.

56. Salomaa $A$, Strandberg TE, Vanharen $H$, Naukarinnen V, Sarna $S$, Miettinen TA

Glucose tolerance and blood pressure: long term follow up in middle aged men.

Br Med J 1991; 302: 493-6.

57. Defronzo RA, Ferranini E.

Insulin resistance. A multifaceted syndrome responsible for NIDDM, obesity,

hypertension "dyslipidaemia and atherosclerotic cardiovascular disease.

Diabetic Care 1991; 14: 173-94.

58. Vague $P$, Juhan-Vague I, Aillaud MF.

Correlation between blood fibrinolytic activity, plasminogen activator inhibitor level, plasma insulin level and relative body weight in normal and obese subjects.

Metabolism 1986; 2: 250-3.

59. Juhan-Vague I, Vague $P_{\text {, Alessi MC. }}$

Relationship between plasma insulin "triglycerides, body mass index and plasminogen activator inkibitor-1.

Diabetes Metab Rev 1987; 13: 331-6.

60. Zavaroni I, Bonora E, Pagliara M.

Risk factors for coronary artery disease in healthy persons with hyperinsulinemia and normal glucose tolerance.

N Engl J Med 1989; 320: 702-6.

61. Kluft $C$.

Disorders of the hemostatic system and the risk of the development of thrombotic and cardiovascular diseases: limitations of laboratory diagnosis.

Am J Obstet Gymecol 1990; 163: 305-12.

62. Berg K.

A new serum type system in man: the Lp(a) system.

Acta Pathol Micirobiol Scand 1963; 59: suppl 166-7.

63. Eaton DL, Fless GM, Kahr WJ, McLean JW, Xu-QT, Miller GG, Lawn RM, Scanu AM.

Partial amino acid sequence of apolopoprotein(a) shows that it is homologous to plasminogen.

Proc Natl Acad Sci USA 1987; 84: 3224-8.

64. McLean JW, Tominson JE, Kuang WJ, Eaton DL, Chen EY, Fless GM, Scanu AM, Lawm RM.

CDNA sequence of human apolipoprotein(a) is homologous to plasminogen.

Nature 1987; 330: 132-7. 
65. Scanu AM.

Review article. Lipoprotein(a): a genetically determined cardiovascular pathogen in search of a function.

J Lab Clin Med 1990; $116: 142-6$.

66. Loscalzo d.

Review: Lipoprotein(a). A unique risk factor for atherothrombotic disease.

Arteriosclerosis $1990 ; 10: 672-9$.

67. Brown MS, Goldstein JL

Plasma lipoproteins: teaching old dogmas new tricks.

Nature $1987 ; 330: 113 \% 4$.

68. Miles LA, Plow EF

Lp(a): an interloper into the fibrinolytic system?

Thromb Haemost 1990; 63: 331-5.

69. Edelberg. JM, Pizzo SV.

Lipoprotein(a): the link between impaired fibrinolysis and atherosclerosis.

Fibrinalysis 1991; 5: 135-43. 
Chapter 1

\section{Lipoprotein(a): a hereditary risk factor for atherosclerotic disease}

S.H.J. Donders, J.W.J. van Wersch

Neth J Med 1992;40:96-104 


\section{Introduction}

Considering the mortality and morbidity due to atherosclerotic vascular disease, it is not surprising that a vast amount of research has been carried out in this field during the last decennia to reveal risk factors and their associated mechanisms. Hypertension, diabetes mellitus, overweight, smoking and hyperlipidaemia were identified as risk factors for cardiovascular disease. The fractions of the lipid spectrum appeared to have disparate effects on the progression of atherosclerosis. Whereas elevated low density lipoprotein (LDL) cholesterol and very low density lipoprotein (VLDL) triglyceride levels were determined as risk factors, high density lipoprotein (HDL) cholesterol was negatively correlated with atherosclerosis.

Lipoprotein(a) or Lp(a), discovered by K. Berg in 1963 (1), is a distinct lipid fraction. It consists of an apo B-100 protein and lipid moieties similar to LDL. Additionally, it contains a unique glycoprotein, apolipoprotein(a) or apo(a). In the 1970 's Lp(a) has been associated with coronary artery disease (2-4), but in the meantime numerous studies have shown $L p(a)$ to be an independent risk factor for atherosclerotic disease (7-19). These reports, together with the discovery of the amino acid and cDNA sequence of apo(a) by investigators at the Chicago University and Genentech in $1987(20,21)$ have stimulated further intensive research in the $L p(a)$ area. Apo(a) thas been shown to be highly homologous to plasminogen but to lack its fibrinolytic capacity $(20,21)$. Speculations occurred that the atherogenicity of $L p(a)$ was due to interference with the pro-fibrinolytic function of plasminogen, thus promoting thrombosis. $L p(a)$ has been suggested to be the "long sought link' between thrombosis and atherosclerosis (22).

\section{Lp(a) and atherosclerosis}

In 1972, Dahlen et all. (2) reported the association between coronary heart disease and a genetically determined plasma lipoprotein with an electrophoretic mobility on agarose gel between $\beta$ lipoprotein and pre- $\beta$-lipoprotein. This lipoprotein, designated pre- $\beta$ 1-lipoprotein, was later identified as $L p(a)$ (3). Originally, $L p(a)$ was suggested to be a qualitative autosomal dominant genetic marker present in $35 \%$ of Caucasian populations (1). Walton et al. (4), using a sensitive immunochemical technique, reported that $L p(a)$ was detectable in $75 \%$ of a British population, with considerable variation in concentration between individuals. The same paper reported the abundant presence of apo(a) colocalized with apo B in atherosclerotic plaques, a finding which has been confirmed by several other studies $(5,6)$. In a study of 76 post-infarction middleaged men and a comparable control group, Kostner et al. (7) reported the 
relative risk for myocardial infarction $(\mathrm{MI})$ in normolipaemic subjects to be 1.75 and 2.3 for $L p(a)$ levels exceeding $300 \mathrm{mg} / \mathrm{l}$ and $500 \mathrm{mg} / \mathrm{l}$, respectively. In a prospective study of 303 Hawaiian men with Japanese ancestry and a prior MI, an increased risk for $M l$ was determined for $L p(a)$ levels exceeding $200 \mathrm{mg} / /(8)$. The relative risk for MI was 2.5, 1.6, and 1.2 for men under 60 , aged 60 to 69 and 70 years and older, respectively. The significance of $L p(a)$ as an independent risk factor was confirmed by a multiple logistic model.

Following Frick et al. (9), who established an association between a positive qualitative assay for $L p(a)$ and coronary artery disease assessed by coronary arteriography, Armstrong and co-workers (10) studied 594 middle-aged Swedish men who were submitted to coronary arteriography over a period of one year. Coronary artery disease was diagnosed if at least $50 \%$ stenosis was present in one or more of the major coronary vessels. In persons with elevated $L p(a)$ values $(\geq 300 \mathrm{mg} / \mathrm{l}$ ) the odds ratio for coronary artery disease was 2.7 compared to individuals with the lowest $L p(a)$ levels $(\leq 50 \mathrm{mg} / \mathrm{l})$. The association between elevated $L p(a)$ levels and coronary artery disease was independent of smoking, hypertension, diabetes mellitus and the plasma levels of triglycerides and HDL-cholesterol. With regard to LDL-cholesterol and total cholesterol values, odds ratios of 1.6 and 1.7 were determined for levels below median values and 4.5 and 6.0 for levels exceeding the median values. These data indicate an increased risk for coronary artery disease in patients with elevated $L p(a)$ levels in the presence of enhanced LDL cholesterol. A similar study has been published by Dahlen et al. (11) who investigated 307 white patients submitted for coronary angiography. Using multivariate analysis, they found an independent association between $L p(a)$ levels and coronary artery disease in men under 55 years of age and in women of all ages. It was concluded that $L p(a)$ levels appear to be a major coronary risk factor in white patients, comparable in magnitude with LDL cholesterol-levels.

During a four-month period in 1986, Hoefler et al. (12) investigated 1486 males aged 18 years who underwent routine physical examination for Austrian military service in the county of Styria. The men were divided into probands whose parents (father and/or mother) had suffered an MI and those whose parents had not. In the first group, $32 \%$ had $L p(a)$ levels above $250 \mathrm{mg} / \mathrm{l}$ whereas in the latter group only $13.4 \%$ had elevated $L p(a)$ levels, a highly significant difference. Parents of male children with Lp(a) levels above $250 \mathrm{mg} / \mathrm{l}$ had an odds ratio of 2.5 for having suffered myocardial infarction, compared to parents of male children with low $L p(a)$ levels. In a prospective case-control study of 776 50-year-old Swedish men in 1983 and 1984 (13), serum samples were obtained at the start of the study and kept at $-70^{\circ} \mathrm{C}$. After six years, Lp(a) levels of the 26 men who died or survived after a myocardial infarction were determined as well as those of 109 randomly selected controls without MI. Mean Lp(a) level in the MI group was $278 \mathrm{mg} / \mathrm{l}$ versus $173 \mathrm{mg} / \mathrm{l}$ in the controls. The controls and $\mathrm{MI}$ patients together were classified, according to their $L p(a)$ levels, into five groups each consisting of 27 persons. The odds ratios for a $\mathrm{Ml}$ in persons with the highest $L p(a)$ levels ( $\geq 365 \mathrm{mg} /$ ) were more than three-fold higher than the odds 
ratios for those with the lowest $L p(a)$ levels ( $\leq 38 \mathrm{mg} / /$ ). A multiple logistic regression analysis confirmed $L p(a)$ to be independently associated with coronary heart disease. Recently "two studies were published concerning the impact of $L p(a)$ in coronary heart disease in patients with heterozygous familial hypercholesterolaemia. In both studies patients with coronary artery disease had significantly elevated median apo(a) (14) and Lp(a) levels (15), and these were more than double those in the hyperlipidaemic patients without coronary heart disease. In contrast, mean total cholesterol and LDL-cholesterol levels were the same in patients with or without coronary heart disease. Both studies concluded that $L p(a)$ was a major risk factor for coronary heart disease in familial hypercholesterolaemia, independent of other risk factors.

Költinger and Jürgens (16) were the first to publish the role of $L p(a)$ in cerebrovascular disease. In 1985 they reported highly significantly elevated $L p(a)$ levels in subjects with atherosclerotic changes in the carotid arteries documented by bidirectional Doppler ultrasonic imaging. The same investigators and coworkers (17) studied $L p(a)$ levels in 87 patients suffering from ischaemic cerebrovascular disease. The mean $L p(a)$ values were significantly elevated in the patient group ( $205 \pm 230 \mathrm{mg} / \mathrm{l}$ versus $142 \pm 230 \mathrm{mg} / \mathrm{l}$ in the controls). In another study, $L p(a)$ llevels were determined in 46 patients with cerebrovascular disease, in 28 survivors of a myocardial infarction and in a control group of 37 healthy persons (18). The median $L p(a)$ values of the patients with cerebrovascular disease did not differ significantly from those in the MI group but were twice the median LP(a) levels in the control group and were significantly elevated. In a subgroup of patients aged between 40 and 65 years, $L p(a)$ levels correlated with the stage of the vascular lesions in the carotid system classified by a Duplex Doppler score system. Murai et all. (19) investigated $L p(a)$ in Japanese patients with cerebral infarction, coronary artery disease and controls. All the subjects were divided into two groups according their $L p(a)$ levels. A significant association was reported between $L p(a)$ values above $170 \mathrm{mg} / \mathrm{l}$ and coronary artery disease and cerebral infarction in the distribution of the cortical artery.

We are not aware of studies concerning the association of $L p(a)$ with peripheral vascular disease.

The studies summarized above leave little doubt about the atherogenicity of Lp(a) in white and Japanese populations. However, in a black population in Houston, USA, no increased rate of cardiovascular disease was registered despite mean $L p(a)$ levels twice as high as those in white residents (23). Thus, the atherogenic role of $L p(a)$ in black populations has not been established.

\section{Structural characteristics and genetics of $L p(a)$}

After the discovery of $L P(a)$ in 1963, the suggestion was made that it was inherited as an autosomal dominant trait under the control of two alleles (1). In the 1970 's, $L p(a)$ was determined to be identical to 'sinking" pre-beta-lipoprotein 
and pre-beta, - lipoprotein (3). The distribution of $L p(a)$ appeared to be highly skewed in Caucasian populations. The observed variation of $L p(a)$ values was attributed to a multifactorial mechanism largely dependent on a polygenic mode of inheritance (24). In the $1980^{\prime} \mathrm{s}$, it was established that $L p(a)$ consisted of an LDL-like particle, including its apo B-100, and a unique glycoprotein, apo(a). Apo(a) is linked to the lipid particle by disulphide bridging with the apo B-100 (25). Apo(a) is a heavily glycosylated protein polymorphic in size with molecular weights varying from 400.000 to 700.0000 Daltons (26). According to their relative electrophoretic mobility compared with apo $B-100$, six apo(a) isoforms have been reported: $F$ (faster than apo B-100), B (similar to apo B-100) and S1, S2, S3 and S4 (slower than apo B-100) (26). Isoforms F, B, S1 and S2 are associated with high $L p(a)$ levels and low apo(a) molecular weights, whereas isoforms S3 and S4 have high apo(a) molecular weights and are associated with low $L p(a)$ levels (26). Each individual expresses either one or two of these isoforms. In family studies this polymorphism appeared to be controlled by a series of six autosomal alleles and an operational 'null' allele at the apo(a) locus (26). The apo(a) gene has been localized to the long arm of chromosome 6 where it is closely linked to the gene encoding for plasminogen (27). The apo(a) phenotypes do not dictate a fixed $L p(a)$ value but show a limited distribution of $\mathrm{Lp}(\mathrm{a})$ levels. The variation at the apo(a) locus explains $40 \%$ of the total variation in $L p(a)$ levels (28), so that other (as yet unidentified) factors, which may also be genetic, must determine the remainder of the $L p(a)$ level variation.

The elucidation of the apo(a) structure at protein and cDNA level in 1987 has revealed a high degree of homology with plasminogen $(20,21)$. Plasminogen, a single chain protein of 791 amino acids, is a serine protease zymogen of the fibrinolytic system. It consists of a protease domain and five sequentially repeated homologous domains called kringles. Kringles are structures containing approximately a hundred amino acids with a pretzel-like structural appearance due to 3 internal disulphide bridges. The name 'kringles' is derived from their structure which resembles a Danish cake called kringle, similar to the Dutch 'Krakeling'. Kringle structures have been identified in many proteins involved in coagulation and fibrinolysis, including prothrombin, factor XII, t-PA and urokinase (29). Apo(a) contains two types of plasminogen-like kringle domains. The first is homologous to kringle 5 of plasminogen and is present in apo(a) as a single copy. The other is highly homologous to plasminogen kringle 4 and is present in multiple copies up to $37(20,21,30$, figure 1$)$. The serine protease domain of apo(a), for $94 \%$ homologous to the serine protease domain of plasminogen, cannot be converted into a fibrinolytically active agent by t-PA or streptokinase, due to the critical substitution of arginine by serine at the activation site of the molecule (20,21, figure 2). Gavish et al. (30) have shown the ratio of kringle $4 /$ kringle 5 encoding domains in the apo(a) gene to be positively correlated with the molecular weight of apo(a) and inversely correlated with $L p(a)$ levels. Differences in the degree of glycosylation of apo(a) might also influence the apo(a) molecular weight. In addition to $L p(a)$, the occurrence of free apo(a) and apo(a)-apo B-100 complexes has also been reported in trigiyceride rich particles and lipid-poor complexes in a-beta-lipoproteinaemia (31, review). 


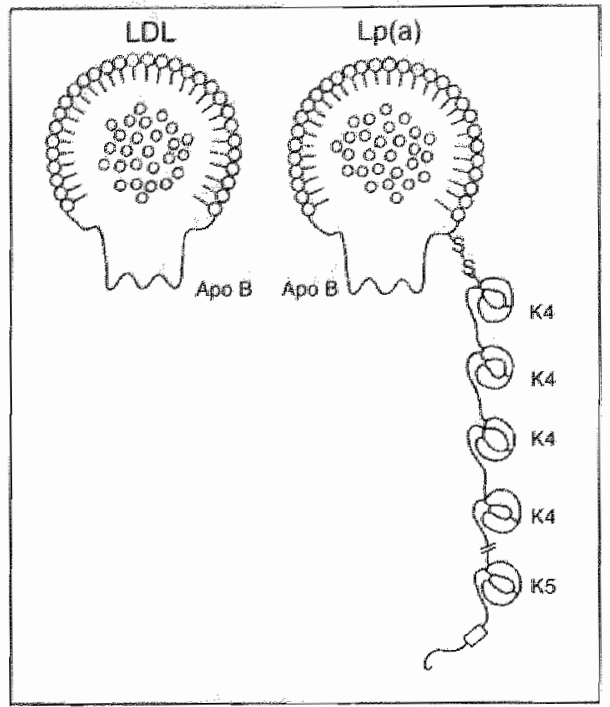

Figure 1:

Structure of LDL and lipoprotein(a); $K 4$ and $K 5$ donate kringles 4 and 5 respectively. (Illustration derived from Rees A, Bishop A, Morgan A: The apo(a) gene. British Medical Bulletin 1990; $46: 879$ with permission from the author and from Churchill Liwingstone).

Below Figure 2:

Gene structure comparison of plasminogen and apolipoprotein(a). The top structure is plasminogen CDNA and the lower structure apolipoprotein(a) cDNA 5',5', untranslated sequence; $S$, signal peptide; $T$, tail region; $I$, $I I, I I, I V, V$, kringle domains; $P$, protease domain; $3^{\prime \prime}, 3^{\prime} u n t r a n s l a t e d ~ s e q u e n c e$ (II/ustration derived from reference 21 with permission from the author and from Nature).

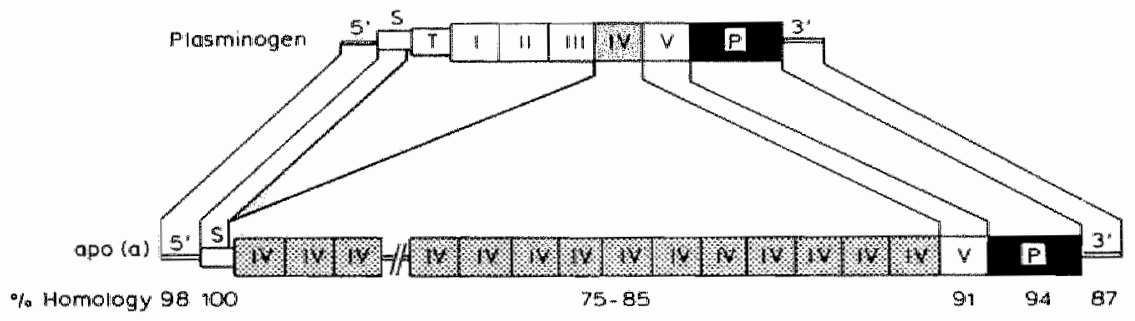

\section{The measurement of plasma Lp(a) concentrations}

In the 1960's Lp(a) was identified by gel diffusion studies and was considered a variant of LDL present in $30-45 \%$ of the Caucasian race (32). In 1974, Albers and Hazzard (33) reported that $L p(a)$ could be detected in $92 \%$ of the tested persons by means of a quantitative radial immunodiffusion assay (RID). The same group of investigators developed a sensitive and specific radioimmunoassay (RIA) capable of detecting $L p(a)$ in nearly all subjects (34). The commercially available and later developed enzyme-linked immuno-sorbent assay (ELISA) systems show coefficients of variation below $5 \%$ (35). The striking homology between apo(a) and plasminogen (21) implied the possibility of cross-reactivity of $L p(a)$ assays with plasminogen. The problem of crossreactivity can be solved by using very specific antibodies to apo(a) which have minimal cross-reactivity with plasminogen (36), or by the use of a second (sandwich) antibody directed to the apo B-100 moiety of $L p(a)(35,37)$. An advantage of the latter approach is that isolated apo(a) does not interfere with 
$L p(a)$ measurement. Traditionally, plasma $L p(a)$ concentrations have been expressed in terms of total $L p(a)(33,34)$. This approach is nowadays still common practice although some investigators use plasma apo(a) concentrations (e.g. 14). It is also possible to express $L p(a)$ concentrations in terms of its other constituents such as cholesterol or apo B-100. Lp(a) particle size, composition and density have been shown to vary between as well as within individuals. Therefore, it would seem possible that the immunoreactivity can vary with the number of kringle units and the size of the Lp(a) particle (see section structural characteristics).

in conclusion, standardization of $L p(a)$ measurement has not yet been achieved but must be given high priority if $L p(a)$ is to become a generally accepted marker for atherosclerosis.

\section{Lp(a) level determining factors among populations and in individuals}

The $L p(a)$ distribution in randomly selected Caucasian populations is highly skewed, with the highest frequencies at the lower levels $(4,7)$. Plasma Lp(a) levels vary from being undetectable to more than $2000 \mathrm{mg} / \mathrm{l}$. The predominance of the lower $L p(a)$ levels is compatible with the established high incidence of the $L p(a)$ phenotypes S3 and S4. There is no apparent difference in $L p(a)$ levels between men and women. Age and diet do not substantially influence the $L p(a)$ levels. Randomly selected Japanese men living in Hawaii have been reported to show the same $L p(a)$ distribution as white men (8), whereas an American black population in Houston showed a bell-shaped Lp(a) distribution with mean Lp(a) levels twice as high as those of whites; this might indicate a race-dependency of Lp(a) levels (23, figure 3 ).

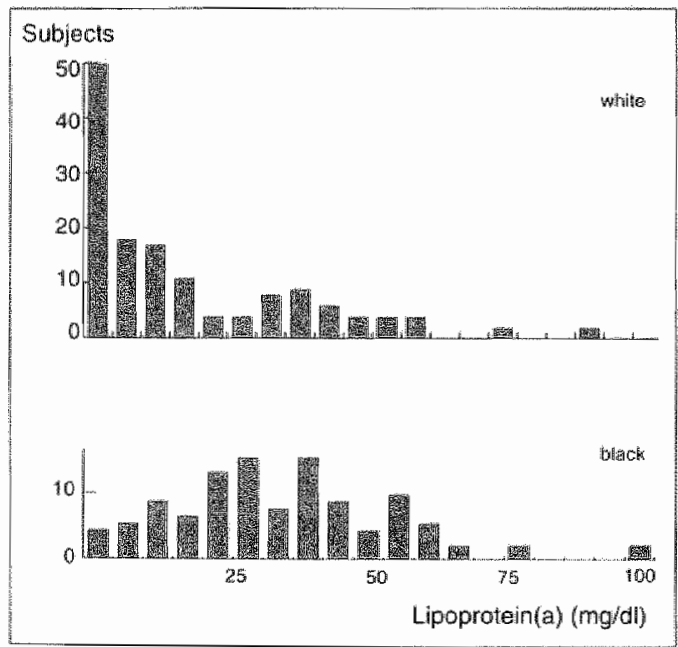

Figure 3:

Lipoprotein(a) distribution in white and black populations in Houston, USA dorived from reference 23 with permission from the author and from the American Heart Association Inc.) 
Little is known about synthesis and catabolism of $L p(a)$. The liver appears to be the major $L p(a)$ production site. Apo B-100, the other apolipoprotein of $L p(a)$ is predominantly of hepatic origin. Low Lp(a) levels have been found in patients with alcoholic liver cirrhosis (38) whereas phenotypical apo(a) conversion into donor apo(a) phenotype has been reported after liver transplantation (39). In vivo turnover studies show $L p(a)$ to be catabolised at a stable rate. Fractional catabolic rates in individuals with low LP(a) levels and individuals with high levels are essentially the same. Considering the conflicting data reported on this subject, the contribution of the LDL-receptor in $L p(a)$ catabolism remains controversial. $L p($ a) appeared not to be derived from LDL, VLDL or chylomicrons (40). In general, $L p(a)$ levels are not correlated with other apolipoprotein levels. Transiently elevated $L p(a)$ levels have been reported following myocardial infarction and surgery, suggesting that $L p(a)$ reacts like an acute phase protein (41). This finding is compatible with elevated $L p(a)$ levels reported in patients with active rheumatoid arthritis (42). Lp(a) does not show a circadian rhythm (43).

\section{Lp(a) lowering drugs}

$L p(a)$ in plasma of normal and hypercholesterolaemic individuals is stable and is scarcely affected by dietary manipulations or by lipid-lowering drugs such as cholestyramine, fibrates or 3-hydroxy-3-methyl-glutaryl (HMG)-CoA-reductase inhibitors (44, review). Stanozolol, an anabolic steroid for the treatment of osteoporosis administered to postmenopausal women, reduced $L p$ (a) levels substantially by $65 \pm 23 \%$ whereas plasma apo B levels increased (45). Niacin, given as monotherapy or in combination with neomycin or colestipol, has been reported to lower $L p(a)$ levels considerably. Carlson et al. (46) treated 31 unselected hyperlipidaemic patients with 4 grams of nicotinic acid daily for 6 weeks. The mean decrease in $L p(a)$ amounted to $38 \%$. The individual reduction was correlated with the pretreatment $L p(a)$ level $(r=0.91)$. The authors reported the proportional decrease of $L p(a)$ and $L D L$-cholesterol to be correlated ( $r=$ 0.88 ) and suggested that this might be due to inhibition of the synthesis of apo B-100, the apolipoprotein present in both lipoproteins. Furthermore, LDL apheresis has been reported to lower $L p(a)$ levels by $35 \%$. Recently, Gavish and Breslow (47) found an $L p(a)$ reduction of $65 \%$ in two patients with elevated $L p(a)$ levels who were treated with 4 grams of $\mathrm{N}$-acetylcysteine daily. Stalenhoef et al. (48) however, reported unsuccessful treatment of twelve patients with elevated Lp(a) using a dose of 1.2 grams $\mathrm{N}$-acetyl-cysteine daily.

\section{Potential atherogenic mechanisms of $L p(a)$.}

Until now, the physiological role of $L p(a)$ has not been elucidated whereas the absence of $L p(a)$ in plasma has not been reported to cause any kind of disease or noticeable deficiency state. Concerning the atherogenic effects of $L P(a)$, 
several mechanisms have been proposed. The covalent linkage of apo(a) to apo B-100 has given rise to the hypothesis of a disturbed interaction of $L p(a)$ with the LDL-receptor, and this has been confirmed by several studies $(49,50)$. Hereby $L p(a)$ might be preferentially taken up by the scavenger receptor pathway, leading to intracellular accumulation of cholesterol and the transformation of macrophages into foam cells, thus inducing early atherosclerotic changes in the vessel wall. This hypothesis is compatible with the observed lack of ability of LDL-cholesterol-lowering drugs to reduce $L p(a)$ levels. Another possible mechanism is the preferential $L p(a)$ uptake by the scavenger receptor due to LDL-particle saturated LDL-receptors. In keeping with this hypothesis is the study of Armstrong et al. (10) who reported the cardiovascular risk of $L p(a)$ to increase progressively with LDL-cholesterol levels. The fact that in patients with heterozygous familial hypercholesterolaemia, a disease caused by LDL-receptor malfunction, $L p(a)$ levels for all apo(a) phenotypes are three-fold higher than in matched controls might be compatible with LDL-receptor involvement in $L p(a)$ regulation. However, conflicting data have been published concerning the in vitro binding and uptake of $L p(a)$ by the LDL-receptor.

Interaction of $L p(a)$ with fibrin or proteoglycans, a substance very abundant in intercellular matrices, has been described in several studies as a possible mechanism for $L p(a)$ accumulation in the vessel wall $(31,51)$. The extracellularly deposited $L p(a)$ might contribute directly to cholesterol deposition in the arterial wall. It is also feasible that macrophages, after clearing $L p(a)$ or $L p(a)$ proteoglycan complexes, convert to foam cells and thus induce atherosclerotic changes.

Another line of thought on the pathophysiology of $L p(a)$ was induced by the discovery of the apo(a) structure. The homology of apo(a) with plasminogen, together with the established inability of apo(a) to exert fibrinolytic activity, has given rise to speculation that $L p(a)$ might interfere with the fibrinolytic potential of plasminogen (20-22). In vitro data supporting this hypothesis are accumulating. $L p(a)$ has been shown to inhibit interaction of plasminogen to its endothelial binding sites with a consequent reduction in generation of plasmin by t-PA. Also, $L p(a)$ has been reported to compete with plasminogen and t-PA for the fibrinbinding site and to disturb the fibrin-dependent enhancement of t-PA activity and clot lysis (31, review). Macrophage uptake of $L p(a)$, instead of plasminogen attached to fibrin or the plasminogen receptor at the endothelial cell surface, might induce atherosclerotic changes. These reports of in vitro studies suggest that $L p(a)$ might be a link between lipoprotein metabolism and the thrombolytic system. However, confirmation of these data in vivo has not yet been delivered.

\section{Conclusion}

Substantial progress has been achieved recently in $L p(a)$ research. The revelation of the apo(a) structural characteristics and then the identification and localization of an apo(a) phenotype and an Lp(a) plasma level regulating gene 
locus are considered to be important breakthroughs; however, not all the mysteries of L.p(a) have been solved. For instance, apart from the apo(a) locus, which other factors determine the variation in Lp(a) plasma level? Is Lp(a) catabolised by the LDL receptor pathway? If so, how does one explain the disparity of $L p(a)$ and $L D L$-cholesterol levels? If not, what causes the elevated $L p$ (a) levels in heterozygous familial hypercholesterolaemia? Why are $L p(a)$ levels generally resistant to LDL-cholesterol lowering drugs? What is the physiological role of $L p(a)$, if any? Does $L p(a)$ induce atherogenicity by a thrombotic mechanism or not? Although many questions await clarification the atherogenicity of $L P(a)$ in white and Japanese populations has not been disputed. It seems obvious that in the presence of elevated LDL-cholesterol, especially in individuals with heterozygous familial hypercholesterolaemia, high Lp(a) levels are associated with severe progression of coronary heart disease. Lp(a) might also have synergistic effects with other risk factors. From this point of view, high $L p(a)$ levels should be considered in relation to the overall riskspectrum of the individual patient and can be used as an additional argument for treating risk factors such as elevated LDL-cholesterol, hypertension, hyperlipidaemia in diabetics and overweight. Furthermore, elevated Lp(a) levels might be implicated in cardiovascular disease in a subpopulation of younger patients.

The introduction of several reliable commercially available $L p(a)$ immunoassays has to be accompanied by the question: in which patients are plasma Lp(a) determinations indicated? The answer depends on the implications for the treatment of the individual patient with a proven elevated $L p(a)$ level. It is important to consider the fact that the effect of drug-induced $L p(a)$ lowering on cardiovascular disease is unknown. Furthermore, treatment with $L p(a)$ reducing drugs such as stanozolol and neomycin has unacceptable side effects. At the moment only nicotinic acid, being a frequently prescribed lipid-lowering drug in the USA, might be considered as an appropriate LP(a) reducing drug. However, treatment with nicotinic acid in effective doses is hampered by serious side effects such as severe flushing, gastrointestinal complaints and, infrequently, hepatitis. In the Netherlands, these side effects have precluded nicotinic acid from becoming a popular lipid-lowering drug, and at the moment nicotinic acid is not commercially available here in lipid-reducing doses.

Determination of the atherogenic mechanism of $L p(a)$ would stress the importance of $L p(a)$ as an already established epidemiological risk factor for atherosclerotic disease. Plasma $\mathbb{L p}(a)$ determinations are not yet indicated in routine medical practice, but progress in atherosclerosis research might alter this situation in the near future. 


\section{References}

1. Berg K.

A new serum type system in man - the Lp system.

Acta Path Microbiol Scand 1963; 59: 369-82.

2. Dahlen G, Ericson C. Furberg $C$. Lundkvist L, Svardsudd $K_{x}$

Angina of effort and an extra beta lipoprotein fraction.

Acta Med Scand 1972; 531 (suppl): 6- 15.

3. Dahlen $G$, Berg $K$, Gillnas $T$, Ericson $C$.

Lp(a) lipoprotein/pre- $\beta_{1}$-lipoprotein in Swedish middle-aged males and in patients with coronary heart disease.

Clin Genet 1975; 7: 334-41.

4. Walton $\mathrm{KW}$, Hitchens J, Magnani HN, Khan $M$.

A study of methods of identification and estimation of $L p(a)$ lipoprotein and of its significance in health, hyperlipidaemia and atherosclerosis.

Atherosiclerosis $1974 ; 20: 323-46$.

5. Rath $M$, Niendorf $A$, Reblin T, Dietel M, Krebber HJ, Beisiegel U.

Detection and quantification of lipoprotein(a) in the arterial wall of 107 coronary bypass patients.

Arteriosclerosis $1989 ; 9: 579-92$.

6. Cushing GL, Gaubatz JW, Nava ML, Burdick Bd, Bocan TMA, Guyton JR, Weilbaecher D, DeBakey ME, Lawrie GM, Morrisett JD.

Quantitation and localization of apolipoproteins(a) and B in coronary artery bypass vein grafts resected at re-operation.

Arteriosclerosis 1989; 9:593-603.

7. Kostner GM, Avogaro P, Cazzolato G, Marth E, Bittolo-Bon G, Qunici GB. Lipoprotein $L p(a)$ and the risk for myocardial infarction.

Atherosclerosis $1981 ; 38: 51-61$.

8. Rhoads GG, Dahien G, Berg K, Morton NE, Dannenberg AL.

LP(a) Lipoprotein as a risk factor for myocardial infarction.

J Am Med Assn 1986; 256: 2540-4.

9. Frick MH, Dahlen $G$, Berg $K$, Valle M, Hekall $P$.

Serum lipids in angiographically assessed coronary atherosclerosis.

Chest $1978 ; 73: 62-5$.

10. Armstrong WW, Cremer P, Eberle E, Manke A, Schulze F, Wleland H, KreuzerH, Seidel D. The association between serum $L p(a)$ concentrations and angiographically assessed coronary atherosclerosis.

Atherosclerosis 1986; 62: 249-57.

11. Dahlien GH, Guyton JR, Attar M, Farmer JA, Kautz JA, Gotto AM Jr.

Association of levels of lipoprotein Lp(a), plasma lipids, and other lipoproteins with coronary artery disease documented by angiography.

Circulation 1986; 74 (4):758-65.

12. Hoefler G, Harnoncount F, Paschke E, Mirt W "Pfelffer IKH, Kostner GM. Lipoprotein $L p(a)$. A risk factor for myocardial infarction.

Arteriosclerosis 1988; 8: $398-401$. 
13. Aosengren $A_{t}$ Wilhelmsen $L$, Eriksson $E$, Fisberg $B$, Wedel $H$. Lipoprotein(a) and coronany heart disease: a prospective case-control study in a general population sample of middle aged men.

Br Med J 1990; 301: 1248-51.

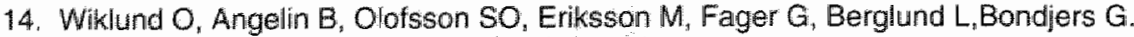
Apolipoprotein(a) and ischaemic heart disease in tamilial hypercholesterolaemia. Lancet 1990; 335: 1360-3.

15. Seed M, Hoppichler F, Reaveley D, McCarthy S, Thompson GR, Boerwinkle E, Utermam G. Relation of serum lipoprotein(a) concentration and apolipoprotein(a) phenotype to coronary heart disease in patients with familial hypercholesterolemia N Engl J Med 1990; 322; 1494-9.

16. Költringer $P$, Jürgens $G$.

A dominant role of lipoprotein(a) in the investigation and evaluation of parameters indicating the development of cervical atherosclerosis.

Atherosclerosis $1985 ; 58: 187-98$.

17. Jürgens $G$, Költuringer $P$.

Lipoprotein(a) in ischemic cerebrovascular disease: a new approch to the assessment of risk for stroke.

Neuralogy 1987; 37: 513-5.

18. Zenker $G$, Költringer $P_{n}$ Boné $G$, Niederkorn $K$, Pfeiffer $K_{n}$ Jürgens $G$.

Lipoprotein(a) as a strong indicator for cerebrovascular disease.

Stroke 1986; 17: 942-5.

19. Murai A, Miyahara T, Fujimoto N, Matsuda M, Kameyama M.

Lp(a) lipoprotein as a risk factor for coronary heart disease and cerebral infarction.

Atherosclerosis 1986; 59: 199-204.

20. Eaton DL, Fless GM, Kohr WJ, McLean JW, Xu-QT, Miler CG, Lawn RM, Scanu AM.

Partial amino acid sequence of apolopopratein(a) shows that it is homologous to

plasminogen.

Proc Natl Acad Sci USA 1987; 84: 3224-8.

21. McLean JW, Tomlinson JE, Kuang WJ, Eaton DL, Chen EY, Fless GM., ScanuAM, Lawn RM. cDNA sequence of human apolipoprotein(a) is homologous to plasminogen.

Nature 1987; $330: 132-7$.

22. Brown MS, Goldstein JL.

Plasma lipoproteins: teaching old dogmas new tricks.

Nature 1987; 330:113-4.

23. Guyton JR, Dahlen GH. Patsch W, Kautz JA, Gotto AM JP.

Relationship of plasma lipoprotein $L p(a)$ levels to race and to apolipoprotein $B$.

Arteriosclerosis $1985 ; 5: 265-72$.

24. Albers $J \mathrm{~J}$, Wahl P, Hazzard WR.

Quantitative genetic studies of the human plasma $L p(a)$ lipoprotein.

Biochem Genet 1974; 11:" 474-86.

25. Gaubatz JW, Heideman C, Gotto AM Jr, Morrisett JD, Dahlen GH.

Human plasma lipoprotein(a).

Jiol Chem 1983; $258: 4582-9$.

26. Utermann $G$, Menzel $H J$, Kraft $H G$, Duba $H C$, Kemmler $H G$, Seitz $C$.

$L p($ a) glycoprotein phenotypes.

$\downarrow$ Clin Invest 1987; 80: 458-65. 
27. Frank SL, Klisak I, Sparkes RS, Mohandas T, Tomlinson JE, Malean JW, LawnRM, Lusis A. The apolipoprotein(a) gene resides on human chromosome $6926-27$, in close proximity to the homologous gene for plasminogen.

Hum Genet 1988; 79: 352-6.

28. Boerwinkle E, Menzel HJ, Kraft HG, Utermann G.

Genetics of the quantitative LP(a) lipoprotein trait III. Contribution of Lp(a)glycoprotein phenotypes to normal lipid variation.

Hum Genet 1989; 82: 73-8.

29. Patthy L.

Evolution of the proteases of blood coagulation and fibrinolysis by assembly from modulles.

Cell $1985 ; 41: 657-63$.

30. Gavish D, Azrolan N, Breslow JL.

Plasma Lp(a) concentration is inversely correlated with the ratio of kringle IV/kringle $\mathrm{V}$ encoding domains in the Apo(a), gene.

J Clin Invest 1989; 84: 2021-7.

31. Miles LA, Plow EF.

Lp(a): an interloper into the fibrinolytic system?

Thromb Haemost 1990; 63: 331-5.

32. Berg K.

The Lp system.

Ser Haematol 1968; 1 : 1111-36.

33. Albers JJ, Hazzard WR.

Immunochemical quantification of human plasma Lp(a) lipoprotein.

Lipids $1974 ; 9$ : 15-26.

34. Albers JJ, Adolphson JL, Hazzard WR.

Radioimmunoassay of human plasma $L p(a)$ lipoprotein.

J Lipid Res 1977; 18: 331-8.

35. Vu-Dac N, Mezdour H "Parra HJ, Luyeye I, Fruchart dC.

A selective bi-site immunoenzymatic procedure for human $L p(a)$ lipoprotein quantification using monoclonal antibodies against apo(a) and apo-B.

J Lipid Res 1989; 30: 1437-43.

36. Duvic CR, Smith G, Sledge WE, Lee TE, Murray MD, Roheim PS, GallaherwA, Thomson JJ.

Udentification of a mouse momoclonal antibody, LHLP-1 specific for human $L p(a)$.

J Lipid Res 1985; 26: 540-8.

37. Wong WLT, Eaton DL, Berloni A, Ferdly B, Hass PhE.

A monoclonal antibody-based enzyme-linked immunosorbent assay of lipoprotein(a).

Clin Chem 1990; 36: 192-7.

38. Marth E, Cazzolato G, Bittolo Bon G, Avogaro P, Kostner GM.

Serum concentrations of $L p(a)$ and other lipoprotein parameters in heavy alcohol consumers.

Ann Nutr Metab 1982; 26: 56-62.

39. Kraft HG, Menzel HJ, Hoppichler F, Vogel W, Utermann G.

Changes of genetic apolipoprotein phenotypes caused by liver transplantation.

$\mathrm{J}$ Clin Invest 1989; 83: 137-42. 
40. Krempler F, Kostner GM, Bolzano K, Sandhofer F.

Tumover of lipoprotein(a) in man.

J Clin Invest 1980; 65: 1483-90.

41. Kawade Maeda $S$, Abe A, Yamashino M.

Afterations in plasma $L p($ a) lipoprotein and acute phase proteins after surgical operation. Clin Chem 1984; $30: 941$.

42. Wăllberg Jonsson $S$, Rantapää-Dahilvist $S$, Stömquist $M$, Dahlen $G M$. Lipids and apolipoprotein in rheumatoid arthritis.

Scand J Rheumatol 1988; 17:505.

43. Chandier WL, Loo SC.

Lipoprotein(a) does not sthow circadian variations.

Thromb Haemost 1990; 63: 151.

44. Brewer HB.

Effectiveness of diet and drugs in the ireatment of patients with elevated

Lp(a) levels.

In: Scanu AM, ed. Lipoprotein(a). New York, Academic Press Inc. 1990: 211-20.

45. Albers JU, Taggart HM, Applebaum-Bowden D, Haffner S, Chesnut CH III,Hazzard WR. Reduction of lecithin-cholesterol acyltransferase, apolipoprotein $D$ and the

Lp(a)lipoprotein with the anabolic steroid stanozolol.

Biochim Biophys Acta 1984; 795: 293-6.

46. Carlson LA, Hamsten $A$, Asplund A.

Pronounced lowering of serum levels of lipoprotein $L p(a)$ in hyperlipidaemic subjects treated with nicotinic acid.

J Intern Med 1989; 226: 271-6.

47. Gavish D, Breslow JL.

Lipoprotein(a) reduction by $N$-acetylcysteine.

Lancet 1991; 337: 203-4.

48. Stalenhoef AFH, Kroon AA, Demacker PNM.

N-acetylcysteime and lipoprotein(a)

Lancet 1991; 337: 491.

49. Martmann-Moe $K$, Berg K.

Lp(a) lipoprotein enters cultured fibroblasts independently of the plasma membrane low density lipoprotein receptor.

Clin Genat $1981 ; 20: 352-62$

50. Steyer $E$, Kostner GM.

Interaction of lipoprotein LP(a) with the B/E-receptor: a study using isolated bovine adrenal cortex and human fibroblast receptors.

$J$ Lipid Res 1990; 31 : 1247-53.

51. Dahlen $\mathrm{G}$, Ericson $\mathrm{C}$, Berg K

In vitro studies of the interaction of isolated Lp(a) lipoprotein and other serum lipoproteins with glycosaminoglycans.

Clim Genet 1978; $14: 36-42$. 
Chapter 2

\section{On lipoprotein(a) and the coagulation/ fibrinolysis balance in the acute phase of deep venous thrombosis}

S.H.J. Donders, F.A.T. Lustermans, J.W.J. van Wersch

Submitted for publication 


\section{Summary}

In vitro studies have suggested that lipoprotein(a) or $L p(a)$, an important risk factor for the development of atherosclerotic cardiovascular and cerebrovascular disease, might interfere with fibrinolysis. We studied the correlations in vivo between $L p(a)$ and various coagulation and fibrinolysis factors in acute deep venous thrombosis, a state associated with an activated coagulation system and increased reactive fibrinolysis. In 31 patients with established acute deep venous thrombosis of the lower limb, coagulation parameters (fibrin monomers, thrombin-antithrombin III) and fibrinolysis parameters (D-dimers, tissue plasminogen activator antigen, plasminogen) were studied in relation to $L P(a)$ concentrations. Elevated thrombin-antithrombin III and fibrin monomer levels were found together with enhanced D-dimers and tissue plasminogen activator concentrations, signs of an activated coagulation system and of increased reactive fibrinolysis. Significant correlations were obtained between fibrin monomers and thrombin-antithrombin III and D-dimers $(r=0.56 ; p=0.002$ and $r=$ $0.68 ; p=0.0002$ respectively), between fibrin monomers and plasminogen ( $r=$ $0.38 ; p=0.03$ ) and between thrombin-antithrombin III and tissue plasminogen activator antigen $(r=0.64 ; p=0.006)$.

These data are indicative of a normally functioning coagulation/fibrinolysis axis in acute deep venous thrombosis. No correlation between $L p(a)$ concentrations and coagulation or fibrinolysis parameters was found in these patients with acute deep venous thrombosis, which suggests that variations in $L p(a)$ concentrations are not accompanied by parallel changes in coagulation or fibrinolysis parameters.

\section{Introduction}

Lipoprotein (a) or Lp(a), discovered in 1963 by K. Berg (1) as a distinct genetically determined lipoprotein, has been established as an important risk factor for the development of atherosclerotic cardiovascular and cerebrovascular disease (e.g. 2-4). Lp (a) is not correlated with gender, age, other lipid parameters, diet or, with a few exceptions, medication (5-8). Until now the atherogenic mechanism of $L p(a)$ is unknown.

In 1987 Eaton, McLean et al. $(9,10)$ reported that apo(a) was homologous to plasminogen and the possibility of a relation between increased $L p(a)$, disturbed fibrinolysis by enhanced tissue plasminogen activator ( $t$-PA) activity inhibition and coronary heart disease has arisen $(11,12)$. The proven affinity for plasminogen binding sites on fibrin and endothelial cell surfaces suggested the possibility of a modulating effect for $L p(a)$ on fibrinolysis. Numerous reports of in 
vitro studies are now appearing (13-18) and show a concentration-dependent inhibitory effect of $L p(a)$ on fibrinolysis by competition with plasminogen and t-PA for their receptor binding sites on fibrin and endothelial and monocytic cells, hereby reducing tissue plasminogen activator or streptokinase-induced fibrinalytic activity.

To our knowledge, data concerning the effect of $L p(a)$ on the plasma fibrinolytic system in vivo are scarce. Sundell et al. (19) investigated the interrelations between $L p(a)$ and fibrinolysis factors t-PA and PAI in 260 subjects aged between 30 and 60 years who were participating in a health intervention programme in Sweden. No correlations between $L p(a)$ concentrations and t-PA or PAl values were found and Garcia Frade et al. (20) also reported the absence of correlations between $L p(a)$ concentrations with these two and several other fibrinalysis parameters in patients with coronary artery disease.

Our group studied the interrelations of $L p(a)$ with several lipid and haemostasis parameters in 54 patients with essential hypertension, in 65 patients with noninsulin-dependent diabetes mellitus and in 116 insulin-regulated diabetic patients (21). In none of these patient groups was any correlation between $\operatorname{Lp}(a)$ concentrations and various coagulation or fibrinolysis parameters found. However, an inhibitory effect of $L p(a)$ on fibrinolysis might be detectable only in a state of increased fibrinolysis. We therefore investigated the correlations between $L p(a)$ and the haemostasis parameters fibrin monomers, thrombin antithrombin \|ll-complexes (TAT), fibrin split products (D-dimer), tissue plasminogen activator antigen and plasminogen in patients with deep venous thrombosis, known to be in a state of coagulation activation with increased reactive fibrinolysis.

\section{Patients and methods}

\section{Patients}

Thirty-one outpatients (14 males and 17 females) with clinically suspected and later confirmed acute DVT of the lower limb who presented at the Department of Internal Medicine were included in this study. The time span from the onset of symptoms of DVT to the confirmation of the diagnosis varied between 1 and 7 days (median: 2 days). The patients had not taken anticoagulant medication at the time of the study and were not known to have had prior thromboembolic disease. Every patient suspected of DVT underwent real-time B-mode ultrasonography of the leg veins.

The single criterion of full vein compressibility (no thrombosis) and noncompressibility (thrombosis) was used, a method regarded as being highly specific for the establishment of the diagnosis of proximal vein thrombosis (22). A sample of venous blood was drawn prior to heparin administration. 


\section{Samples}

Blood was collected by venepuncture with sodium citrate as anticoagulant (final concentration 0.11 mol/1). Plasma was prepared by centrifugation at $1,600 \mathrm{~g}$ for $30 \mathrm{~min}$. When stored at $-70^{\circ} \mathrm{C}$, the samples were thawed at $37{ }^{\circ} \mathrm{C}$ for $5 \mathrm{~min}$ before use.

\section{Methods}

For the ELISA D-dimer determinations the test kit of Boehringer Mannheim (Germany), product No 998117 was used. The measurements were carried out on the Behring microtiter reader system. The reactions were performed in polystyrene microtitre plates Nunc. The thrombin-antithrombin III analyses were performed using the ELISA test kit Enzygnost-TAT (Behring, Hoechst, Marburg Germany), product No OURC 10/11. The FM concentrations were determined with the chromogenic COA-set FM-test of Kabi Vitrum. The antigenic tissue plasminogen activator test was an ELISA test kit from Kabi Vitrum Diagnostica (Coaliza t-PA test). Plasminogen reagents were also from Kabi Vitrum Diagnostica (Mölndal, Sweden) and employed the chromogenic substrate S2251.

Standardization of $L p(a)$ measurement has not yet been achieved and in view of the results of our own laboratory investigations we selected the sandwich ELISA test kit of Biopool (Sweden). In the mean time the good performance of this assay has been confirmed by others (23).

\section{Statistics}

The significance of the differences was assessed by the Mann-WhitneyWilcoxon test. The different parameters were correlated with each other by the Spearman rank test.

\section{Results}

The mean age of the 31 patients included in this study was 62 years, with a range from 22 to 91 years. In six patients (19\%) pulmonary embolism was diagnosed additionally by means of a ventilation-perfusion lung scan. The summary statistics of haemostasis parameters and $L p(a)$ data, together with the percentages of values under the lower and above the upper reference range limits for each parameter, are given in table 1.

Thrombin-antithrombin III levels were elevated in all patients and fibrin monomers in all but one. Elevated values for D-dimer were found in all patients, for tissue plasminogen activator antigen in $32 \%$ of the patients and for plasminogen in $48 \%$. 


\begin{tabular}{|c|c|c|c|c|c|}
\hline $\begin{array}{l}\text { Parameters } \\
\text { (ref, range) }\end{array}$ & Median & Min & Max & $\begin{array}{l}\text { Percentages } \\
\text { of values } \\
\text { under the } \\
\text { lower ref. } \\
\text { range limit }\end{array}$ & $\begin{array}{l}\text { Percentages } \\
\text { of values } \\
\text { above the } \\
\text { upper ref } \\
\text { range limit }\end{array}$ \\
\hline $\begin{array}{l}\text { Lipoprotein(a) } \\
(0-250 \mathrm{mg} / 1)\end{array}$ & 102 & 1 & 634 & 0 & 13 \\
\hline $\begin{array}{l}\text { Fibrin monomers } \\
(8.4-13.2 \mathrm{nmol} / 1)\end{array}$ & 22 & 13 & 143 & 0 & 97 \\
\hline $\begin{array}{l}\text { Thrombin-antithrombin III } \\
(1.0-4.0 \mu g / l)\end{array}$ & 15 & 4.8 & 78 & 0 & 100 \\
\hline $\begin{array}{l}\text { ELISA D-dimer } \\
(0-450 \mu \mathrm{g} / \mathrm{l})\end{array}$ & 4,343 & 672 & 71,808 & 0 & 100 \\
\hline $\begin{array}{l}\text { Tissue plasminogen activator } \\
\text { antigen }(0.9-12.1 \mu \mathrm{g} / 1)\end{array}$ & 8.8 & 2 & 113 & 0 & 32 \\
\hline $\begin{array}{l}\text { Plasminogen } \\
(80-120 \%)\end{array}$ & 119 & 86 & 156 & 0 & 48 \\
\hline
\end{tabular}

Table 1

Summary statistics of lipoprotein(a) and the coagulation and fibrinolysis parameters and the percentages of values under the lower or above the upper reference range limits in patients with deep venous thrombosis $(n=31)$

\begin{tabular}{|c|c|c|}
\hline Lipoprotein(a) versus parameter & r-value & p-value \\
\hline Fibrin monomers & -0.34 & 0,06 \\
\hline Thrombin-antithrombin III & -0.18 & NSS. \\
\hline D-dimer & -0.18 & NS \\
\hline Tissue plasminogen activator & -0.17 & NS \\
\hline Plasminogen & -0.12 & NS \\
\hline
\end{tabular}

\section{Table 2}

Spearman rank correlations between $L p(a)$ and several coagulation and fibrinolysis parameters in patients with deep venous thrombosis $(n=31)$.

\begin{tabular}{|l|c|c|c|}
\hline Parameters & D-dimer & t-PA & Plasminogen \\
\hline Fibrin monomers & 0.56 & 0.28 & 0.38 \\
& $(0.002)$ & $(0.13)$ & $(0.03)$ \\
Thrombin-antithrombin III & 0.68 & 0.64 & -0.03 \\
& $(0.0002)$ & $(0.0006)$ & $(0.88)$ \\
\hline
\end{tabular}

Table 3

Spearman rank correlation r-values ( $p$-values) between coagulation and fibrinolysis parameters in patients with deep wenous thrombosis $(n=31)$. 
Table 2 shows the correlations between coagulation and fibrinolysis data and $L p(a)$. A tendency towards a negative correlation between $L p(a)$ and fibrin monomers was found $(r=-0.34, p=0.06)$, whereas no correlation between $L p(a)$ and the fibrinolytic parameters was obtained.

Table 3 gives the correlations between coagulation and fibrinolysis parameters. Strong positive correlations for fibrin monomers and thrombin-antithrombin III with $D$-dimers ( $r=0.56, p=0.002$ and $r=0.68, p=0.0006$ respectively) were noted and significant correlations between fibrin monomers and plasminogen ( $r=$ $0.38, p=0.03)$ and between thrombin-antithrombin III and t-PA ( $r=0.64$, $p=0.006$ ) were also found.

\section{Discussion}

Although in vitro studies investigating the effect of $L p(a)$ on fibrinolysis are not unanimous in their conclusions, a substantial majority of them report evidence for a diminished fibrinolysis on vascular and fibrin surfaces due to lipoprotein(a) interference. Plasminogen binds weakly to its target fibrin and its precursor fibrinogen (24), which is of importance for the formation of the tissue plasminogen activator (t-PA)-fibrin-plasminogen complex needed for plasminogen activation and fibrinolysis. Loscalzo and co-workers (17) and Harpel et al. (25) reported that $L p(a)$ competed with plasminogen and less effectively with t-PA for fibrinogen and fibrin binding. The affinity of $L p(a)$ for plasminogen and t-PA binding sites seems to induce functional alterations in fibrinolysis. Enhancement of plasminogen activation on the endothelial cell surface by fibrin was reported to be diminished in the presence of $L p(a)$ (13). The activity of the fluid phase plasmin was not affected by $L p(a)$. Edelberg et al. (18) reported that physiological concentrations of $L p(a)$ inhibited plasminogen activation by t-PA bound to fibrinogen fragments, and calculated that $L p(a)$ concentrations greater than $300 \mathrm{mg} / \mathrm{l}$ could reduce normal fibrinolysis by $80 \%$. The same investigators reported $L p(a)$ to attenuate plasminogen conversion to plasmin by streptokinase binding. Competitive inhibition of plasminogen activation occurred at normal $L p(a)$ concentrations $(140 \mathrm{mg} / \mathrm{l})$, non-competitive inhibition at elevated Lp(a) concentrations $(420 \mathrm{mg} / \mathrm{l})(15)$.

In the group of patients studied here, we found activation of the coagulation system and enhanced reactive fibrinolysis in acute deep venous thrombosis as expected. Strong correlations were obtained for fibrin monomers and thrombinantithrombin III (coagulation) with $D$-dimers (fibrinolysis) $(r=0.56, p=0.002$ and $r=0.68, p=0.0002$ respectively). Furthermore, correlations between fibrin monomers and plasminogen $(r=0.38 ; p=0.04)$ and between thrombinantithrombin III and $t-P A$ antigen $(r=0.64 ; p=0.0006)$ were found. These data are indicative of a normally functioning coagulation/fibrinolysis axis.

$L p(a)$ did not correlate with coagulation or fibrinolysis parameters in these patients. After dividing the patients into those with $L p(a)$ concentrations below 
and those above $L p(a)$ cut off levels of $100 \mathrm{mg} / /, 200 \mathrm{mg} / /$ and $300 \mathrm{mg} / \mathrm{l}$ respectively, no differences were seen in coagulation and fibrinolysis parameters between those with low and those with high $L p(a)$ concentrations (data not shown). Thus, in spite of numerous in vitro studies showing that $L p(a)$ interferes with fibrinolysis, we were unable to find a correlation between LP(a) concentrations and the coagulation and fibrinolysis parameters studied in patients with acute deep venous thrombosis. This conclusion is in line with the results obtained in the study of März et al. (26) who reported that elevated Lp(a) concentrations were not related to the development of deep venous thrombosis.

In summary, if an effect of $L p(a)$ on the plasmatic fibrinolysis system existed, it might well be overwhelmed by other influences. The results nevertheless show that variations in $L p(a)$ concentrations are not accompanied by parallel alterations in coagulation and fibrinolysis parameters.

\section{References}

1. Berg K.

A new serum type system in man - the Lp system.

Acta Path Microbial Scand 1963; 59: 369-82.

2. Walton KW, Hitchens J, Magnani HN, Khan M.

A study of methods of identification and estimation of LP(a) lipoprotein and of its significance in health, hyperlipidaemia and atherosclerosis.

Atherasclerosis $1974 ; 20: 323-46$.

3. Armstrong WW, Cremer P, Eberle E, Manke A, Schulze F, Wieland H, KreuzerH, Seidel D. The association between serum $L p(a)$ concentrations and angiographically assessed coronary atherosclerosis.

Atherosclerosis 1986; 62: 249-57.

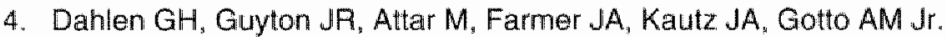

Assaciation of levels of lipoprotein Lp(a), plasma lipids, and other lipoproteins with coronary artery disease documented by angiography.

Circulation 1986; 74:758-65.

5. Dahlen GH.

Incidence of $L p(a)$ lipoprotein among populations.

In: Scanu, AM, ed. Lipoprotein(a). Acad Press, New York, 1990: 151-73.

6. Carlson LA, Hamsten A, Asplund A.

Pronounced lowering of serum levels of lipoprotein $L p(a)$ in hyperlipidaemic subjects treated with nicotinic acid.

J Intern Med 1989; 226: 271-6.

7. Albers Jل Jaggart AH, Applebaum-Bowden D, Haffner S, Chesnut $\mathrm{CH}$ 3rd, Hazzard WR. Reduction of lecithin-cholesterol acyltransferase apolipoprotein D and the Lp(a)lipoprotein with the anabolic steroid stanozolol.

Biochim Biophys Acta 1984; 795: 293-6.

8. Gurakar A, Hoeg JM, Kostner G, Papadopoullos NM, Brewer HB Jr. Levels of lipoprotein $L p(a)$ decline with neomycin and miacin treatment.

Atherosclerosis 1985; 57 : 293-301. 
9. Eaton DL, Fless GM, Kohr WJ, McLean JW, XU-QT, Miller CG, Lawn RM, Scanu AM. Partial amino acid sequence of apolipoprotein(a) shows that it is homologous to plasminogen.

Proc Natl Acad Sci USA 1987; 84: 3224-8.

10. McLeam JW, Tominson JE, Kuang WJ, Eaton DL, Chen EY, Fless GM., ScanuAM, Lawn RM. CDNA sequence of human apolipoprotein(a) is homologous to plasminogen.

Nature $1987 ; 330 ; 132-7$.

11. Hamsten $A$, de Faire U, Walldius $G$, Dahten $G$, Szamosi $A$, Landou $C$ "Blombäck $M$, Wiman $B$.

Plasminogen activator inhibitor in plasma: risk factor for recurrent myocardial infarction. Lancet 1987; ii: 3-9.

12. Brown MS, Goldsteiri dL.

Plasma lipoproteins: teaching old dogmas new tricks.

Nature 1987; 330: 113-4.

13. Hajjar KA, Gavish $\mathrm{D}$, Breslow JL, Nachman $\mathrm{RL}$.

Lipoprotein(a) modulation of endothelial cell surface fibrinolysis and its potential role in atherosclerosis.

Nature 1989; 339: 303-5.

14. Miles LA, Fless GM, Levin EG, Scanu AM, Plow EF.

A potential basis for the thrombotic risk associated with lipoprotein(a). Nature 1989; 339: 301-3.

15. Edelberg JM: Gonzalez-Gronow M, Pizzo SV.

Lipoprotein(a) inhibits streptokinase-mediated activation of human plasminogen.

Biochemistry 1989; 28: 2370-4

16. Gonzalez-Gronow M, Edelberg JM, Pizzo SV.

Further characterization of the cellular plasminogen binding site: evidence that

plasminogen 2 and lipoprotein a compete for the same site.

Blochemistry $1989 ; 28: 2374-7$.

17. Loscalzo J, Weinfeld M, Fless GM, Scanu AM.

Lipoprotein(a), fibrin binding, and plasminogen activation.

Arteriosclerosis 1990; 10: 240-5.

18. Edelberg JM, Gonzalez-Gronow M, Pizzo SV.

Lipoprotein(a) inhibition of plasminogen activation by tissue-type plasminogen activator. Thromb Res 1990; 57 : 155-62.

19. Sundell $1 B$, Nilsson TK, Hallmans $G$, Hellsten $G$, Dahilen GH.

Interrelationship between plasma levels of plasminogen activator inhibitor, tissue plasiminogen activator, lipoprolein(a), and established cardiovascular risk factors in a North Swedish population.

Atherosclerosis $1989 ; 80: 9-16$.

20. Garcia Frade LJ, Alvarez JJ, Rayo I, Torrado MC, Lasuncion MA. Garcia Avello A, Hernandez A, Marin E.

Fibrinolytic parameters and lipoprotein(a) levels of patients with coronary artery disease. Thromb Res 1991; 63: 407-18.

21. Donders SHJ, Lustermans FAT, van Wersch JWJ.

Low order correlations of lipoprotein(a) with other blood lipids and with coagulation and fibrinolysis parameters in hypertensive and diabetic patients.

Blood Coaguiation and Fibrinolysis 1992; in press.

22. Lensing AW, Prandoni P, Brandjes D, Huisman PM, Vigo M, Tomasella G, Krekt J, Ten Cate JW. Huisman MV, Büller HR.

Detection of deep-vein thrombosis by real-time B-mode ultrasonography.

N Engl J Med 1989; 320: 342-5. 
23. Dagen MM, Packard CJ, Shepherd J.

A comparison of commercial kits for the measurement of lipoprotein(a). Ann Clin Biochem 1991; 28: 359-64,

24. Lucas MA, Fretto LJ, McKee PA.

The binding of human plasminogen to fibrin and fibrinogen.

J Biol Chem 1983; 258: 4249-52.

25. Harpel PC, Gordon BR, Parker TS.

Plasmin catalyzes binding of lipoprotein(a) to immobilized fibrinogen and fibrin.

Proc Natl Acad Sci USA 1989; 86: 3847-51.

26. März W, Trommlitz M, Scharier I, Crop W.

Apolipoprotein(a) concentrations are not related to the risk of venous thrombosis.

Blood Coagulation and Fibrinolysis 1991; 2 : 595-9. 

Chapter 3

Low order correlations of lipoprotein(a) with other blood lipids and with coagulation and fibrinolysis parameters in hypertensive and diabetic patients

S.H.J. Donders, F.A.T. Lustermans, J.W.J. van Wersch

Blood Coagulation and Fibrinolysis 1992; in press 


\section{Summary}

Lipoprotein(a) or (Lp(a) has been established as an important independent risk factor for the development of cardiovascular disease. Apolipoprotein(a), together with apo B-100 the apolipoprotein of $L p(a)$, is homologous to plasminogen but lacks fibrinolytic capacity and appeared to intertere with fibrinolysis in 'in vitro' experiments. The correlations between $L p(a)$ with other blood lipids (serum cholesterol, LDL-cholesterol, HDL-cholesterol, triglycerides), coagulation parameters (fibrinogen, factor VII, factor VIIIC, fibrin monomers, thrombinantithrombin $\mathrm{II}$ ) and fibrinolysis parameters (tissue plasminogen activator antigen, plasminogen activator inhibitor- 1 and D-dimers) were investigated in 54 patients with essential hypertension, in 65 non-insulin-dependent diabetic patients and in 116 insulin-regulated diabetic patients.

Signs of an activated coagulation system and reactive fibrinolysis were found in all three patient groups. In the hypertensive patients, correlations of $L p(a)$ with LDL-cholesterol $(r=0.25, p=0.04)$ and triglycerides $(r=-0.30, p=0.03)$ were established. In the insulin-regulated diabetic patients we also found a correlation between $L p(a)$ and LDL-cholesterol $(r=0.20, p=0.03)$. In the hypertensive patient group and in both diabetic patient groups no correlation of $L p(a)$ with coagulation or fibrinolysis parameters could be found.

These data show that $L p(a)$ concentrations are not related to coagulation or fibrinolysis parameters in hypertensive or diabetic patients. Furthermore, they confirm the presence of an activated coagulation system in these patient groups

\section{Introduction}

Hypertension, overweight, carbohydrate and lipid disorders are among the main risk factors for the development of atherosclerotic vascular disease and its complications. Hypercholesterolaemia has been established as an independent risk factor $(1,2)$, whereas the question whether an elevated serum triglyceride concentration is an independent risk factor is still controversial $(3,4)$. Lipoprotein(a), or $L p(a)$, discovered in 1963 by $K$. Berg as a distinct lipid fraction (5) , has turned out to be another independent risk factor for cardiovascular (610) and cerebrovascular disease $(11,12)$. Lp(a) consists of an LDL-like particle with an additional apolipoprotein, apolipoprotein(a) or apo(a), (13). Apo(a) shows a striking homology with plasminogen, the key pro-enzyme of fibrinolysis $(14,15)$. The substitution of one amino acid at the activation site of the serine protease domain of apo(a) ( $94 \%$ homologous to the serine protease domain of plasminogen) prevents apo(a) having fibrinolytic activity. The structure of $L p(a)$ has given rise to speculations that $L p(a)$ accelerates atherogenesis by interference 
with fibrinolysis (14-16). This hypothesis has been supported by numerous in vitro experiments which show that $L P(a)$ decreases fibrinolytic activity (17, review).

An activated coagulation system (18-24) and impaired fibrinolysis (25-27) have also been related to the development of coronary heart disease. The occurrence of an activated coagulation system in hypertension (28-30) and diabetes mellitus (31-33) has been reported by our group and by other investigators. In these patient groups an inhibitory effect of $L p(a)$ on the plasma fibrinolytic system might further facilitate the development of atherosclerotic lesions.

To determine whether $\operatorname{Lp}(a)$ concentrations are related to blood coagulation or fibrinolysis parameters we investigated $L p(a)$ together with blood lipid parameters (cholesterol, LDL-cholesterol, HDL-cholesterol and triglycerides), coagulation parameters (fibrinogen, fibrin monomers and thrombin-antithrombin (TAT) III complexes) and fibrinolysis parameters (D-dimer, tissue plasminogen activator (t-PA) and plasminogen activator inhibitor-1 (PAl-1)) in patients with hypertension and in patients with diabetes mellitus.

\section{Patients, materials and methods}

\section{Hypertensive patients}

The criterion for hypertension was a repeated measurement of a diastolic pressure $\geq 95 \mathrm{mmHg}$ or a systolic pressure $\geq 160 \mathrm{mmHg}$ both on the left and right hand sides. Fifty-four otherwise healthy patients (27 males and 27 females) meeting these criteria were evaluated. Their ages varied between 19 and 70 years (mean age 50 years). The mean established duration of hypertension was 5 years (range $0.5-20$ years). At the time of the study eleven hypertensive patients were not receiving any antihypertensive drugs, 23 patients used calcium antagonists, 13 patients were taking angiotensin converting enzyme (ACE) inhibitors, 16 patients were under treatment with diuretics and 7 patients used beta-blockers as monotherapy or together with other antihypertensive drugs. The patients treated with antihypertensive drugs who were included in this study were still hypertensive in spite of their treatment and met the criteria concerning blood pressure mentioned above.

The systolic blood pressure ranged from $130-200 \mathrm{mmHg}$ (mean $170 \mathrm{mmHg}$ ). The diastolic blood pressure varied between 90 and $144 \mathrm{mmHg}$ (mean 104 $\mathrm{mmHg}$ ). For the classification of the hypertension we considered three subgroups: essential hypertension, renal hypertension and hormonal hypertension. In this study all patients could be classified as belonging to the essential hypertension group. Patients with signs of malignant hypertension, intercurrent illnesses, liver, renal or endocrine diseases were excluded. Four patients were cigarette smokers. 


\section{Non-insulin-dependent diabetic patients treated with oral hypoglycaemic agents}

Sixty-five diabetic patients ( 41 females, 24 males) were included in the study. The mean age was 65 years (age range 43 to 86 years), and the mean established duration of diabetes mellitus was 8 years (range 0.5 to 40 years). All patients were taking oral hypoglycaemic agents.

The patients did not have intercurrent illnesses, hypertension, liver, renal or other endocrine diseases. Patients with macroalbuminuria (i.e. an urinary albumin excretion exceeding $200 \mu \mathrm{g}$ per min.) were excluded from the study. The blood samples were collected when the patients attended their routine diabetes control. Nine patients were cigarette smokers.

\section{Insulin-treated diabetic patients}

One hundred and sixteen insulin-treated diabetic patients, consisting of 47 males (mean age 55.3 years, range 20-80) and 69 females (mean age 60.1 years, range 30-82) were included in the study. Patients with a urinary albumin excretion exceeding $200 \mu \mathrm{g}$ per minute or with intercurrent illnesses, liver, renal, other endocrine diseases or hypertension were excluded from the study.

The number of true type 1 subjects amounted to 62. The blood samples were collected when the patients attended the hospital (St. Gregorius Hospital, Brunssum, The Netherlands) for their routine diabetes control in the Department of Internal Medicine.

\section{Reference group}

The reference values were obtained from 50 healthy non-smoking hospital workers (25 males, 25 females) aged $25-50$ years (mean age 40 years). The females did not use oral contraceptives.

\section{Samples}

Venous blood samples were collected between 8.30-9.00 a.m. and citrated plasma was prepared by centrifugation of nine volumes of freshly drawn blood with one volume of trisodium citrate $(0.11 \mathrm{mo} / / \mathrm{l})$ for $30 \mathrm{~min}$ at $25^{\circ} \mathrm{C}(1600 \mathrm{~g})$. The plasma was used immediately or stored at $-70^{\circ} \mathrm{C}$ in plastic tubes and thawed under tap water for $5 \mathrm{~min}$ before use.

For the glycometabolic determinations, washed red cells were haemolysed and the haemolysate was used for the chromatographic separation of $\mathrm{HbA}_{1 \mathrm{c}}$. 


\section{Methods}

The serum samples were analysed with a Cobas BioR centrifugal fast analyzer and commercial test kits were used according to the manufacturer's instructions.

- Serum triglycerides:

an enzymatic colorimetric test was used in which the triglycerides are enzymatically hydrolysed, the glycerol generated is phosphorylated (glycerol kinase) and oxidised (glycerol phosphate oxidase) and the hydrogen peroxide formed effects the oxidative coupling of 4-chlorophenol and 4-aminophenazone to form a red-coloured quinoneimine derivate; (test kit Roche Diagnostica Basle/Switzerland; art.nr. 0722138).

- Total serum cholesterol:

an enzymatic colorimetric test was used: cholesterin esters are hydrolysed by cholesterin-esterase and the total cholesterol is oxidised by cholesterinoxidase; the hydrogen peroxide, in the presence of peroxidase, effects the oxidative coupling of 4-aminophenazone and phenol to form a red-coloured phenazone derivate; (CHOD-PAP method; test kit Boehringer Mannheim/ Germany; art.nr. 237574).

- HDL-cholesterol:

the CHOD-PAP method was used on the supernatant solution, after removal by precipitation of chylomicrons, VLDL- and LDL-lipoproteins from serum by the phosphostungstic acid/magnesium chloride precipitant; (HDL-cholesterol test kit Boehringer Mannheim/ Germany; art.nr. 400971).

- LDL-cholesterol:

the Friedewald equation was used for the calculation of LDL-cholesterol concentrations. $\mathrm{LDL}$-chol $=$ total chol $-(0.45 \mathrm{x}$ triglyc) $-\mathrm{HDL}$-chol $(\mathrm{mmol} / 1)$.

- Lipoprotein(a):

Sandwich ELISA test kit (Biopool, Sweden).

- $\mathrm{HbA}_{1 \mathrm{C}}$ in haemolysate:

Bio Rad ion exchange column chromatography, product No 192-8001.

- Fibrinogen:

turbidimetric method of Behring, using the CTS-fibrinogen reagent on the Chromotime System (Behring).

- Factor VII:

chromogenic substrate COA-set of Kabi Vitrum Diagnostica, Sweden.

- Factor VIIIC:

an APTT one stage clotting assay was used, employing a deficiẽnt plasma (Behring, Marburg, Germany).

- Fibrin monomers:

chromogenic COA-set FM test Kabi Vitrum Diagnostica. 
- Plasma Thrombin-antithrombin III:

ELISA test kit Enzygnost-TAT, Behring, Hoechst, Marburg (Germany), product $N^{\circ}$ OURC $10 / 11$.

- Plasma D-Dimer:

For the ELISA D-dimer determinations the test kit of Boehringer Mannheim, product $N^{\circ} 998117$ was used. The measurements were carried out on the Bio Rad micro- titer reader system. The reactions were performed in polystyrene micro-titre plates of the Nunc Corporation.

- Tissue plasminogen activator antigen:

An ELISA test kit from Kabi Vitrum Diagnostica (Coaliza activator antigen t-PA test) was used.

- Plasma plasminogen activator inhibitor-1:

the test kit of Kabi Vitrum (COA-SET PAI), with activator inhibitor-1 chromogenic substrate S-2403, was used. PAl-1 values were expressed in Arbitrary Units (AU).

\section{Statistics}

The significance of the differences was assessed by the Mann-WhitneyWilcoxon test. The parameters studied were correlated with each other by the Spearman rank test.

\section{Results}

\section{Hypertensive patients}

The median values of the blood lipid parameters in the hypertensive patient group are shown in table $1 . L p(a)$ concentrations in these patients were significantly elevated with a median value of $122 \mathrm{mg} / \mathrm{l}$ compared with $44 \mathrm{mg} / \mathrm{l}$ in the reference group $(p<0.001)$, whereas $L p(a)$ levels were elevated in $27.8 \%$ of the hypertensive patients. Triglycerides and LDL-cholesterol were elevated in $46.3 \%$ and $27.8 \%$ of the patients respectively, whereas HDL-cholesterol values were decreased in $11.1 \%$ of the patients (data not shown). Lipid and haemostasis parameters did not differ significantly between treated and untreated hypertensive patients (Mann-Whitney-Wilcoxon test).

In table 2 the results of coagulation and fibrinolysis parameters are given in comparison with the reference group. Elevated values for all the coagulation and fibrinolysis parameters studied were found, with the exception of fibrinogen. The coagulation data showed elevated fibrin monomers in $59.2 \%$ of the patients and elevated F V\|I concentrations in $41.7 \%$ of the male patients (table 3 ). $L p(a)$ was 


\begin{tabular}{|c|c|c|c|}
\hline $\begin{array}{l}\text { Parameters } \\
\text { (Refence range) }\end{array}$ & $\begin{array}{c}\text { Hypertensive } \\
\text { patients }\end{array}$ & $\begin{array}{l}\text { NDDDM } \\
\text { patients }\end{array}$ & $\begin{array}{l}\text { Insulin-treated } \\
\text { diabetic patients }\end{array}$ \\
\hline $\begin{array}{l}\text { Total cholesterol } \\
(4,0-7.5 \mathrm{mmol} / 1)\end{array}$ & 6.2 & 6.8 & 6.2 \\
\hline $\begin{array}{l}\text { LDL-cholesterol } \\
(3.0-5.0 \mathrm{mmol} / \mathrm{l})\end{array}$ & 4.1 & 4.5 & 3.9 \\
\hline $\begin{array}{l}\text { HDL-cholesterol } \\
(0.9-1.7 \text { mmot/l) }\end{array}$ & 1.1 & 1.2 & 1.2 \\
\hline $\begin{array}{l}\text { Triglycerides } \\
(0.8-2.0 \mathrm{mmol} / \mathrm{l})\end{array}$ & 1.8 & 2.1 & 1.8 \\
\hline $\begin{array}{l}\text { Lipoprotein(a) } \\
(<300 \mathrm{mg} / 1)\end{array}$ & 122 & 64 & 56 \\
\hline $\begin{array}{l}\mathrm{Hb} \mathrm{A}_{1 \mathrm{c}} \\
(4-7 \%)\end{array}$ & - & 8.5 & 8.1 \\
\hline
\end{tabular}

\section{Table 1}

Median values of the blood lipid parameters in the hypertensive patients $(n=54)$, the NIDDM patients treated with oral antidiabetic agents $(n=65)$ and the insulin-treated diabetic patients $(n=116)$.

\begin{tabular}{|c|c|c|c|c|}
\hline $\begin{array}{l}\text { Parameters } \\
\text { (Refence range) }\end{array}$ & $\begin{array}{l}\text { Hypertensive } \\
\text { patients }\end{array}$ & $\begin{array}{l}\text { NIDDM } \\
\text { patients }\end{array}$ & $\begin{array}{l}\text { Insulin-treated } \\
\text { diabetic patients }\end{array}$ & $\begin{array}{l}\text { Reference } \\
\text { group }\end{array}$ \\
\hline $\begin{array}{l}\text { Fibrinogen } \\
(1,7-4,0 \mathrm{~g} / 1)\end{array}$ & 3.2 & 4.64 & $3.5^{3}$ & 30 \\
\hline $\begin{array}{l}\text { F VII males } \\
(54-138 \%)\end{array}$ & $\left.137^{3}\right)$ & 1394 & 93 & 94 \\
\hline $\begin{array}{l}\text { F VII fermales } \\
(56-200 \%)\end{array}$ & $147^{2 j}$ & 143 & $108^{2 j}$ & 131 \\
\hline $\begin{array}{l}\text { Fvillic } \\
(61-176 \%)\end{array}$ & $116^{1)}$ & 1494 & 98 & 90 \\
\hline $\begin{array}{l}\text { Fibrin monomers } \\
(8.4-13.2 \text { nmol/1) }\end{array}$ & $13.5^{21}$ & $13.9^{43}$ & 13.311 & 10.5 \\
\hline $\begin{array}{l}\text { Thrombin-antithrombin ill } \\
(1.0-4.1 \mu \mathrm{g} / 1)\end{array}$ & $3.0 \%$ & $3.44\}$ & 2.3 & 2.3 \\
\hline $\begin{array}{l}\text { D-dimer } \\
(0-450 \text { ug/l }\end{array}$ & $315^{3)}$ & $277 x$ & $349^{4 i}$ & 199 \\
\hline $\begin{array}{l}\text { Tissue plasminogen activator } \\
\text { antigen }(0.9-12.1 \mu \mathrm{g} /)\end{array}$ & $8.2^{4 !}$ & 6.4 & 5.9 & 5.1 \\
\hline $\begin{array}{l}\text { Plasminogen activator inhibitor } 1 \\
(\mathrm{PAl}-1)\left(0-4.6 \mathrm{AU} .1^{3} / 0\right)\end{array}$ & $\left.2.8^{2}\right\}$ & $4.5^{4)}$ & 20 & 0.8 \\
\hline
\end{tabular}

Table 2

Median values of the haemostasis parameters in the hypertensive patients $(n=54)$. the NIDDM patients treated with oral antidiabetic agents $(n=65)$ and the insulin- treated diabetic patients $(n=116)$ in comparison with a healthy reference group $(n=50)$. 


\begin{tabular}{|c|c|c|c|c|c|c|}
\hline \multirow[t]{2}{*}{$\begin{array}{l}\text { Parameters } \\
\text { (ret, range) }\end{array}$} & \multicolumn{2}{|c|}{ Hypertensive patients } & \multicolumn{2}{|c|}{ NIDOM patients } & \multicolumn{2}{|c|}{$\begin{array}{l}\text { Insulin-treated } \\
\text { diabetic patients }\end{array}$} \\
\hline & $\begin{array}{l}\text { Percentage } \\
\text { brelow ref } \\
\text { range rainge }\end{array}$ & $\begin{array}{l}\text { Percentage } \\
\text { above ref. } \\
\text { range }\end{array}$ & $\begin{array}{l}\text { Percentage } \\
\text { below ret. } \\
\text { range }\end{array}$ & $\begin{array}{l}\text { Percentage } \\
\text { above ref. } \\
\text { rangle }\end{array}$ & $\begin{array}{l}\text { Percentage } \\
\text { below ref. } \\
\text { range. }\end{array}$ & $\begin{array}{l}\text { Percentage } \\
\text { above ref. } \\
\text { range }\end{array}$ \\
\hline $\begin{array}{l}\text { Flarnogen } \\
(17,4090)\end{array}$ & 0 & 91 & 0 & 67.7 & 1.0 & 32 \\
\hline $\begin{array}{l}\text { F VI males } \\
(54-138 \%)\end{array}$ & 0 & 41.7 & 9.5 & 19.0 & 7.0 & 0 \\
\hline $\begin{array}{l}\text { Evil fenales } \\
(56-2009)\end{array}$ & 0 & 4.3 & 2.5 & 27.5 & 10.0 & 2.9 \\
\hline $\begin{array}{l}\text { F VIIIC, } \\
(61,176 \%)\end{array}$ & 18 & 13.0 & 0 & 25.9 & 11.7 & 1.8 \\
\hline $\begin{array}{l}\text { Fibrin monomers } \\
(8.4-13.2 \text { nnolit) }\end{array}$ & 18.5 & 59.2 & 6.7 & 56.7 & 10.9 & 62.4 \\
\hline $\begin{array}{l}\text { Thrombin } \\
\text { antithrombin } 1 \text {. } \\
(1.04 .1 \text { Hgll) }\end{array}$ & 0 & 20.4 & 0 & 42.4 & 0 & 15.9 \\
\hline $\begin{array}{l}\text { D-dimer } \\
(0-450 \mu g / 1\end{array}$ & 0 & 18.5 & 0 & 23.1 & 0 & 41.6 \\
\hline $\begin{array}{l}\text { Tissue plasminogen } \\
\text { activator antigen } \\
(0.9-121 \mathrm{Hg} / \mathrm{l})\end{array}$ & 0 & 13.0 & 0 & 6.2 & 0 & 7.1 \\
\hline $\begin{array}{l}\text { Plasminogen } \\
\text { activator inhibitor-1 } \\
(\mathrm{PAl}-1) \text {, }(0-4.6 \mathrm{Al}, 103 / 1)\end{array}$ & 0 & 6.7 & 1.5 & 46.2 & 0 & 18.7 \\
\hline
\end{tabular}

Table 3

Percentages of values below the lower and above the upper reference range limits of the haemostasis parameters in the hypentensive patients $(n=54)$, the NiDDM patients treated with oral antidiabetic agents $(n=65)$ and the insulin-treated diabetic patients $(n=116)$.

not correlated with blood pressure, Quetelet-index (data not shown), coagulation or fibrinolysis parameters (table 4). Lp(a) correlated with LDL-cholesterol ( $r=$ $0.25, p=0.04)$ and with triglycerides $(r=-0.30, p=0.04)$ (table 4).

\section{Non-insulin-dependent diabetic patients}

Data on glycometabolic control and blood lipid parameters are given in table 1. $L p(a)$ concentrations did not significantly differ from those measured in the reference group and were elevated in $15.4 \%$ of the NIDDM patients. Triglycerides and LDL-cholesterol values were elevated in $50.8 \%$ and $47.7 \%$ of the patients respectively, whereas HDL-cholesterol concentrations were decreased in $10.8 \%$ of the patients (data not shown). 


\begin{tabular}{|c|c|c|c|c|c|c|}
\hline \multirow{2}{*}{$\begin{array}{l}\text { Lpoprotein(a) } \\
\text { versus } \\
\text { Parameter }\end{array}$} & \multicolumn{2}{|c|}{$\begin{array}{l}\text { Hypentens ive } \\
\text { patients (n= 54) }\end{array}$} & \multicolumn{2}{|c|}{$\begin{array}{l}\text { Non-insulin } \\
\text { dependent diabetic } \\
\text { patients }(\mathrm{n}=65)\end{array}$} & \multicolumn{2}{|c|}{$\begin{array}{l}\text { Insulin-regulated } \\
\text { diabetic patients } \\
(n=116)\end{array}$} \\
\hline & $r$ & $p$ & $r$ & p & $r$ & P \\
\hline Total cholesterol & 0.08 & 0.57 & 0,12 & 0.35 & 017 & 0.06 \\
\hline LDL-cholesterol & 0.25 & 0.04 & 0,19 & 015 & 020 & 0.03 \\
\hline HDL-cholesterol & 016 & 0.29 & 0.25 & 0.06 & 012 & 0.21 \\
\hline Triglycerides & 0,30 & 0.04 & 0.24 & 0.07 & 0.03 & 0.72 \\
\hline Fibrinogen & 0.06 & 0.7 & 0.15 & 0.34 & 0,07 & 0.47 \\
\hline F VII & 0,15 & 0.31 & 0009 & 0.49 & 0,09 & 0.93 \\
\hline F VIllo & 018 & 0,18 & 0.09 & 0.55 & 001 & 0.92 \\
\hline Fibrin monomers & 0,04 & 0,78 & 0.01 & 0.94 & 003 & 0.80 \\
\hline $\begin{array}{l}\text { Thrombin } \\
\text { antithrombin I }\end{array}$ & 0.09 & 0.52 & 0.09 & 0.50 & 0.02 & 0.82 \\
\hline IPA ag & -026 & 0.06 & -0.13 & 0,30 & 0.14 & 0.12 \\
\hline $\mathrm{PAl}$ & 0.15 & 0.26 & 0.34 & 0.12 & 0.14 & 0.17 \\
\hline D-dimer & 008 & 0.58 & 0.09 & 0.46 & 008 & 0.37 \\
\hline
\end{tabular}

\section{Table 4}

Correlations between lipoprotein(a) and blood lipid, coagulation and fibrinolysis parameters in patients with hypertension, non-insulin-dependent diabetes mellitus and insulin-regulated diabetes mellitus ( $r=$ Spearman rank correlation, $p=$ significance value).

Table 2 shows the coagulation and fibrinolysis data of the NIDDM patients in comparison with the reference group. Levels of fibrinogen, $F$ VIllc, fibrin monomers, TAT-complex, D-dimer, PAI- 1 and F VII in males were elevated in the NIDDM patient group. The coagulation and fibrinolysis data showed increased concentrations of fibrinogen, fibrin monomers and thrombinantithrombin III in $68 \%, 57 \%$ and $43 \%$ of the patients, respectively (table 3 ).

$L p(a)$ was not correlated with the Quetelet-index, with other lipid parameters or with haemostasis parameters but tended to correlate with $\mathrm{HbA}_{1 \mathrm{c}}$ values $(r=0.23, p<0.07)$ (table 4).

\section{Insulin-treated diabetic patients}

Table 1 shows the median values of glycometabolic control and lipid parameters in the 116 insulin-treated diabetic patients. Lipoprotein(a) concentrations did not differ significantly from those found in the reference group and were elevated in $17.1 \%$ of the patients. Triglycerides and LDL-cholesterol values were elevated in $38.7 \%$ and $12.6 \%$ of the diabetic patients respectively, whereas HDL-cholesterol levels were decreased in $9.9 \%$ of the patients (data not shown). 
In comparison with the results in the reference group, elevated values for the haemostasis parameters fibrinogen, fibrin monomers and D-dimers were found, whereas $F$ VII values appeared to be reduced in the female patients only (table 2). The coagulation parameters fibrinogen and fibrin monomers were enhanced in $32 \%$ and $62.4 \%$ of the patients respectively. The fibrinolysis parameters Ddimer and plasminogen activator inhibitor (PAl-1) concentrations were increased in $41.6 \%$ and $18.7 \%$ of the patients, respectively (table 3 ).

Lipoprotein(a) was not correlated with glycometabolic control, coagulation or fibrinolysis parameters (table 4 ). Of the lipid parameters, $L p(a)$ correlated with LDL-cholesterol $(r=0.20, p=0.03)$.

\section{Discussion}

In the comparison of the $\operatorname{Lp}$ (a) concentrations found in the different patient groups the grossly elevated $L p(a)$ level in the hypertensive patient group $(p<$ 0.0001 ) is remarkable. Both the diabetic patient groups showed $L p(a)$ values that did not differ from those measured in a healthy reference group and were similar to values in healthy Caucasian populations reported in the literature. To our knowledge, elevated L.p(a) levels in hypertensive patients have not been reported previously and we do not know how to account for this finding. Considering the relatively small patient group $(n=54)$ confirmation of these data in a larger hypertensive population is required.

Although the liver appears to be the major production site of $L p(a)$, the steps involved in the intracellular formation of apo B-100-apo(a) complexes, the following stages of lipid incorporation and ultimate secretion have not been worked out. Because Lp(a) carries a modest fraction of the serum cholesterol, the correlations found between $L p(a)$ and LDL-cholesterol concentrations in the hypertensive patients $(r=0.25, p=0.04)$ and in the insulin-regulated diabetic patients $(r=0.20, p=0.03)$ seem understandable. However, in $L p(a)$ catabolism the role of the LDL-receptor is far less important than it is in the clearance of LDL-particles (34, review), whereas dietary and drug-induced alterations in apo B-100 levels do not affect $L p(a)$ values similarly (35, review). It is apparent that $L p(a)$ is under different regulation than $L D L$ and the correlations reported between $L p(a)$ and LDL-cholesterol in the literature are weak or barely significant $(36,37$, reviews). The negative correlation found between $L p(a)$ values and serum triglycerides in the hypertensive patient group $(r=-0.30, p=$ 0.04 ) agrees with the data reported by K. Berg et al. (38) and A. Kaptein et al. (39).

The haemostasis parameters measured in the three patient groups show more or less signs of an activated coagulation system and a reactive fibrinolysis, as indicated by elevated D-dimer levels in all patient groups. An elevated PAl-1 level in the hypertensive and NIDDM patient groups might indicate impaired 
fibrinolysis and thas been reported to be an independent risk factor for coronary heart disease (25-27). However, because the three patient groups consist of slightly older persons than the reference group, and many coagulation variables are known to increase with age, some bias due to age differences can not be excluded. We did not find any correlation between $L p(a)$ values and the coagulation parameters in the hypertensive patients or in either diabetic patient group (table 4). To our knowledge, data on this subject have not been published previously.

As mentioned above on the relation between $L p(a)$ and fibrinolysis, numerous predominantly in vitro studies have been reported. In general they show that $L p(a)$ has an interference effect on fibrinolysis. Vascular endothelial cells play an important role in the regulation of fibrinolysis. They synthesize and secrete tissue plasminogen activator ( $t-P A$ ) and plasminogen activator inhibitor-1 (PAl-1), and show t-PA and plasminogen binding sites at their cellular surfaces. In contrast to LDL-particles, $L p(a)$ has been reported to inhibit plasminogen binding to human umbilical vein endothelial cells in a dosedependent reversible way $(40,41)$. Similar results have been obtained in experiments with the monocytic $U 937$ celll lines $(41,42)$, which show plasminogen receptor characteristics similar to those in platelets (42). Furthermore, $L p(a)$ has been reported to compete with plasminogen and t-PA for fibrin binding $(44,45)$. In other in vitro experiments the competition of $L p(a)$ with plasminogen and t-PA for their binding sites was found to induce functional alterations in fibrinolysis. Fibrin-induced enhancement of plasminogen activation was inhibited by $L p(a)(40)$ whereas $L p(a)$ has been demonstrated to interfere at physiological concentrations with plasminogen activation by t-PA (46) or streptokinase (47). Also $L p(a)$ has been reported to affect the endothelial synthesis of PAl-1, an important inhibitor of fibrinolysis.

As shown in table 4, no correlation between $L p(a)$ and fibrinolysis parameters was found and hereby we confirm the results of Garcia Frade et al. (48) who reported the absence of correlations between $L p(a)$ and fibrinolysis parameters in patients with coronary artery disease. Our results are also in line with the reported lack of effect of higher Lp(a) levels on the clinical outcome of thrombolytic therapy in patients with acute myocardial infarction $(49,50)$. Furthermore, no relation between $L p(a)$ concentrations and the plasma fibrinolytic system was found in patients with deep venous thrombosis (51).

In conclusion, in the hypertensive and diabetic patient groups signs of an activated coagulation system and reactive fibrinolysis were found. In the hypertensive patients and in the insulin-regulated diabetic patients we found a weak positive correlation between $L p(a)$ values and LDL-cholesterol levels whereas a negative correlation between $L p(a)$ and serum triglycerides was established in the hypertensive patients. In the hypertensive patient group and in both diabetic patient groups no correlation of $L p(a)$ with coagulation or fibrinolysis parameters was found.

These results show that $L p(a)$ concentrations are not related to coagulation or fibrinolysis parameters in hypertensive or diabetic patients. Furthermore, they confirm the presence of an activated coagulation system in these patient groups. 


\section{References}

1. Karnel WB, Castelli WP, Gordon T, McNamara PM.

Serum cholesterol lipoprotein and the risk of coronary heart disease.

The Framingham Study.

Ann Intern Med 1971; 74: 1-12.

2. Castelli WP.

Epidemiology of coronary heart disease: the Framingham Study.

Am J Med 1984; 76: 4-12.

3. Austin MA.

Plasma triglyceride as a risk factor for coronary heart disease. The epidemiologic evidence and beyond.

Am J Epidemiol 1989; 129: 249-59.

4. Austin MA.

Plasma triglyceride and coronary heart disease.

Arterioscler Thromb 1991; 11: 2-14.

5. Berg K.

A new serum type system in man - the Lp system.

Acta Path Microbiol Scand 1963; 59: 369-82.

6. Kostner GM, Avogaro P, Cazzolato G, Marth E, Bittolo-Bon G, Qunici GB.

Lipoprotein $L p(a)$ and the risk for myocardial infarction.

Atherosclerosis 1981; 38: 51-61.

7. Armstrong WW, Cremer P, Eberle E, Manke A, Schulze F, Wieland H, KreuzerH, Seidel D. The association between serum $L P$ (a) concentrations and angiographically assessed coronary atherosclerosis. Dependence on serum LDL ilevels.

Atherosclerosis 1986; 62: 249-57.

8. Dahlen GH, Guyton JP, Attar M, Farmer JA, Kautz JA, Gotto AM Jr.

Association of levels of lipoprotein $L p(a)$, plasma lipids, and other lipoproteins with coronary artery disease documented by angiagraphy.

Circulation 1986; 74: 758-65.

9. Rosengren A, Wilhelmsen L, Eriksson $E$, Risberg B, Wedel $H$.

Lipoprotein(a) and coronary heart disease: a prospective case-control study in a general population sample of middle aged men.

Br Med J 1990; 301: 1248-51.

10. Wiklund O, Angelin B, Olofsson SO, Eriksson M, Fager G, Berglund L, Bondjers G Apolipoprotein(a) and ischaemic heart disease in familial hypercholesterolaemia.

Lancet 1990; 335: 1360-3.

11. Jürgens $G_{1}$ Költtringer $P$.

Lipoprotein(a) in ischemic cerebrovascular disease: a new approach to the assessment of risk for stroke.

Neurology $1987 ; 37: 513-5$.

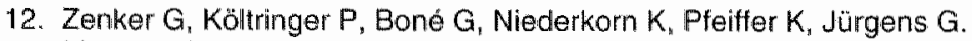

Lipoprotein(a) as a strong indicator for cerebrovascular disease.

Stroke 1986; 17: 942-5.

13. Gaubatz JW, Heideman C, Gotto AM Jr, Morrisett JD, Dahlen GH.

Human plasma lipoprotein(a). Structural properties.

J Biol Chem 1983", 258: 4582-9. 
14. Eaton DL, Fless GM, Kohr WJ, McLean JW, XU-QT, Miller CG. Lawn RM, Scanu AM. Partial amino acid sequence of apolipoprotein(a) shows that it is homologous to plasminogen. Proc Nati Acad Sci USA 1987; 84: 3224-8.

15. MoLean JW, Tomlinson JE, Kuang WJ, Eaton DL, Chen EY, Fless GM, ScanuAM, Lawn RM. CDNA sequence of human apolipoprotein(a) is homologous to plasminogen. Nature 1987; 330: 132-7.

16. Brown MS, Goldstein JL.

Plasma lipoproteins: teaching old dogmas new tricks.

Nature 1987; 330: $113-4$.

17. Miles LA, Plow EF. $L p(a)$ : an interloper into the fibrinolytic system? Thromb Haemost 1990; 63: 331-5.

18. Meade TW, North WR, Chakrabarti $R$, Stirling $Y$, Haines AP, Thompson SG,Brozovic M. Haemostatic function and cardiovascular death: early results of a prospective study. Lancet $1980 ; i: 1050-4$.

19. Meade TW, Mellows S, Brozovic M, Miller GJ, Chakrabarti RR, North WR, Haines AP, Stirling $Y$, Imeson JD, Thompson SG.

Haemostatic function and ischaemic heart disease: principall results of the Northwick Park Heart Study.

Lancet 1986; ii: 533-7.

20. Cooper J, Douglas AS.

Fibrinogen level as a predictor of mortality in survivors of myocardial infarction. Fibrinolysis 1991; 5: 105-8.

21. Broadhurst P, Kelleher C, Hughes L, lmeson JD, Raftery EB.

Fibrinogen, factor VII clotting activity and coronary artery disease severity. Atherosclerosis 1990; 85: 169-73.

22. Tofler GH, Brezinski D, Schafer Al, Czeisler CA, Rutherford JD, Willich SN, Gleason AE, Williams $\mathrm{GH}_{\text {, Muller JE. }}$

Concurrent morning increase in platelet aggregability and the risk of myocardial infarction and sudden cardiac death.

N Engl J Med 1987; 316: 1514-8.

23. Trip MD, Cats VM, van Capelle FJ, Vreeken J.

Platelet hyperreactivity and prognosis in survivors of myocardial infarction.

N Engl J Med 1990; 322: 1549-54.

24. Dalaker K, Hjermann I, Prydz H.

A novel form of factor VII in plasma from men al risk for cardiovascular disease.

$\mathrm{Br} \mathrm{J}$ Haematol 1985; 61: 315-22.

25. Chakrabarti $R$, Hocking ED, Fearnley GR, Mann RD, Attwell TN, Jackson D.

Fibrinolytic activity and coronary artery disease.

Lancet 1968; i: 987-90.

26. Hamsten A, Wiman B, de Faire U, Blömback M.

Increased plasma levels of a rapid inhibitor of tissue plasminogen activator in young survivors of myocardial infarction.

N Engl J Med 1985; 313: 1557-63.

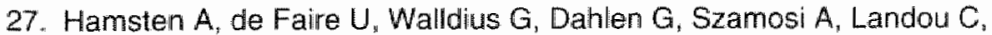
Blömback M, Wiman B.

Plasminogen activator inhibitor in plasma: risk factor for recurrent myocardial infarction. Lancet 1987; ii: $3-9$. 
20. Patrassi GM, Fallo F, Santarossa A, Sartori MT, Casonato A, Girolami A.

Clotting changes in borderline hypertension.

J Hum Hypertens 1987; i: 101-3.

29. Yamanishi $J$, Sano $H$, Saito $K$, Furuta $Y$, Fukuzaki $H$.

Plasma concentrations of platelet-specific proteins in different stages of essential

hypertension: interactions between platelet aggregation, blood lipids and age.

Thromb Haemost 1985; 54: 539-43.

30. van Wersch aWJ, Rompelberg-Lahaye J, Lustermans FAT.

Plasma concentration of coagulation and fibrinolysis factors and the level of platelet furction in hypertension.

Eur J Clin Chem Cin Biochem 1991; 29: 375-9.

31. van Wersch JWJ, Westerhuis LW.JM, Venekamp W.JRR.

Coagulation activation in diabetes mellitus.

Haemostasis 1990; 20: $263-9$.

32. Tschoepe D, Ostermann H, Huebinger A, Ziegler D, Wiefels K, Gries FA.

Elevated platelet activation in type I diabetics with chronic complications under long-term near-normaglycemic control.

Haemostasis 1990; 20: 93-8.

33. Fuller $J H$, Keen $H$, Jarrett $R \sqrt{ }$, Omer $T$, Meade TW, Chakrabarti $R$, North WRS, Stirling $Y$. Haemostatic variables associated with diabetes and its complications.

Br Med J 1979; 2: 964-6.

34. Scanu AM, Fless GM.

Lipoprotein(a). Heterogeneity and biological relevance.

$\mathrm{J}$ Clin Invest 1990; 85: 1709-15.

35. Brewer HB.

Effectiveness of diet and drugs in the treatment of patients with elevated Lp(a) levels. In: Scanu, AM, ed. Lipoprotein(a). New York: Academic Press Inc., 1990:211-20.

36. Dahlen $\mathrm{GH}$,

Incidence of $L p(a)$ lipoprotein among populations.

In: Scanu, AM, ed. Lipoprolein(a). New York: Academic Press Inc., 1990:151-73.

37. Morrisett JD, Guyton JP, Gaubatz JW, Gotto AM Jr.

Lipoprotein(a): structure, metabolism and epidemiology.

In: Gotto, AM .Jr, Ed. Plasma lipoprotein. Elsovier Science Publisher B.V. 1987.

38. Berg $K$, Hames $C$, Dahlen $G$, Frick MH, Krishan I.

Genetic lipoprotein variation and lipid levels in man.

Clin Genet 1976: 10:97-103.

39. Kaptein A, Kempen $H J_{1}$ Laterveer $\mathrm{A}$, Boomsma D, Gevers-Leuven JA, PrincenHM

Plasma levels of lipoprotein(a) in relation to other established risk factors for coronary heart disease in a healthy Dutch population.

9th International Symposium on Atherosclerosis. Rosemont Iltinois USA: International Atherosclerasis Society, 1991: 198, $152 \mathrm{~A}$.

40. Hajjar KA, Gavish D, Breslow لJ, Nachman RL.

Lipoprotein(a) modulation of endothelial cell surface fibrinolysis and its potentiall role in atherosclerosis.

Nature 1989; 339: 303-5.

41. Miles LA, Fless GM, Levin EG, Scianu AM, Plow EF.

A potential basis for the thrombotic risks associated with lipoprotein(a).

Nature 1989; 339: 301-3. 
42. Gonzalez-Gronow M, Edelberg JM, Pizzo SW.

Further characterization of the cellular plasminogen binding site: evidence that plasminogen 2 and lipoprotein(a) compete for the same site.

Biochemistry 1989; 28: 2374-7.

43. Plow EF, Freaney DE, Plescia J. Miles LA.

The plasminogen system and cell surfaces: evidenoe for plasminogen and urokinase receptors on the same cell type.

J Cell Biol 1986; 103: 2411-20.

44. Loscalzo J, Weinfeld M, Fless GM, Scanu AM.

Lipoprotein(a), fibrin binding, and plasminogen activation.

Arteriosclerosis 1990; 10: 240-5.

45. Harpel PC, Gordon BR, Parker TS.

Plasmin catalyzes binding of lipoprotein(a) to immabilized fibrinogen and fibrin.

Proc Natl Acad Sci USA 1989; 86: 3847-51.

46. Edelberg $ل \mathrm{M}$, Gonzallez-Gronow $M$, Pizzo SV.

Lipoprotein(a) inhibition of plasminogen activation by tissue-type plasminogen activator. Thromb Res 1990; 57: 155-62.

47. Edelberg JM, Gonzalez-Gronow M, Pizzo SV.

Lipoprotein(a) inhibits streptokinase-mediated activation of human plasminogen.

Biochemistry 1989; 28: 2370-4.

48. Garcia Frade LJ, Alvarez JJ, Rayo I, Torrado MC, Lasuncion MA, Garcia Avello A. Hernandez A, Marin E.

Fibrinolytic parameters and lipoprotein(a) levels in plasma of patients with coronary artery disease.

Thromb Res 1991; 63: 407-18.

49. Von Hodenberg $E_{1}$ Kreuzer J, Hautmanin $M$, Nordt $T$, Kübler $W$, Bode $C$.

Effects of lipoprotein(a) on success rate of thrombolytic therapy in acute myocardial infarction.

Am J Cardiol 1991; 67: 1349-53.

50. Tranchesi B, Santos-Filho R, Vinagre $C$, Caramelli B, Barbosa V, Gebara O, Belloti G, Pileggi F, Maranhao R.

Lipoprotein(a) levels do not influence the outcome of it-PA therapy in acute myocardial infarction.

Ann Hematol 1991; 62: 141-2.

51. Donder's SHJ, LustermanS FAT, van Wersch JWJ.

On lipoprotein(a) and coagulation/fibrimolysis balance in the acufe phase of deep venous thrombosis.

Submitted for publication. 



\section{Chapter 4}

\section{Haemostasis parameters and lipid composition of the blood in treated and untreated hypertensive patients}

Chapter 4 comprises two separate papers:

- Fibrinolysis factors and lipid composition of the blood in treated and untreated hypertensive patients

Bload Coagulation and Fibrinolysis 1992; 3: 61-67

- Coagulation factors and lipid composition of the blood in treated and untreated hypertensive patients

Submitted for publication 


\section{Summary}

The correlations between the cardiovascular risk factors blood pressure, overweight, hyperlipidaemia, and several coagulation and fibrinolysis parameters were studied in a group of 54 otherwise healthy patients with essential hypertension of moderate severity. Of the 54 hypertensive patients, 43 were treated with antihypertensive drugs and 11 were not. The patients included in this study who were treated with antihypertensive drugs were still hypertensive in spite of their treatment. Lipoprotein levels and haemostasis parameters did not differ between the untreated and treated hypertensive patients.

Substantial percentages of patients were found to have hypertriglyceridaemia $(46 \%)$, elevated LDL-cholesterol ( $28 \%$ ) and elevated lipoprotein(a) $(28 \%)$.

Elevated values for coagulation parameter $F$ VIIIC in comparison with the reference group were found in the hypertensive patients: 116 (53) \% (median value (interquartile range)) versus $90(48) \%$ in the reference group $(p<0.02)$. For fibrin monomers the results were: $13.5(4.6) \mathrm{nmol} / \mathrm{l}$ as against $10.5(2.0)$ $\mathrm{nmol} / \mathrm{l}(\mathrm{p}<0.01)$, and for TAT-complexes: $2.9(1.7) \mu \mathrm{g} / \mathrm{l}$ compared with $2.3(1.4)$ $\mu \mathrm{g} / \mathrm{l}$ in the reference group $(\mathrm{p}<0.02)$.

In the male hypertensive patients $F$ VII values were relatively higher than those in the female patients, with values of $137(32) \%$ versus $94(31) \%(p<0.001)$ and $147(36) \%$ versus $131(56) \%(p<0.01)$ in comparison with their respective reference groups. These data are compatible with a moderate activation of the coagulation system. Correlations were established between systolic blood pressure and serum cholesterol $(r=0.43, p=0.003)$, LDL-cholesterol $(r=0.34$, $p=0.02)$ and triglycerides $(r=0.35, p=0.01)$; Quetelet-index with fibrinogen $(r=$ $0.37, p=0.02)$ and thrombin-antithrombin III $(r=0.30, p=0.04)$; and triglycerides with $F$ VIIC $(r=0.34, p=0.03)$ and fibrin monomers $(r=0.29, p=0.04)$ respectively.

In comparison with the reference group the hypertensive patient group showed a decreased median tissue plasminogen activator activity (interquartile range): $0.23(0.79) \mathrm{IU} .10^{3 / /}$ versus $1.5(0.47) \mathrm{IU} .10^{3 / /}$ in the controls $(\mathrm{P}<0.0001)$, an increased tissue plasminogen activator antigen concentration: $8.2(4.5) \mu \mathrm{g} / \mathrm{l}$ as against $5.1(3.9) \mu \mathrm{g} / \mathrm{l}(\mathrm{p}<0.0001)$, an elevated plasminogen activator inhibitor-1 level: 2.8 (2.5) AU.103// compared with $1.1(2.0) \mathrm{AU} .10^{3 / /}(p<0.01)$ and a slightly increased $\alpha_{2}$-antiplasmin concentration: $110(8) \%$ versus $98(16) \%(p<0.0001)$. Median D-dimer concentration levels were substantially increased in the hypertensive patients: 315 (263) $\mu g / /$ versus $199(146) \mu g / l(p<0.0001)$. Median plasminogen concentrations did not differ significantly between the hypertensive patients and the controls and amounted to $101(16) \%$ versus $108(16) \%$. Triglycerides were correlated with tissue plasminogen activator antigen $(r=0.44$, $p=0.003)$ and with plasminogen activator inhibitor- 1 levels $(r=0.47, p=0.004)$ and 
tended to correlate with plasminogen $(r=0.26, p=0.07)$ and $D$-dimer levels $(r=0.24, p=0.10)$. The Quetelet-index correlated with tissue plasminogen activator antigen $(r=0.32, p=0.03)$.

In conclusion, this group of mildly hypertensive patients showed a disadvantageous blood lipid profile in correlation with signs of an activated coagulation system together with impaired fibrinolysis as indicated by a decreased tissue plasminogen activator activity and an elevated plasminogen activator inhibitor-1 concentration. These data link hypertension and hyperlipidaemia with a state of 'hypercoagulability' due to increased coagulation activity and diminished fibrinolysis and may hereby contribute to our understanding of why these two cardiovascular risk factors promote the progression of atherogenesis.

\section{Introduction}

Hypertensive patients are at risk for the sequelae of atherosclerotic vascular disease presenting as coronary heart disease, stroke, renal insufficiency or peripheral vascular disease (1). The level of the cardiovascular risk of hypertension must, however, be seen in the light of the presence of other known risk factors such as cigarette smoking, diabetes mellitus, hyperlipidaemia and overweight (2-8). Serum lipid concentrations play an important role in the development of atherosclerosis. Serum cholesterol concentration is positively associated with the incidence of cardiovascular heart disease, whereas HDL cholesterol is negatively correlated with cardiovascular risk (3-8). Increased triglycerides in serum have also been related to an elevated risk of ischaemic heart disease $(9,10,11)$, although the evidence that hypertriglyceridaemia is an independent risk factor for coronary heart disease is still inconclusive $(12,13,14$, reviews). HDL-cholesterol and triglycerides are well known to be inversely interrelated, however $(15,16)$.

Apart from the risk factors mentioned above, haemostatic factors also have been connected to cardiovascular disease. Increased concentrations of factor VII, factor VIII, fibrinogen and platelel hyperreactivity have been associated with coronary heart disease (17-23).

A "prethrombotic" or "hypercoagulable state' might induce coronary heart disease in several ways, for example, via platelet aggregation and fibrin formation. Fibrin has been involved in the formation of atherosclerotic plaques as well as in the formation of occlusive thrombi. Signs of an activated coagulation system have been reported in patients with hypertension as well as in patients with hyperlipidaemia. Hyperlipidaemia has been associated with elevated factors VII, VIII, IX, X, prothrombin and platelet hyperreactivity (23-30) whereas in patients with hypertension elevated factors XII, XI, VIII, fibrinogen, fibrin monomers, thrombinantithrombin III complexes and platelet hyperreactivity have been reported (31-35). 
In the 1960 's, decreased fibrinolytic activity was also related to cardiovascular disease (36). The fibrinolytic system consists of a proteolytic enzyme system whose primary function is to degrade fibrin deposits in blood vessels. It is assumed that endothelial cell release of tissue plasminogen activator ( $t$-PA) triggers intravascular fibrinolysis in vivo. The mechanism regulating the secretion of plasminogen activator inhibitor-1 (PAI-1) by the endothelial cell is still unknown. Conversion by t-PA of the fibrinolytic pro-enzyme plasminogen to its active form (plasmin) preferably occurs at the closely linked t-PA and plasminogen binding sites on fibrin and endothelial cell surfaces. Elevated PAI-1 activity seems to be the most important cause of impaired fibrinolysis with respect to cardiovascular disease (37-39). A strong correlation has been established between PAI-1 levels and serum triglycerides (37-40). An association between decreased t-PA levels and myocardial infarction has also been suggested (41). In hypertension, impaired fibrinolysis due to elevated PAl1 levels has been reported by several investigators $(42-45)$.

Aim of this study was to correlate the risk factors hypertension, body composition (as indicated by the Quetelet-index) and blood lipids (cholesterol, HDL-cholesterol, LDL-cholesterol, triglycerides and lipoprotein(a)) with several coagulation parameters (fibrin monomers, thrombin-antithrombin III complex, fibrinogen, factor VII,factor VIII:C and factor VIII von Willebrand factor) and with the fibrinolysis parameters plasminogen, $\alpha_{2}$-antiplasmin, tissue plasminogen activator (t-PA) antigen, t-PA activity, PAl-1 and D-dimers. To avoid repetition as much as possible, this chapter contains the contents of two separate papers. In the results and discussion section, however, coagulation (section A) and fibrinolysis (section B) are addressed separately and this gives rise to some repetition which is inevitable.

\section{Patients, materials and methods}

\section{Patients}

As criterion for hypertension we used the repeated measurement of a diastolic pressure $\geq 95 \mathrm{mmHg}$ or a systolic pressure $\geq 160 \mathrm{mmHg}$ both on the left and right hand sides. Fifty-four otherwise healthy patients ( 27 males and 27 females) meeting these criteria were evaluated in this study. The age varied between 19 and 70 years (mean age 50 years). The mean established duration of hypertension was 4 years (range $0.5-20$ years). At the time of the study eleven hypertensive patients were not being treated with antihypertensive drugs, 23 patients took calcium antagonists, 13 patients used angiotensin converting enzyme (ACE) inhibitors, 16 patients were treated with diuretics and 7 patients were receiving beta-blockers as monotherapy or together with other antihypertensive drugs. The patients treated with antihypertensive drugs who were included in this study were still hypertensive in spite of their treatment and met the criteria concerning blood pressure as mentioned above. The systolic 
blood pressure ranged from $130-200 \mathrm{mmHg}$ (mean $170 \mathrm{mmHg}$ ). The diastolic blood pressure varied between 90 and $144 \mathrm{mmHg}$ (mean $104 \mathrm{mmHg}$ ). For the classification of the hypertension we considered three subgroups: essential hypertension, renal hypertension and hormonal hypertension. In this study all patients could be classified as belonging to the essential hypertension group. Patients with signs of malignant hypertension were excluded. Four of the hypertensive patients were cigarette smokers.

\section{Reference group}

The reference group consisted of 50 non-smoking subjectively healthy hospital workers ( 25 males, 25 females) aged $24-50$ years (mean age 40 years) without hypertension.

\section{Blood samples}

Blood samples were drawn after fasting overnight after a resting period of 20 min. All coagulation parameters and fibrinolysis parameters except for tissue plasminogen activator activity were determined in citrated plasma. This was prepared by centrifugation of a mixture of nine volumes freshly drawn blood with one volume trisodium citrate $(0.11 \mathrm{~mol} / \mathrm{l})$ for $30 \mathrm{~min}(1600 \mathrm{~g})$ at $25^{\circ} \mathrm{C}$. The plasma was stored at $-70^{\circ} \mathrm{C}$ in plastic tubes and thawed under tap water for 5 min before serial analysis.

A separate tube was prepared with $0.5 \mathrm{ml}$ acetate buffer $(\mathrm{pH}=3.9)$ and filled with $1 \mathrm{ml}$ citrated blood for the measurement of tissue plasminogen activator activity. The tube was centrifuged immediately $(30 \mathrm{~min} 1800 \mathrm{~g}$ ) and the plasma separated. The collected plasma was acidified with $20 \%$ acetic acid (final $\mathrm{pH}$ of the plasma sample 4.0-4.1), then stored at $-70^{\circ} \mathrm{C}$ in plastic tubes; it was thawed under tap water for 5 min before analysis.

For the serum determinations the blood was allowed to clot at room temperature for 60 minutes, after which the collection tube was centrifuged (15 min, 3000g).

\section{Methods}

Fibrinogen was determined by the clotting assay of Clauss. Factor VIII von Willebrand factor was quantitated with an ELISA test kit (Boehringer Mannheim Corp. Mannheim, Germany). For the factor VIII:C determination an aPTT onestage clotting assay was performed with use of a deficient plasma of Behring (Marburg, Germany). Fibrin monomer concentrations were assessed by means of the chromogenic COA-Set FM-test (Kabi Vitrum Diagnostica).

Thrombin-antithrombin III was determined with an ELISA kit of the Behring Corporation (Marburg, Germany). For factor VII, the chromogenic substrate 
COA-Set of Kabi Vitrum Diagnostica (Mölndal, Sweden) was employed. D-dimer was assayed in plasma using an ELISA method (Boehringer Mannheim Corp., Mannheim, Germany). For plasminogen activator inhibitor-1 determination the test kit of Kabi Vitrum Diagnostica (Mölndal, Sweden) COA-Set PAl was used. The tissue plasminogen activator activity test, with chromogenic substrate S-2251, was also from Kabi Vitrum Diagnostica, as well as the antigenic tissue plasminogen activator test (Coaliza t-PA test) with chromogenic substrate S-2403.

Plasminogen and $\alpha_{2}$ antiplasmin reagents were from Kabi Vitrum Diagnostica (Coatest plasminogen and Coatest $\alpha_{2}$-antiplasmin), both using the chromogenic substrate S-2251.

The serum samples were analysed on a Cobas Bio centrifugal fast analyzer using commercial test kits according to the manufacturer's instructions for determination of serum triglycerides, total serum cholesterol, HDL-cholesteral and LDL-cholesterol as described in chapter 3.

\section{Statistics}

The significance of the differences was assessed by the Mann-WhitneyWilcoxon test. The parameters studied were correlated with each other by the Spearman rank test.

\section{Results}

\section{A: Coagulation and cardiovascular risk factors}

The summary statistics of coagulation and blood lipid parameters in the hypertensive group are given in tables 1.1 and 1.2. As shown in table 1.1 several coagulation parameters were significantly elevated in the hypertensive patient group in comparison with the results in the reference group. The median F VIIlc (interquartile range) was $116(53) \%$ in the hypertensive patient group versus $90(48) \%$ in the controls $(P<0.02)$, fibrin monomers were $13.5(4.6)$ $\mathrm{nmol} / \mathrm{l}$ versus $10.5(2.0) \mathrm{nmol} / \mathrm{l}(\mathrm{p}<0.01)$ and TAT-complexes $2.9(1.7) \mu \mathrm{g} / \mathrm{l}$ as against $2.3(1.4) \mu \mathrm{g} / \|(p<0.02)$ in the controls. The median $F$ VII value in the hypertensive patient group was relatively more elevated in the male patients (137\% versus $94 \%$ in the male controls) than in the female patients (147\% versus $131 \%$ in the female controls). The other coagulation and lipid parameters studied did not differ significantly between the male and female patients (data not shown). The lipid data given in table 1.2 show a noticeable elevated median lipoprotein(a) value (122 mg/l) whereas this value is normally below $50 \mathrm{mg} / \mathrm{l}$. 


\begin{tabular}{|c|c|c|c|c|c|c|c|}
\hline \multirow[b]{2}{*}{$\begin{array}{l}\text { Parameters } \\
\text { (refi, range) }\end{array}$} & \multicolumn{3}{|c|}{ Hypertensive patients } & \multicolumn{3}{|c|}{ Controls } & \multirow[b]{2}{*}{$\begin{array}{l}\text { signifi- } \\
\text { cancel) }\end{array}$} \\
\hline & median & $\begin{array}{l}\text { lower } \\
\text { quartile }\end{array}$ & $\begin{array}{l}\text { upper } \\
\text { quartile }\end{array}$ & median & $\begin{array}{l}\text { lower } \\
\text { quartile }\end{array}$ & $\begin{array}{l}\text { upper } \\
\text { quartile }\end{array}$ & \\
\hline $\begin{array}{l}\text { Fibrinogen } \\
(1.7-4.0 \mathrm{~g} / \mathrm{l})\end{array}$ & 3.2 & 2.7 & 3.8 & 3.0 & 2.5 & 3.4 & NS \\
\hline $\begin{array}{l}F \text { VIllc } \\
(61-176 \%)\end{array}$ & 116 & 95 & 148 & 90 & 71 & 119 & $<0.02$ \\
\hline $\begin{array}{l}\text { F Vill VWF } \\
(52-145 \%)\end{array}$ & 85 & 67 & 106 & 90 & 64 & 120 & N.S. \\
\hline $\begin{array}{l}\text { F VII } \\
\text { Males }(54-138 \%) \\
\text { Females }(56-200 \%)\end{array}$ & $\begin{array}{l}1372) \\
\left.147^{2}\right)\end{array}$ & $\begin{array}{l}119 \\
123\end{array}$ & $\begin{array}{l}151 \\
159\end{array}$ & $\begin{array}{l}94 \\
131\end{array}$ & $\begin{array}{l}78 \\
104\end{array}$ & $\begin{array}{l}109 \\
160\end{array}$ & $\begin{array}{l}<0.001 \\
<0.01\end{array}$ \\
\hline $\begin{array}{l}\text { Fibrim monomers } \\
(8.4-13.2 \text { nmol/ } /)\end{array}$ & 13.5 & 11.7 & 16.3 & 10.5 & 9.8 & 11.8 & $<0.01$ \\
\hline $\begin{array}{l}\text { Thrombin- } \\
\text { antithrombin III } \\
(1.0-4.1 \mu \mathrm{g} / 1)\end{array}$ & 2.9 & 2.1 & 3.8 & 2.3 & 1.7 & 3.1 & $<0.02$ \\
\hline
\end{tabular}

\section{Table 1.1}

Summary statistics of the coagulation data in the hypertensive patient group $(n=54)$ in comparison with a healthy control group $(n=50)$

\begin{tabular}{|c|c|c|c|}
\hline \multirow[b]{2}{*}{$\begin{array}{l}\text { Parameters } \\
\text { (ref. range) }\end{array}$} & \multicolumn{3}{|c|}{ Hypertensive patients } \\
\hline & Median & $\begin{array}{l}\text { Lower } \\
\text { quartile }\end{array}$ & $\begin{array}{l}\text { Upper } \\
\text { quartile }\end{array}$ \\
\hline $\begin{array}{l}\text { Tatal cholesterol } \\
(4.0-7.5 \mathrm{mmol} / \mathrm{l})\end{array}$ & 6.3 & 5.4 & 7.1 \\
\hline $\begin{array}{l}\text { HDL-cholesterol } \\
(0.9 .1 .7 \mathrm{mmol} / \mathrm{l})\end{array}$ & 1.2 & 0.9 & 1.4 \\
\hline $\begin{array}{l}\text { LDL-cholesterol } \\
(3.0-5.0 \mathrm{mmol} / \mathrm{h})\end{array}$ & 4.2 & 3.2 & 4.8 \\
\hline $\begin{array}{l}\text { Triglycerides } \\
(0.8 \cdot 2.0 \mathrm{mmol} / \mathrm{l})\end{array}$ & 1.8 & 1.3 & 2.2 \\
\hline $\begin{array}{l}\text { Lp(a) } \\
(0-300 \mathrm{mg} / \mathrm{l})\end{array}$ & 122 & 57 & 338 \\
\hline
\end{tabular}

Table 1.2

Summary statistics of the lipid data in the hypertensive patient group ( $n=54)$. 


\begin{tabular}{|c|c|c|c|c|}
\hline $\begin{array}{l}\text { Parameters } \\
\text { (ref. rainge) }\end{array}$ & $\operatorname{Min}^{*}$ & $\operatorname{Max}$ & $\begin{array}{l}\text { Percentages } \\
\text { of values } \\
\text { beneath the } \\
\text { lower ref. } \\
\text { range limit }\end{array}$ & $\begin{array}{c}\text { Percentages } \\
\text { of values } \\
\text { above the } \\
\text { upper ref. } \\
\text { range limit }\end{array}$ \\
\hline $\begin{array}{l}\text { Fibrinogen } \\
(1.7-4.0 \mathrm{~g} / \mathrm{l})\end{array}$ & 1.8 & 5.2 & 0 & 9.1 \\
\hline $\begin{array}{l}\text { Fville } \\
(61-176 \%)\end{array}$ & 52 & 300 & 1.9 & 13.0 \\
\hline $\begin{array}{l}\text { F VIII WWF } \\
(52-145 \%)\end{array}$ & 41 & 18 & 11.1 & 9.3 \\
\hline $\begin{array}{l}\text { F VIII } \\
\text { Males }(54-138 \%) \\
\text { Fomales }(56-200 \%)\end{array}$ & $\begin{array}{r}84 \\
117\end{array}$ & $\begin{array}{l}215 \\
2118\end{array}$ & $\begin{array}{l}0 \\
0\end{array}$ & $\begin{array}{r}41.7 \\
4.3\end{array}$ \\
\hline $\begin{array}{l}\text { Fibrin monomers } \\
(8.4-13.2 \text { nmolll) }\end{array}$ & 1.9 & 26.4 & 18.5 & 59.2 \\
\hline $\begin{array}{l}\text { Thrombin-antithrombin III } \\
(1.0-4.1 \mu \mathrm{g} / 1)\end{array}$ & 1.4 & 9.3 & 0 & 20.4 \\
\hline
\end{tabular}

Table 2.1

Minimum and maximum values measured and percentages of values above the upper and under the lower reference ranges of the respective coagulation parameters in the hypertensive patient growp $(n=54)$.

\begin{tabular}{|c|c|c|c|c|}
\hline $\begin{array}{l}\text { Parameters } \\
\text { (ref. range) }\end{array}$ & $\operatorname{Min}^{*}$ & Max & $\begin{array}{c}\text { Percentages of } \\
\text { values beneath } \\
\text { the lower ref. } \\
\text { range limit }\end{array}$ & $\begin{array}{l}\text { Percentages of } \\
\text { values above } \\
\text { the upper ref. } \\
\text { range limit }\end{array}$ \\
\hline $\begin{array}{l}\text { Total cholesterol } \\
(4.0-7.5 \mathrm{mmol} / \mathrm{l})\end{array}$ & 3.3 & 9.3 & 0 & 18.5 \\
\hline $\begin{array}{l}\text { HDL-cholesterol } \\
(0.9-9.7 \mathrm{mmol} / 1)\end{array}$ & 0.6 & 2.5 & 14.8 & 6.3 \\
\hline $\begin{array}{l}\text { LDL-cholesterol } \\
(3.0-5.0 \mathrm{~mm} \mathrm{~m} / \mathrm{l})\end{array}$ & 1.1 & 7.1 & 7.4 & 27.8 \\
\hline $\begin{array}{l}\text { Triglycerides } \\
(0.8-2.0 \mathrm{mmol} / \mathrm{l})\end{array}$ & 0.7 & 6.8 & 1.9 & 45.8 \\
\hline $\begin{array}{l}\operatorname{Lp}(\mathrm{a}) \\
(0-300 \mathrm{mg} / \mathrm{l})\end{array}$ & 1 & 1566 & $a$ & 27.8 \\
\hline
\end{tabular}

Table 2.2

Minimum and maximum values measured and percentages of values above the upper and under the lower reference ranges of the blood lipid parameters in the hypertensive patient group $(n=54)$. 
In tables 2.1 and 2.2 the minimum and maximum values and the percentages of values under the lower and above the upper reference range limits for each coagulation and lipid parameter are given respectively. The high percentages of hypertensive patients with elevated triglycerides (46.3\%), LDL-cholesterol (27.8\%), $L p(a)(27.8 \%)$, fibrin monomers $(59.2 \%)$ and $F$ VII in male patients $(41.7 \%)$ are remarkable.

In table 3 the correlations between systolic blood pressure and triglycerides ( $r=$ $0.35, p=0.01)$ cholesterol $(r=0.43, p=0.003)$ and LDL-cholesterol $(r=0.43, p=$ $0.02)$ are shown. None of these parameters were correlated with the diastolic blood pressure. The Quetelet-index tended towards a positive correlation with systolic and diastolic blood pressure.

In table 4 the correlations between coagulation and blood lipid parameters in the hypertensive patient group are given. Triglycerides were correlated with $F$ VII ( $r=$ $0.34, p=0.03)$ and with fibrin monomers $(r=0.29, p=0.04)$. For triglycerides and cholesterol a tendency towards a positive correlation with fibrinogen was found. The Quetelet-index was correlated with fibrinogen $(r=0.37, p=0.02)$ and with thrombin- antithrombin $\mathrm{III}(r=0.30, p=0.04)$ (not shown).

\begin{tabular}{|c|c|c|c|c|}
\hline$x:$ & \multicolumn{2}{|c|}{ Diastolic pressure } & \multicolumn{2}{|c|}{ Systolic pressure } \\
\hline & r & p & $r$ & p \\
\hline Quetelet index & 0.24 & 0.10 & 021 & 0,14 \\
\hline Triglycerides & 0,20 & NS. & 0.35 & 0,01 \\
\hline Total cholesterol & 0.06 & NS. & 0.43 & 0.000 \\
\hline LDL-cholesterol & 0.02 & NS. & 0.34 & 0.02 \\
\hline
\end{tabular}

Table 3

Spearman rank correlation $r$-values with indication of significance ( $p$-value) between diastolic/systolic blood pressure and Quetelet index, triglycerides and cholesterol.

\begin{tabular}{|c|c|c|c|c|c|c|}
\hline & FI & $F$ VII & F VIII:C & $\begin{array}{l}\text { F VIII } \\
\text { VWF }\end{array}$ & $\mathbf{F M}$ & TAT \\
\hline Cholesterol & $\begin{array}{r}0,30 \\
(0.06)\end{array}$ & $\begin{array}{c}0.10 \\
(0.52)\end{array}$ & $\begin{array}{l}-0.16 \\
(0.27)\end{array}$ & $\begin{array}{c}-0.03 \\
(0.82)\end{array}$ & $\begin{array}{c}0.05 \\
(0.71)\end{array}$ & $\begin{array}{r}0.02 \\
(0.86)\end{array}$ \\
\hline HDL-cholesterol & $\begin{array}{l}0.007 \\
(0.97)\end{array}$ & $\begin{array}{c}0.04 \\
(0.77)\end{array}$ & $\begin{array}{l}0.07 \\
(0.64)\end{array}$ & $\begin{array}{c}0.03 \\
(0.82)\end{array}$ & $\begin{array}{l}-0.24 \\
(0.11)\end{array}$ & $\begin{array}{c}0.23 \\
(0.12)\end{array}$ \\
\hline LDL-cholesterol & $\begin{array}{c}0.12 \\
(0.43)\end{array}$ & $\begin{array}{c}-0.06 \\
(0.67)\end{array}$ & $\begin{array}{c}-0.19 \\
(0.19)\end{array}$ & $\begin{array}{c}-0.07 \\
(0.63)\end{array}$ & $\begin{array}{c}0.06 \\
(0.64)\end{array}$ & $\begin{array}{c}0.02 \\
(0.88)\end{array}$ \\
\hline $\operatorname{Lp}(\mathrm{a})$ & $\begin{array}{r}-0.06 \\
(0.7)\end{array}$ & $\begin{array}{c}-0.15 \\
(0.31)\end{array}$ & $\begin{array}{c}0.05 \\
(0.72)\end{array}$ & $\begin{array}{c}0.18 \\
(0.18)\end{array}$ & $\begin{array}{l}-0.04 \\
(0.78)\end{array}$ & $\begin{array}{r}0.09 \\
(0.52)\end{array}$ \\
\hline Triglycerides & $\begin{array}{c}0.30 \\
(0.06)\end{array}$ & $\begin{array}{c}0.34 \\
(0.03)\end{array}$ & $\begin{array}{c}0.03 \\
(0.83)\end{array}$ & $\begin{array}{c}0.03 \\
(0.82)\end{array}$ & $\begin{array}{c}0.29 \\
(0.04)\end{array}$ & $\begin{array}{c}0.08 \\
(0.59)\end{array}$ \\
\hline
\end{tabular}

Tabie 4

Spearman rank correlation r-values with indication of significance ( $p$-values) between coagulation factors and lipids in hypertensive patients ( $n=54$ ) 


\begin{tabular}{|c|c|c|c|c|c|c|c|}
\hline \multirow[b]{2}{*}{$\begin{array}{l}\text { Parameters } \\
\text { (ref. range) }\end{array}$} & \multicolumn{3}{|c|}{ Hypertensive patients } & \multicolumn{3}{|c|}{ Controls } & \multirow[b]{2}{*}{ Significance } \\
\hline & thedian & $\begin{array}{l}\text { Lower } \\
\text { quartille }\end{array}$ & $\begin{array}{l}\text { Upper } \\
\text { quartife }\end{array}$ & Median: & $\begin{array}{l}\text { Lower } \\
\text { quartile }\end{array}$ & $\begin{array}{l}\text { Upper } \\
\text { quartile }\end{array}$ & \\
\hline D-dimer $(0-450 \mu \mathrm{g} / \mathrm{l})$. & 315 & 220 & 483 & 199 & 148 & 294 & $<0.001$ \\
\hline $\begin{array}{l}\text { Tissue plasminogen activator activity } \\
\left(0.5-2,310,10^{3} / \mathrm{l}\right)\end{array}$ & 0.23 & 0,10 & 0.89 & 1.50 & 1.24 & 1.71 & $<0.0001$ \\
\hline $\begin{array}{l}\text { Tissue plasminogen activator antigen } \\
(0.912 .1 \mathrm{jg} d)\end{array}$ & 8.2 & 5.8 & 10.3 & 5.1 & 3.7 & 7.6 & $<0.0001$ \\
\hline $\begin{array}{l}\text { Plasminogen activator inhibitor- } \\
(0.4 .6 \mathrm{AU} .103 / 1)\end{array}$ & 12.8 & 1.7 & 4.2 & 1.1 & 0.6 & 2.6 & $<0.01$ \\
\hline$\alpha_{2}$ antiplasmin $(80-120 \%)$ & 110 & 107 & 115 & 98 & 90 & 106 & $<0.0001$ \\
\hline Plasminogen $(80-120 \%)$ & 101 & 95 & 111 & 108 & 100 & 116 & $N . S_{n}$ \\
\hline
\end{tabular}

Table 5. 1

Summary statistics of the fibrinolysis parameters of the hypertensive patient group $(n=54)$ in comparison with a healthy control group $(n=50)$.

\begin{tabular}{|c|c|c|c|c|}
\hline $\begin{array}{l}\text { Parametersi } \\
\text { (ref. range) }\end{array}$ & $\operatorname{Min}^{\star}$ & Max** & $\begin{array}{c}\text { Percentages of } \\
\text { values under } \\
\text { the lower ref. } \\
\text { range limit }\end{array}$ & $\begin{array}{l}\text { Percentages of } \\
\text { values above } \\
\text { the upper ref. } \\
\text { range limit }\end{array}$ \\
\hline $\begin{array}{l}\text { D-dimer } \\
(0-450 \mu g / 1)\end{array}$ & 21 & 1800 & 0 & 18.5 \\
\hline $\begin{array}{l}\text { Tissue plasminogen activator activity } \\
\left(0.5-2.3 \mathrm{IU} .10^{3} / \mathrm{h}\right)\end{array}$ & 0.09 & 2.0 & 66.7 & 0 \\
\hline $\begin{array}{l}\text { Tissue plasminogen activator antigen } \\
(0.9-12.7 \mu g / l)\end{array}$ & 3.0 & 24.3 & 0 & 13.0 \\
\hline $\begin{array}{l}\text { Plasminogen activator inhibitor-1 } \\
\left(0-4.6 \mathrm{AU} .10^{3} / \mathrm{l}\right)\end{array}$ & 0.2 & 8.9 & 0 & 16.7 \\
\hline $\begin{array}{l}\alpha_{2} \text { antiplasmin } \\
(80-120 \%)\end{array}$ & 86 & 134 & 0 & 11.1 \\
\hline $\begin{array}{l}\text { Plasminogen } \\
(80-120 \%)\end{array}$ & 70 & 149 & 3.7 & 13.0 \\
\hline \multicolumn{5}{|c|}{ *Min $=$ minimum values $* *$ Max $=$ maximum values } \\
\hline
\end{tabular}

Table 5.2

Minimum and maximum values measured and percentages of values above the upper and under the lower reference ranges of the fibrinolysis parameters in the hypertensive patient group $(n=54)$. 


\section{B: Fibrinolysis and cardiovascular risk factors}

The summary statistics of blood lipid and fibrinolysis parameters in the hypertensive patients are given in tables 1.2 and 5.1. Table 5.1 shows the fibrinolysis data in the hypertensive patients in comparison to those in a healthy control group. Noticeable is a substantially decreased median tissue plasminogen activator activity (interquartile range): $0.23(0.79) \mathrm{IU} .10^{3 / /}$ versus $1.5(0.47) \cup \cup .10^{3 / /}$ in the controls ( $\left.p<0.0001\right)$, an increased tissue plasminogen activator antigen: $8.2(4.5) \mu \mathrm{g} / \mathrm{l}$ compared to $6.5(2.8) \mu \mathrm{g} / \mathrm{l}$ in the controls $(p<0.0001)$ and moderately elevated PAI-1 levels: 2.8 (2.5) AU.103// versus 1.1 (2.0) AU.103// in the controls $(p<0.01)$. The $\alpha_{2}$-antiplasmin concentrations were also slightly increased: $110(8) \%$ versus $98(16) \%$ in the controls $(p<0.0001)$, whereas the median D-dimer level was found to be substantially increased in the hypertensive patients: 315 (263) $\mu \mathrm{g} / /$ versus $199(146) \mu \mathrm{g} / \mathrm{l}$ in the controls $p<$ 0.0001 ).

In tables 2.2 and 5.2 the minimum and maximum values measured and the percentages of patients with values beneath the lower and above the upper reference range limits for each lipid and fibrinolysis parameter are given respectively. Tissue plasminogen activator activity was found to be decreased in two thirds of the patients whereas the antigen levels were above the lower reference range limit in all the hypertensive patients and exceeded the reference range in $13.0 \%$ of them. LDL-cholesterol and $L p(a)$ levels were elevated in $27.8 \%$ and $27.8 \%$ of the patients respectively, whereas serum triglycerides were elevated in $45.8 \%$ of the patients.

In table 3 the correlations between systolic blood pressure and triglycerides ( $r=$ $0.35, p=0.01)$, cholesterol $(r=0.43, p=0.003)$ and LDL-cholesterol $(r=0.43, p=$ 0.02 ) are shown. There was no correlation between diastolic blood pressure and blood lipid parameters. The Quetelet-index tended to a positive correlation with diastolic and systollic blood pressure.

In table 6 the correlations between fibrinolysis and lipid parameters are given. Triglycerides were correlated with tissue plasminogen activator antigen $(r=0.44$, $p=0.003)$ and with PAl- $1(r=0.42, p=0.004)$ and tended to correlate with plasminogen $(r=0.26, p=0.07)$ and $D$-dimers $(r=0.24, p=0.10)$. The Queteletindex correlated with tissue plasminogen activator antigen $(r=0.32, p=0.03)$. Systolic and diastolic blood pressure were not correlated with any of the fibrinolysis parameters (data not shown). 


\begin{tabular}{|c|c|c|c|c|c|c|}
\hline & $0_{2} A P$ & PLG & D-dimer & t-PAact & I PAag & PAl-1 \\
\hline Total cholesterol & $\begin{array}{l}0.01 \\
(0.97)\end{array}$ & $\begin{array}{l}028 \\
(006)\end{array}$ & $\begin{array}{l}0.02 \\
(0.88)\end{array}$ & $\begin{array}{l}0.19 \\
(0.28)\end{array}$ & $\begin{array}{l}0.19 \\
(0,18)\end{array}$ & $\begin{array}{c}0.03 \\
(0.85)\end{array}$ \\
\hline HDL cholesterol & $\begin{array}{c}0,08 \\
(0,60)\end{array}$ & $\begin{array}{l}0.06 \\
(0.69)\end{array}$ & $\begin{array}{l}022 \\
(013)\end{array}$ & $\begin{array}{l}0.17 \\
(0.34)\end{array}$ & $\begin{array}{l}0,14 \\
(0,63)\end{array}$ & $\begin{array}{l}0.28 \\
(0.06)\end{array}$ \\
\hline LDL-cholesterol & $\begin{array}{l}0,07 \\
(0,16)\end{array}$ & $\begin{array}{l}0.22 \\
(0.11)\end{array}$ & $\begin{array}{r}0.09 \\
(0.53)\end{array}$ & $\begin{array}{l}0.03 \\
(0,88)\end{array}$ & $\begin{array}{l}0,10 \\
(0.49)\end{array}$ & $\begin{array}{r}0.14 \\
(0.32)\end{array}$ \\
\hline$L p(a)$ & $\begin{array}{l}0,15 \\
(0.29)\end{array}$ & $\begin{array}{l}0,11 \\
(0,41)\end{array}$ & $\begin{array}{l}0.08 \\
(0.58)\end{array}$ & $\begin{array}{l}0.08 \\
(0.61)\end{array}$ & $\begin{array}{l}0.26 \\
(0.26)\end{array}$ & $\begin{array}{l}0.15 \\
(0.26)\end{array}$ \\
\hline Triglycerides & $\begin{array}{r}0,08 \\
(0,60)\end{array}$ & $\begin{array}{r}0.26 \\
(0.07)\end{array}$ & $\begin{array}{l}0,24 \\
(0.10)\end{array}$ & $\begin{array}{l}-0.24 \\
(0.17)\end{array}$ & $\begin{array}{r}0.44 \\
(0.003)\end{array}$ & $\begin{array}{l}0.42 \\
(0.004)\end{array}$ \\
\hline
\end{tabular}

Table 6

Spearman rank correlation r-values with indication of significance ( $p$-values) between fibrinalysis factors and lipids in the hypertensive patient group $(n=54)$.

\section{Discussion}

\section{A: Coagulation and cardiovascular risk factors}

The blood lipid values and haemostasis parameters did not differ significantly (Mann-Whitney-Wilcoxon test) between the untreated hypertensive patients and the patients who were still hypertensive in spite of their treatment with calcium antagonists, ACE-inhibitors, diuretics, beta-blockers or a combination of these drugs (data not shown). It was therefore decided to study the data of all the patients together as one group.

In the hypertensive population a high-risk blood lipid composition was found with elevated LDL-cholesterol in $28 \%$ and hypertriglyceridaemia in $46 \%$ of the patients. A remarkable finding was that lipoprotein(a), recently confirmed as an independent risk factor for cardiovascular disease in a major prospective casecontrol study (46), was elevated in $28 \%$ of the hypertensive patients.

Although well-known risk factors for the development of atherosclerosis such as hypertension, hypercholesterolaemia, cigarette smoking, diabetes mellitus and overweight have been established as such, their pathophysiological mechanisms and interactions are still unknown. In Uganda in the late 1960's Roberts investigated many patients with severe hypertension and left ventricular hypertrophy but found virtually no atherosclerotic plaques (47) by means of coronary arteriography. In this population total serum cholesterol varied from 
2.4 to $3.6 \mathrm{mmol} / \mathrm{l}$. In the author's opinion, hypertension accelerates atherosclerosis only in the presence of serum cholesterol values above 4.0 mmol/l (47). In western countries hypertensive patients are more likely to have hyperlipidaemia and low HDL-cholesterol levels (48). The mechanisms by which these lipid abnormalities occur in hypertension are unknown, whereas antihypertensive treatment may have a further unfavourable effect on the blood lipid profile (49).

Insulin resistance has been recognized as a common feature in hypertensive patients and could contribute to the disadvantageous lipid profile seen in these patients (50-52). The co-occurrence of the risk factors hypertension, overweight of the central 'android' type and hypertriglyceridaemia together with insulin resistance has been designated syndrome $X(51)$, allo called the 'deadly quartet'. The association between insulin resistance and hypertension was supported by an epidemiological investigation (53) and an intervention trial (45).

The endothelium is of crucial importance for the regulation of vascular permeability, metabolic interactions between blood components and tissues, haemostasis and vascular tone by releasing vasodilators such as prostacyclin and endothelium-derived relaxing factor (EDRF) (54). Recently abnormal endothelium-dependent vascular relaxation after intra-arterial infusion of acetylcholine has been reported in hypertensive patients (55). In animal models in hypertension, in contrast to the findings on endothelium in normotensive animals, increased adhesion of monocytes to endothelium as well as migration of these cells to the subendothelium was demonstrated $(56,57)$, whereas lipid accumulation in the vessel wall was not seen with hypertension alone but only occurred when hypertension was superimposed on hypercholesterolaemia $(58,59)$.

In the present group of hypertensive patients we found elevated coagulation factors VIIIc, VII, fibrin monomers and thrombin-antithrombin III complexes as indicators of an activated coagulation system. We have to consider that the patient group is older than the reference group and that this might introduce some bias with respect to the differences in coagulation parameters, but an age difference of ten years alone does not explain the significant elevations in coagulation parameters found. It is remarkable that elevated levels of F VII predominantly occurred in the male patients, an observation that might be of interest in the context of the male sex being a risk factor for cardiovascular disease.

In the hypertensive patient group, a positive correlation between systolic blood pressure and triglycerides and cholesterol was established (table 3 ). The diastolic blood pressure was not correlated with any of the other parameters studied and showed only a tendency towards a correlation with the Queteletindex (table 3).

Triglycerides were correlated with F VII and fibrin monomers. Cholesterol and triglycerides tended towards a positive correlation with fibrinogen (table 4). The correlation between triglycerides and F VII coagulant activity has also been 
reported in normotensive patients $(17,18,20,23-28,60)$. An association between dietary-induced alterations in plasma triglyceride concentrations and the activated phospholipase $\mathrm{C}$ - sensitive $\mathrm{F}$ VII-phospholipid complex concentrations as well as to a lesser degree $F$ VIlc vaiues has been demonstrated $(60,61)$. The mechanism by which plasma triglycerides interact with coagulation factor VII is unknown, but it might be secondary to activation of the intrinsic coagulation pathway by negatively charged surfaces of large lipoprotein particles as chylomicrons, VLDL's and their remnants. An increased conversion of F VII to the activated F VII-phospholipid complex could cause a further activation of the coagulation system such as found in the hypertensive patients. The presence of a damaged and more adhesive endothelium, platelet hyperreactivity and an activated coagulation system together with elevated $L p(a)$ and $L D L-c h o l e s t e r o l$ levels seems perfectly capable of promoting the development of fibrin, $L p(a)$ and LDL-cholesterol containing atherosclerotic plaques (62-64).

In conclusion, our data link hypertension and hyperlipidaemia with coagulation activity and may hereby contribute to an understanding of the mechanism why these two cardiovascular risk factors promote atherogenesis. Whether this is a primary or a secondary phenomenon and whether effective antihypertensive or lipid-lowering treatment decrease coagulation activity are questions that remain to be solved by further investigation.

\section{B: Fibrinolysis and cardiovascular risk factors.}

Signs of impaired fibrinolysis, indicated by decreased tissue plasminogen activator activity and elevated PAI-1 concentrations, were found in the hypertensive patient group. This group consisted of slightly older persons than the reference group, whereas tissue plasminogen activator activity has been reported to decrease with age (65) and some bias in this respect could be accounted for. However, the significant differences found, with values for this parameter under the reference range in two thirds of the patient group, were such that they could not solely be attributed to a mean age difference of ten years between the two groups (65).

Integrity of the endothelium is of importance for the regulation of vascular tone and, as has been mentioned above, in hypertension abnormalities concerning endothelial vasomotor control have been demonstrated $(54,55,66,67)$. Disorders in lipoprotein metabolism have also been reported to interfere with endothelial cell functions. Elevated VLDL concentrations have been shown to reduce prostacyclin and EDRF release of these cells in "in vitro" experiments (68). Both substances might have protective effects against atherosclerotic changes by means of their antiproliferative actions (69). In this way, diminished release of EDRF and prostacyclin could accelerate atherosclerosis, an effect which might be amplified by superoxide radicals released from activated macrophages in atherosclerotic lesions. Superoxide radicals seem capable of degradating both vasodilator substances (70). The fibrinolytic functions of endothelial cells are mediated by release of t-PA and PAI-1. Few studies have 
been published on fibrinolytic activity in hypertension but they all report impaired fibrinolysis due to elevated PAl- 1 levels $(42-45)$. In a group of hypertensive patients which was comparable to our patient group Landin et al. $(44,45)$ found elevated PAl-1 levels associated with hypercholesterolaemia and hypertriglyceridaemia. Elevated VLDL levels have been reported to induce PAl-1 release from endothelial cells in vitro by VLDL binding to the $B, E$ receptor $(71)$, whereas elevated LDL and VLDL levels appear to reduce t-PA release from human umbilical vein endothelial cells (HUVEC) (72). The mechanisms of the interaction between VLDL binding and PAl-1 release are still unknown. Insulin has been suggested as a direct regulator of PAl-1 activity (73) although hyperinsulinaemia is also associated with increased hepatic VLDL synthesis. A direct dose-dependent stimulating effect of insulin on hepatic cell synthesis and release of PAI-1 in vitro has been demonstrated $(74,75)$. In 1966 Welborn et al. (76) reported elevated insulin concentrations in hypertensive patients. In the meantime, numerous studies have confirmed that insulin resistance, hyperinsulinaemia and hypertriglyceridaemia are more likely to occur in hypertensive patients (50-52) and, as has been mentioned above, the presence of hypertension together with overweight of the central type, hypertriglyceridaemia and insulin resistance has beem designated syndrome $X(51)$. The question whether insulin resistance is of aetiological importance or an epiphenomenon still has to be clarified. Vague et al. (77) demonstrated that in healthy subjects fasting plasma insulin levels correlated negatively with blood fibrinolytic activity and positively with plasminogen activator inhibitor levels.

A remarkable finding in our own patient group was a decreased t-PA activity in two thirds of the patients together with an elevated mean t-PA antigen concentration. A negative correlation between these two parameters was found $(r=-0.37, p=0.02)$. Together with a disturbed endothelial vasomotor control in hypertension, the imbalance between t-PA activity and antigen concentration could point in the direction of endothelial cell dysfunction and might be associated with insulin resistance. Landin et al. (45) treated nine non-obese, non-diabetic untreated hypertensive men with metformin in order to try and enhance insulin action at the cellular level without raising the plasma insulin concentrations (78). After six weeks of treatment, a substantial decrease was noticed in systolic and diastolic blood pressure, total and LDL-cholesterol, triglycerides, insulin levels and insulin resistance determined by the glucose disposal rate (measured by means of the hyperinsulinaemic euglycaemic insulin clamp technique). PAI-1 activity remained unchanged whereas t-PA activity increased and t-PA antigen decreased. Except for decreased levels of t-PA antigen and t-PA activity two months after withdrawal of metformin treatment, the parameters studied had returned to their pre-treatment values. In obese females, Vague et al. (73) reported after a 15 day metformin treatment that there was a significant decrease of elevated insulin concentrations, triglycerides and PAl-1 levels together with a less impaired euglobulin fibrinolytic activity. Another explanation for the disparity of t-PA activity and antigen levels in our patients could be an elevated t-PA-PAll complex level secondary to elevated PAI-1 
concentrations. This hypothesis seems however incompatible with a decreased t-PA antigen level, an increased t-PA activity and unchanged PAl-1 concentrations during metformin treatment as mentioned above (45). In this group of hypertensive patients we previously reported the presence of an activated coagulation system (35), which might explain their elevated D-dimer levels as an indicator of reactive fibrinolysis.

In conclusion, this group of mildly hypertensive patients showed a disadvantageous lipid profile together with and partly correlated with indicators of impaired fibrinolysis as shown by a decreased tissue plasminogen activator activity and elevated PAl-1 levels. These data link fibrinolysis parameters with hypertension and hyperlipidaemia and are compatible with a multifactorial interaction of cardiovascular risk factors.

\section{References}

1. Kannel WB, Dawber TR, McGee DL.

Perspectives on systolic hypertension. The Framingham Study.

Circulation 1980; 61: 1179-82.

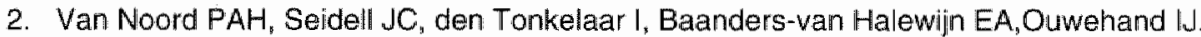
The relationship between fat distribution and some chronic diseases in 11,825 women participating in the DOM-project.

Int $J$ Epidermiol 1990; 19: 3.

3. Stamler J, Wentworth D, Neaton JD. MRFIT Research Group.

Is relationship between serum cholesterol and risk of premature death from coronary heart disease continuous and graded? The Multiple Risk Factor Intervention Trial. J Am Med Assn 1986; 256: 2823-8.

4. Kannel WB.

Lipids, diabetes and coronary heart diseasie: Insight from the Framingham Study. Am Heart J 1985; 110: 1100-7.

5. Kannel WB, Castelli WP, Gordon T, McNamara PM.

Serum cholesterol lipoprotein and the risk of coronary heart disease.

The Framingham Study.

Ann Iintern Med 1971; 74: 1-12.

6. Castelli WP.

The epidemiology of coronary heart disease: the Framingham Study.

Ain J Med 1984:76:4-12.

7. Kannel WB

High deinsity lipoproteins: Epidemiologic profile and risks of coronary artery disease.

Am $\Downarrow$ Cardiol 1983; 52 suppl: 9B-12B.

8. Jacobs DR, Mevane JC, Bangdiwala SI, Criqui MH, Tyroler HA.

High density lipoprotein cholesterol as a predictor of cardiovascular disease mortality in men and women: the follow-up of the Lipid Research Clinics prevalence study.

Am J Epidemiol 1990; 131: 32-47. 
9. Castelli WP.

The triglyceride issue: a view from Framingham.

Am Heart J 1986; 112: 432-7.

10. Carlson CA, Böttiger LE.

Ischaemic heart disease in relation to factual values of plasma triglycerides and cholesterol.

Lancet; 1972: i: 865-8.

11. Aberg $H$, Lithell $H$, Selinns I, Hedstrand $H$.

Serum triglycerides are a risk factor for myocardial infarction but not for angina pectoris.

Results from a 10-year follow-up of Uppsala primary preventive study.

Atherosclerosis 1985; 54: 89-97.

12. Hulley SH, Rosenman RH, Bawol RD, Brand RJ.

Epidemiology as a guide to clinical decisions.

N Engl J Med 1980; 25: 1383-9.

13. Austin MA.

Plasma trigiyceride as a risk factor for coronary heart disease: the epidemiologic evidence and beyond.

Am J Epidemiol 1989; 129: 249-59.

14. Austin MA.

Review: plasma triglyceride and coronary heart disease.

Arteriosclerosis and Thrombosis $1991 ; 11: 2-14$.

15. Schaefer EJ, Levy RI, Anderson DW, Danner RN, Brewer HB Jr, BlackwelderWC.

Plasma triglycerides in regulation of $\mathrm{HDL}$-cholesteroll levels.

Lancet 1978; ii: 391-3.

16. Davis CE, Gordon D, LaRosa J, Wood PD, Halperin $M$.

Correlations of plasma high-density lipoprotein cholesterol levels with other

plasma lipid and lipoprotein concentrations: the Lipid Research Clinics Program

Prevalence Study.

Circulation 1980; 62: suppl IV: IV-24-30.

17. Meade TW, North WRS, Chakrabarti $R_{*}$, Stining $Y$, Haines AP, Thompson SG,Brozovic M. Haemostatic function and cardiovascular death: early results of a prospective study.

Lancet 1980; 1: 1050-4.

18. Meade TW, Mellows $S$, Brozovic M, Miller GJ, Chakrabarti RR, North WRS, Haines AP, Stirling $Y$, Imeson JD, Thompson SG.

Haemostatic function and ischaemic heart disease: principal results of the Northwick Park Heart Study

Lancet 1986; ii: $533-7$.

19. Cooper J Douglas AS.

Fibrinogen level as a predictor of mortality in survivors of myocardial infarction.

Fibrinolysis 1991 ; 5 : 105-8.

20. Broadhurst $P$, Kelleher $C$. Hughes L, Imeson JD, Raftery EB.

Fibrinogen, factor VII clotting activity and coronary artery disease severity,

Atherosclerosis 1990; 85: 169-73.

21. Tofler GM, Brezinski D, Schafer Al.

Concurrent morning increase in platelet aggregability and the risk of myocardial infarction and sudden cardiac death.

N Engl J Med 1987; 316: 1514-8. 
22. Trip MD, Manger Cats $V$, van Capelle FJL, Vreeken $\downarrow$.

Platelef hyperreactivity and prognosis in survivors of myocardial infarction.

N Engl d Med 1990; 322: 1549-54.

23. Dalaker K, Hjermann 1 , Prydz $\mathrm{H}$.

A novel form of factor VII in plasma from men at risk for cardiovascular disease.

Br J Haematol 1985; $61: 315-22$

24. Constantino M, Merskey $\mathrm{C}$. Kudzma DJ, Zucker MB.

Increased activity of vitamin K-dependent clotting factors in human hyperlipoproteinaemia association with cholesterol and triglyceride levels.

Thromb Haemost 1977; 38: 465-75.

25. Elkeles RS, Chakrabarti R, Vickers M, Stirling $Y$, Meade TW.

Effect of treatment of hyperlipidaemia on haemostatic variables.

Br Med J 1980; $281:$ 973-4.

26. Simpson HCR, Mann Jl, Meade TW, Chakrabarti R, Stirling Y, Woolf L.

Hypertigy yceridaemia and hypercoagulability.

Lancet 1983; i: 786-90.

27. Nordoy $A_{i}$ llingworth DR, Connor WE, Goodnight S Jir.

Increased activity of factor VII and factor VII-phospholipid complex measured using a Normotest system in subjects with hyperlipidemia.

Haemostasis 1990; 20: 65-72.

28. Carvalho de Sousa J. Bruckert E, Giral P, Sonia C, Chapman J,Truffert J,Dairou $F, D e$ Gennes JC, Caen JP.

Coagulation factor VII and plasma triglycerides: decreased catabolism as a possible mechanism of factor VII hyperactivity.

Haemostasis 1989; 19: 125-3.

29. Nordoy A, Rodset JM.

Platelet function and platelet phospholipids in patients with hyperbetalipoproteinemia.

Acta Med Scand 1971; 189: 385-9.

30. Zahavi J. Betteridge JD, Jones NAG, Galton DJ, Kakkar VV.

Enhanced in vivo platelet release reaction and matondialdehyde formation in patients with hyperlipidemia.

Am J Med "1981; 70: 59-64.

31. Patrassi GM, Fallo F, Santarossa A, Sartori MT, Casonato A, Girolami A.

Clotting changes in borderline hypertension.

J Hum Hyperten 1987; 1: 101-3.

32. Boneu $B_{n}$ Durand $D$, Counillon $F_{n}$ Charlet JP, Bierme $R$, Sue JM. Increased level of factor VII complex in severe arterial hypertension.

Haemostas is 1978; 7: 332-8.

33. Patrassi GM, Fallo F, Martinelli $S$, Mantero F, Boeri $G$, Girolami $A$.

The contact phase of blood coagulation and renin activation in essential hypertension before and after captopril.

Eur Heart J 1984; 5: 561-7.

34. Yamanishi J, Sano H, Saito K, Furuta Y, Fukuzaki H.

Plasma concentrations of platelet-specific proteins in different stages of hypertension:

interaction between platelet aggregation, blood lipids and age.

Thromb Haemost 1985; 54: 539-43.

35. van Wersch JWJ, Rompelberg-Lahaye J, Lustermans FAT.

Plasma concentration of coagulation and fibrinolysis factors and the level of platelet

runction in hypertension.

Eur J Clin Chem Clin Biochem 1991; 29: 375-9. 
36. Chakrabarti $\mathrm{R}_{1}$ Hocking ED, Fearntey GR, Mann RD, Attwell TN, Jackson D.

Fibrinolytic activity and coronary artery disease.

Lancet 1968; 1: $987-90$.

37. Hamsten A, Wiman B, de Faire U, Blomback M.

Increased plasma levels of a rapid inhibitor of tissue plasminogen activator in young survivors of myocardial infarction.

N Engl J Med 1985; 313: 1557-63.

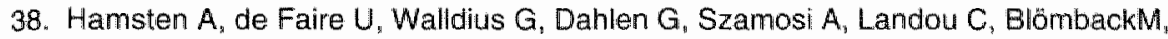
Wiman $B$.

Plasminogen activator inhibitor in plasma: risk factor for recurrent myocardial infarction.

Lancet 1987; ii: 3-9.

39. Mehta J, Mehta P. Lawson D, Saldeen T.

Plasma tissue plasminogen activator inhibitor levels in coronary artery disease:correlation with age and serum triglyceride concentrations.

J Am Coll Cardiol 1987; 9: 263-8.

40. Andersen $P$, Smith P, Seljeflat I, Brataker S, Arnesen H.

Effects of gemfibrozil on lipids and haemostasis after myocardial infarction.

Thromb Haemost 1990; 63: 174-7.

41. Gram J, Jespersen J.

A selective depression of tissue plasminogen activator ( $t$-PA) activity in euglobulins characterises a risk group among survivors of acute myocardial infarction.

Thromb Haemost 1987; 57: 137-9.

42. Ettenger MM, MacCarthy EP, Glas-Greenwalt P, Clyne DH, Pollak VE.

Abnormalities of fibrinolysis in essential hypertension.

J Hypertens Suppl 1984; 2: S175-8.

43. Palermo A, Bertalero P, Pizza $N$, Amelotti R, Libretti A.

Decireased fibrinolytic response to adrenergic stimulation in hypertensive patients.

J Hypertens Suppl 1989; 7: S162-3

44. Landin $K$, Tengborn $L$, Smith $U$.

Elevated fibrinogen and plasminogen activator inhibitor (PAl-1) in thypertension are

related to metabolic risk factors for cardiovascular disease.

J Intern Med 1990; 227: 273-8.

45. Landin K, Tengborn L, Smith U.

Treating insulin resistance in hypertension with metformin reduces both blood pressure and metabolic risk factors.

J Intern Med 1991; 229: 181-7.

46. Rosengren $A$, Wilhelmsen $L$, Eriksson $E$, Risberg $B$, Wedel $H$.

Lipoprotein(a) and coronary heart disease: a prospective case control study in a general population sample of middle aged men.

Br Med J 1990; 301: 1248-51.

47. Roberts WC

Atherosclerotic risk factors: are there ten or is there onlly one?

Am J Cardiol 1989; 64: 552-4.

48. Castelli WP, Anderson K.

A population al risk: prevalence of high cholesterol levels in hypertensive patients in the

Framinghan study.

Am J Med 1986; 80 (suppl 2a): 23-32.

49. Leren P, Foss OP, Helgeland A, Hiermann 1, Holime 1, Lund-Larsen PG.

Effect of propanolol and prazosin on blood lipids. The Oslo Study.

Lancel 1982; ii: 4-6. 
50. Shen DC, Shieh SH, Fuh MT, Wu DA, Chen Y DC, Reaven GM.

Resistance to insulin stimulated glucose uptake in patients with hypertension.

J Clin Endocrinol Metab 1988; 66: 580-3.

51. Reaven GM.

Banting lecture 1988: Role of insulin resistance in human disease.

Diabetes 1988; 37 : 1595-1607.

52. Ferranin E, Buzzigali $G$, Bonadonna $R$, Giorico MA, Oleggini $M_{s}$ Graziadei L,Pedrinelli $R$, Brandi L, Bevilacqua $S$.

Insulin resilstance in essential hypertension.

N Eng J Med 1987; 317: 350-7.

53. Salomaa $A$, Strandberg TE, Vanharen $H$, Naukarinnen $V$, Sarna S, Miettinen TA.

Glucose tolerance and biood pressure: long term follow up in middle aged men.

Br Med J 1991; 302; 493-6.

54. Vane $J R$, Anggard EE, Botting RM.

Review article: regulatory function of the vascullar endothelium.

N Engl J Med 1990; 323: 27-36.

55. Panza JA, Quyyumi AA, Brush JE, Epstein SE.

Abnormal endothelium dependent wascular relaxation in patients with essential

hypertension.

N Engl J Med 1990; 323: 22-7.

56. Haudenschild CC, Prescott MF, Chobanian AV.

Effects of hypertension and its reversal on aortic intima lesions of the rat.

Hypertension 1979: 2; 33-44.

57. Limas $C$, Westrum B, Iwai J, Limas CJ.

Aortic marphology in salt-dependent genetic hypertension.

Am J Pathol 1982; 107: 378-94.

58. Chobanian AV.

The influence of hypertension and other hemodynamic factors in atherogenesis.

Prog Cardiovasc Dis 1983; 26: 177-96.

59. Chobanian AV, Lichtenstein AH, Nilakhe $V$, Haudenschild CC, Drago R, Nickerson $C$. Influence of hypertension on aortic atherosclerosis in the Watanabe rabbit.

Hypertension 1989; 14: 203-9.

60. Miller $G$ J, Walter $S_{\Downarrow}$, Stirling $Y$, Thompson SG, Esnout MP, Meade TW.

Assay of facto" VII activity by two techniques: evidence for increased conversion of VII to a VII in hyperlipidaemia, with possible implications tor ischaemic heart disease.

Br J Haematol 1985; 59: 249-58.

61. Skartlien AH, Lyberg-Beckmann S, Holme I, Hjermann I, Prydz $\mathrm{H}$.

Effect of alteration in triglyceride levels on factor Vill-phospholipid complexes in plasma.

Arteriosclerosis 1989; $9: 798-801$

62. Smith EB, Staples EM, Dietz HS, Smith RH.

Role of endothelium in sequestration of lipoprotein and fibrinogen in aorticlesions, thromb: and graft pseudo-intimas.

Lancet 1979 ii: $812-6$.

63. Smith EB, Staples EM.

Haemostatic factors in human aortic intima.

Lancet 1981; î: 117-9.

64. Niendorf A, Rath M, Wolf K. Peters S, Arps H, Beisiegel H, Dietel M.

Morphological detection and quamtification of lipoprotein(a) deposition in atheromatous lesions of human aorta and coronary arteries.

Virchows Archiv A 1990; 417: 105-11. 
65. Hashimoto $Y$, Kobayashi $A_{9}$ Yamazaki $N$, Sugawara $Y$, Takada $Y$ and Takada $A$. Relationship between age and plasma t-PA, P.A-inhibitor and PA activity.

Thromb Res 1987; 46: 625-33.

66. Furchgott RF, Zawadzki JV.

The obligatory role of endothelial cells in the relaxation of arterial smooth muscle by acettylcholine.

Nature 1980; $288: 373-6$.

67. Furchigott RF.

Role of endothelium in responses of vascular smooth muscle

Circ Res $1983 ; 53: 557-73$.

68. Andrews HE, Bruckdorfer KR, Dunn RC, Jacobs M.

Low-density lipoproteins inhibit endothelium-dependent relaxation in rabbit aorta.

Nature 1987; 327: 237-9.

69. Garg UC, Hassid A.

Nitric oxide-generating vasodilators and 8-bromo-cyclic guanosine monophosphate inhibit mitogenesis and proliferation of cultured rat vascular smooth muscle cells.

$\mathrm{J}$ Clin Invest 1989; 83: 1774-7.

70. Gryglewski RJ, Paimer RM, Moncada S.

Superaxide anion is involved in the breakdown of endothelium-derived vascular relaxing factor.

Nature 1986; $320: 454-6$.

71. Stiko-Rahm A, Wiman B, Hamsten A, Nilssion J.

Secretion of plasminogen activator inhibitor-1 from cultured human umbilical vein endothellial cells is induced by very low density lipoprotein.

Arteriosclerosis 1990; 10: 1067-73.

72. Wojta $J_{y}$ Binder BR, Swift L, Hoover RL.

Effect of lipoproteins on the fibrinolytic potential of human endothelial cells

Thromb Haemosit 1989; 62: 91 (abstract).

73. Vague P, Juhan-Vague I, Alessi MC, Badier C, Valadier J.

Metformin decreases the high plasminogen activation inhibitor capacity, plasma insulin and triglyceride levels in non-diabetic obese subjects.

Thromb Haemost 1987; 57:326-8.

74. Allessi MC, Juhan-Vague I, Kooistra T, Declerck PJ, Collen D.

Insulin stimulates the synthesis of plasminogen activator inhibitor 1 by the human

hepatocellular cell line Hep G2.

Thromb Haemost 1988; 60: 491-4.

75. Kooistra T, Bosma PJ, Töns HA, van den Berg AP, Meyer P, Princen HM.

Plasminogen activator inhibitor 1: biosynthesis and $M$ RNA level are increased by insulin in cultured human hepatocytes.

Thromb Haemost 1989; 62: 723-8.

76. Welborn TA, Breckeniridge A, Rubinstein AH, Dollery CT, Fraser TR.

Serum insulin in essential hypentension and in peripheral vascular disease.

Lancel 1966; i: 1336-7.

77. Vague P, Juhan-Vague I, Aillaud MF, Badier C, Viard R, Alessil MC, Collen D.

Correlation between blood fibrinolytic activity, plasminogen activator inhibitor level, plasma insulin level, and relative body weight in normal and obese subjects.

Metabolism 1986; 35: 250-3.

78. Cigolini $M$, Bosello $O$, Zancanaro $C$, Orlandi $P G, F e z z i$, Smith $U$.

influence of metformin on metabolic effect of insulin in human adipose tissue in vitro.

Diabete Metab 1984; 10: 311-5. 



\section{Chapter 5}

\section{Prothrombin fragment 1.2 in both treated and untreated hypertensive patients}

S.H.J. Donders, F.A.T. Lustermans, J.W.J. van Wersch

Submitted for publication 


\section{Summary}

The coagulation parameters factor VII, fibrin monomers, thrombin-antithrombin III (TAT) complexes and prothrombin fragment 1.2 (F 1.2) were studied in 43 treated and 11 untreated patients (27 males, 27 females age range 19-70 years) with hypertension of moderate severity. The patients included in this study who were treated with antihypertensive drugs were still hypertensive in spite of their treatment. The median $F 1.2$ leveis (interquartile range) in the hypertensive patients were more than double those of the reference group: $1.47(0.79) \mathrm{nmol} / \mathrm{l}$ as against 0.66 (0.26) $\mathrm{nmol} / \mathrm{l}(\mathrm{p}<0.0001)$. Median concentrations of TAT complexes $2.9(1.7) \mu \mathrm{g} / \mathrm{l}$ versus $2.3(1.4) \mu \mathrm{g} / \mathrm{l}(\mathrm{p}<0.02)$ as well as those of fibrin monomers $14.2(4.6) \mathrm{nmol} / \mathrm{l}$ as against $10.5(2.0) \mathrm{nmol} / \mathrm{l}(\mathrm{p}<0.01)$ also were significantly elevated in the hypertensive patients, but to a lesser extent. For factor VII a significant difference was found between males and females. The median factor VII value in the male patients was $137 \%$ (32) compared with 94 (31) \% in the male reference group $(\mathrm{p}<0.001)$. In the hypertensive female patients this median value was $147(36) \%$ in comparison with $131(56) \%$ in the female reference group $(p<0.01)$. By the Spearman rank test, no correlations were found between the coagulation parameters and systolic or diastolic blood pressure, age or duration of hypertension. $F 1.2$ values were correlated with fibrin monomers ( $r=$ $0.33, p<0.03$ ) but not with the other coagulation parameters sturdied.

The elevated $F 1.2$ levels in this hypertensive patient group confirm the presence of an activated coagulation system in hypertension, which might be a primary or a secondary phenomenon.

\section{Introduction}

Hypertension is a well known risk factor for the development of atherosclerotic vascular disease, especially in the presence of other cardiovascular risk factors as diabetes mellitus, overweight, hyperlipidaemia and cigarette smoking (1). A hypercoagulable state which has been reported to occur in hypertension also has been implicated in cardiovascular disease. Elevated concentrations of coagulation factors VII and VIII and fibrinogen, together with platelet hyperreactivity have been associated with coronary heart disease $(2-8)$, whereas in hypertensive patients elevated levels of factors XII, XI, VIII, fibrinogen, fibrin monomers, thrombinantithrombin III (TAT) complexes and platelet hyperreactivity have all been reported (9-13). Conversion of prothrombin to thrombin mediated by the prothrombinase complex (factor $\mathrm{Xa}, \mathrm{Va}$, calcium and phospholipid) is the key event in blood coagulation and produces a peptide designated prothrombin fragment $1.2(F 1.2)$. The F1.2 plasma level can be regarded as an indicator of the activity of the prothrombinase complex. Mean F 1.2 concentrations have been demonstrated to be elevated in patients at risk for, or actually suffering from, thrombotic events $(14,15)$, but are depressed in patients treated with anticoagulant therapy (15). To our knowledge, data on plasma $\mathrm{F} 1.2$ concentrations in hypertensive patients have not yet been published. 
This analyte and factor VII, fibrin monomers and TAT complexes were determined in the 54 hypertensive patients described in chapter 4 to investigate whether or not signs of an activated coagulation system were present in these patients.

\section{Patients, materials and methods}

\section{Patients}

The hypertensive patient group has been described in the patient section of chapter 4.

\section{Reference group}

The reference group consisted of 50 non-smoking subjectively healthy hospital workers ( 25 males, 25 females) aged $24-50$ years (mean age 40 years) without hypertension.

\section{Blood samples}

The processing of the blood sampling has been described in chapter 4 .

\section{Methods}

Fibrin monomer concentrations were assessed by means of the chromogenic COA-Set FM-test of Kabi Vitrum Diagnostica (Mölndal, Sweden). Thrombinantithrombin III was determined with an ELISA kit of the Behring Corporation (Marburg, Germany). The prothrombin fragment 1.2 was assayed in plasma using an ELISA method (Behring Corporation, Marburg, Germany). Factor VII was quantitated by means of the chromogenic substrate test of Kabi Vitrum Diagnostica (Mölndal, Sweden).

\section{Statistics}

The significance of the differences was assessed by the Mann-WhitneyWilcoxon test. The parameters studied were correlated with each other by the Spearman rank test.

\section{Results}

The summary statistics of the coagulation data of the hypertensive patients in comparison with the reference group are given in table 1 . The median $F 1.2$ levels (interquartile range) were $1.47(0.79) \mathrm{nmol} / \mathrm{l}$ in the patients, as against $0.66(0.26) \mathrm{nmol} / \mathrm{l}$ in the controls $(p<0.0001)$. Fibrin monomers were $14.2(4.6)$ $\mathrm{nmol} / / \mathrm{l}$ versus $10.5(2.0) \mathrm{nmol} / \mathrm{l}(\mathrm{p}<0.01)$, TAT complexes $2.9(1.7) \mu \mathrm{g} / \mathrm{l}$ versus 2.3 (1.4) $\mu \mathrm{g} / \mathrm{I}(\mathrm{p}<0.02)$ and factor VII in male patients $137(32) \%$ versus 94 (31) \% in the controls $(p<0.001)$. In females, the median factor VII levels were $147(36)$ $\%$ in the hypertensive patients and $131(56) \%$ in the controls $(p<0.01)$.

Table 2 shows the percentages of hypertensive patients with values for the respective coagulation parameters under the lower reference range and above 
the upper reference range limit. The coagulation parameters measured did not differ significantly between the untreated patients and the patients treated with diuretics, calcium antagonists, ACE-inhibitors or beta-blockers. Median factor VII concentrations in male patients $(137 \%)$ were relatively higher than those in female patients $(147 \%)$ in comparison with their respective reference groups, whereas in absolute percentages F VII concentrations tended to be higher in the female hypertensive patients $(p=0.07)$. We compared the other parameters studied in the hypertensive patients after dividing them into male and female subgroups. $F 1.2$ values were significantly higher in the male subgroup with median values of $1.96 \mathrm{nmol} / \mathrm{l}$ ws $1.29 \mathrm{nmol} / \mathrm{l}$ in the female patients $(\mathrm{p}=0.004)$. Fibrin monomers and levels of TAT complexes in male and female hypertensive patients did not significantly differ (data not shown).

No correlation between systolic or diastolic blood pressure and any of the coagulation parameters studied could be found. The coagulation parameters were not correlated with age or known duration of hypertension. $F 1.2$ was correlated with fibrin monomers $(r=0.33, p<0.03)$ but not with any of the other coagulation parameters studied, which were also not correlated with each other.

\begin{tabular}{|c|c|c|c|c|c|c|c|}
\hline \multirow{2}{*}{$\begin{array}{l}\text { Parameters } \\
\text { (ref, range) }\end{array}$} & \multicolumn{3}{|c|}{ Hypertensfive patlent group } & \multicolumn{3}{|c|}{ Reference group } & \multirow{2}{*}{$\begin{array}{l}\text { Signiff } \\
\text { cance } \\
\text { p-value }\end{array}$} \\
\hline & Median & $\begin{array}{l}\text { Lower } \\
\text { guartile }\end{array}$ & $\begin{array}{l}\text { Upper } \\
\text { quartile }\end{array}$ & Madian & $\begin{array}{l}\text { Lower } \\
\text { quartile }\end{array}$ & $\begin{array}{l}\text { Upper } \\
\text { quartile }\end{array}$ & \\
\hline$F 12(0.44-141 \mathrm{nmol} / \mathrm{l})$ & 1,47 & 1,14 & 1.93 & 0.66 & 0.53 & 079 & $<0,0001$ \\
\hline Fibrin monomers $(8.413 .2 \mathrm{nmol} / \mathrm{l})$ & 14.2 & 117 & 163 & 10.5 & 9.8 & 118 & 50.01 \\
\hline TAT complex $(1.0-4.1 \mu \mathrm{g} / \mathrm{l})$ & 29 & 2.1 & 38 & 2.3 & 1.7 & 31 & $<0.02$ \\
\hline F VII males $(54-138 \%)$ & 137 & 119 & 151 & 94 & 78 & 109 & $<0.001$ \\
\hline females $(56-200 \%)$ & 147 & 123 & 159 & 131 & 104 & 160 & $<0.01$ \\
\hline
\end{tabular}

* Significance was assessed with the Mann-Whitney-Witcoxon test

Table 1

Coagulation data in the hypertensive patients $(n=54)$ in comparison with the group of healthy controls $(n=50)$.

\begin{tabular}{|c|c|c|}
\hline \multirow{2}{*}{$\begin{array}{l}\text { Parameters } \\
\text { (ret range) }\end{array}$} & \multicolumn{2}{|c|}{ Hypertensive patients $(n=54)$} \\
\hline & $\begin{array}{l}\text { Percentages under the } \\
\text { lower reference range }\end{array}$ & $\begin{array}{l}\text { Percentages above the } \\
\text { upper reference range }\end{array}$ \\
\hline$F 1.2(0.44-7.11 \mathrm{nmo} / 1)$ & 1.9 & 72.2 \\
\hline Fibrin monomers $(8.4 \times 13.2 \mathrm{nmol} / \mathrm{l})$ & 18.5 & 59.2 \\
\hline TAT complex $(1.0-41 \mu \mathrm{g} / \mathrm{l})$ & 0 & 20.4 \\
\hline F Vll males $(54-138 \%)$ & 0 & 41.7 \\
\hline females $(56-200 \%)$ & 0. & 4.3 \\
\hline
\end{tabular}

Table 2

Percentages under the lower and above the upper reference range limits of the coagulation parameters in the hypertensive patient group. 


\section{Discussion}

The coagulation parameters measured did not differ significantly (MannWhitney-Wilcoxon test) between the untreated hypertensive patients and the patients who were still hypertensive despite treatment with calcium antagonists, ACE-inhibitors, diuretics, beta-blockers or a combination of these drugs (data not shown). It was therefore decided to study the data of all the hypertensive patients together as one group. In these patients with hypertension of moderate severity we found elevated concentrations of $F 1.2$ in comparison with those in the reference group. In evaluating the results of this study we have to consider that the patient group was older than the reference group and because $F 1.2$ levels tend to increase with age (16) some bias in this respect could be accounted for. However, in this patient group $F 1.2$ concentrations were not correlated with age (Spearman rank test $(r=0.05, p=0.75)$ ). The significant elevations of the coagulation parameters in the hypertensive patient group found with $72 \%$ and $59 \%$ of the patients exceeding the upper reference range limit for F 1.2 and fibrin monomer values respectively (table 2) were such that they could not solely be attributed to an age difference of ten years between the patient group and the reference group (16). The elevated $F 1.2$ concentrations were more pronounced in the male patients. Together with elevated $F 1.2$ vallues, F VII percentages were substantially higher in male patients than in female patients in comparison with the respective reference groups. This observation might be of interest in the light of the male gender being a risk factor for the development of cardiovascular disease. To our knowledge, data on $F 1.2$ levels in hypertension have not been published previously. The established elevated $F 1.2$ values, together with elevated $F$ VII, fibrin monomers and TATcomplexes, are an indication of an activated coagulation system in hypertensive patients. The $F 1.2$ elevation in these hypertensive patients was more pronounced than the elevation in TAT-complexes and fibrin monomers which might indicate that $F 1.2$ is a more sensitive indicator of coagulation activity than the latter two. Whether an activated coagulation system is a primary or a secondary phenomenon in hypertension and whether effective antihypertensive treatment may decrease coagulation activity are questions that remain to be solved by further investigation.

\section{References}

1. Kannel WB, Dawber TR, McGee DL.

Perspectives on systolic hypertension. The Framingham Study.

Circulation 1980; 61: 1179-82.

2. Meade TW, North WRS, Chakrabarti $R$, Stirling $Y$, Haines AP, Thompson SG, Brozovic M. Haemostatic function and cardiovascular death: early results of a prospective study.

Lancet 1980; i: 1050-4. 
3. Meade TW, Mellows S, Brozovic M, Miller GJ, Chakrabarti RR, North WRS, Haines AP, Stirling $Y$, Imeson JD, Thompson SG.

Haemostatic function and ischaemic heart disease: principal results of the Northwick Park Heart Study

Lancet 1986; it: $533-7$.

4. Cooper J, Douglas AS.

Fibrinogen level as a predictor of mortality in survivors of myocardial infarction.

Fibrinolysis 1991; 5: 101-8.

5. Broadhurst $P$, Kelleher $C$ s Hughes $L$, Imeson JD, Raftery EB.

Fibrinogen, factor VII clotting activity and coronary artery disease severity.

Atherosclerosis $1990 ; 85: 169-73$.

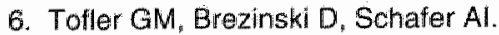

Concurrent morning increase in platelet aggregability and the risk of myocardial infarction and suidden cardiac death.

N Engl J Med 1987; 316: 1514-8.

7. Trip MD, Manger Cats $V_{\text {i }}$ van Capelle FJL, Vreeken $J$.

Platelet hyperreactivity and prognosis in survivors of myocardial infarction.

N Engl J Med 1990; 322: 1549-54.

8. Dalaker K, Hiermann I, Prydz H.

A novel form of factor VII in plasma from men at risk for cardiovascular disease.

Br J Haematol 1985; 61: 315-22.

9. Patrassi GM, Fallo F, Santarossa A, Sartori MT, Casonato A, Girolami A.

Clotting changes in borderline hypertersion.

J Hum Hyperten 1987; i: 101-3.

10. Boneu B, Durand D, Counillon F, Charlet JP, Bierme R, Sue JM.

Increased level of factor $V I I$ complex in severe arterial hypertension.

Haemostasis 1978; 7: 332-8.

11. Patrassi GM, Fallo F, Martinelli S, Mantero F, Boeri G, Girolami A.

The contact phase of blood coagulation and renin activation in essential hypertension before and after captopril.

Eur Heart $\mathrm{J} 1984 ; 5 ; 561-7$.

12. Yamanishi J, Sano $H$, Saito $K$, Furuta $Y$, Fukuzaki $H$.

Plasma concentrations of platelet-specific proteins in different stages of hypertension:

interaction between platelet aggregation, blood lipids and age.

Thromb Haemoet 1985; 54: 539-43.

13. Van Wersch JWJ, Rompelberg-Lahaye J, Lustermans FAT.

Plasma concentration of coagulation and fibrinolysis factors and the level of platelet function in hypertension.

Eur J Clin Chem Clin Biochem 1991; 29: 375-9.

14. Mc Gehee W. Francis RBB, Patch Md.

Prothrombin fragment 1.2 (F 1.2) in patients with venous thromboembolism.

Blood 1990; 76 (10): supp 1: 2049A.

15. Estivals $M$, Pelzer $H$, Sie P, Pichon J, Boccalon $H$, Boneu $B$.

Prothirombin fragment $1+2$, thrombin-antithrombin 111 complexes and D-dimers in acute deep vein thrombosis: effect of heparin treatment.

$\mathrm{Br}$ „ Haematol 1991; 78:421-4

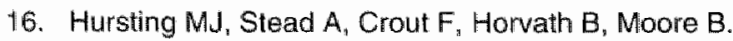

Effects of age, race, sex and smoking on plasma prothrombin fragment 1.2 (F 1.2) leveis in a healthy population.

Blood 1990; 76 (10): supp 1: 1684A. 


\section{Chapter 6}

\section{Interrelations of glycometabolic control, lipids, coagulation parameters and micro- albuminuria in non-insulin-dependent diabetes mellitus}

S.H.J. Donders, F.A.T. Lustermans, J.W.J. van Wersch

Submitted for publication 


\section{Summary}

Diabetes mellitus and hyperlipidaemia are associated with coronary heart disease and with hypercoagulability, another independent risk factor for the development of coronary heart disease. In sixty-five, with antidiabetic agents treated, non-insulin-dependent diabetes mellitus (NIDDM) patients ( 41 females, 24 males) with a median age of 66 years (range 43 to 81 years) we studied the glycometabolic control ( $\mathrm{HbA}_{4 \mathrm{fc}}$ ), lipids (Quetelet-index and blood lipids), coagulation parameters and urinary albumin excretion rate in correlation with each other and in comparison with a reference group.

Median values for serum lipid parameters (interquartile range) were elevated for triglycerides: $2.3(1.3) \mathrm{mmol} / \mathrm{l}$ versus $1.6(0.7) \mathrm{mmol} / \mathrm{l}$ in the controls $(p<0.001)$, whereas the median lipoprotein(a) concentration was 65 (157) $\mathrm{mg} / \mathrm{l}$ in the NIDDM patients versus 44 (114) $\mathrm{mg} / \mathrm{l}$ in the control group (not significantly different). Median HDL-cholesterol concentrations were slightly decreased in the NIDDM patients: $1.2(0.3) \mathrm{mmol} / \mathrm{l}$ as compared with $1.3(0.4) \mathrm{mmol} / \mathrm{l}$ in the control group $(p<0.02)$.

Elevated median concentrations (interquartile range) for fibrinogen: 4.6 (1.2) $\mathrm{g} / \mathrm{l}$ versus $2.5(2.6) \mathrm{g} / \mathrm{l}$ in the reference group $(\mathrm{p}<0.0001)$, fibrin monomers: 13.8 (7.1) $\mathrm{nmol} / \mathrm{l}$ as against 10.5 (1.9) nmol/l $(p<0.0001)$, thrombin-antithrombin $\mathrm{III}$ complex: $3.4(4.6) \mu \mathrm{g} / \mathrm{l}$ versus $2.4(2.5) \mu \mathrm{g} / \mathrm{l}(\mathrm{p}<0.001)$, F VIllc: $149(49) \%$ versus $90(48) \%(p<0.0001)$ and $F$ VII in the male NIDDM patients: $139(38) \%$ versus $94(31) \%$ in the male reference group $(p<0.0001)$ are indicators of an activated coagulation system in these diabetic patients. By the Spearman rank test $\mathrm{HbA}$ values were, of all the parameters studied, only correlated with antithrombin III $(r=0.27, p<0.03)$ and showed a tendency towards a correlation with lipoprotein(a) $(r=0.23, p<0.07)$. Triglycerides were correlated with the Queteletindex $(r=0.27, p<0.03)$, HDL-cholesterol $(r=-0.41, p<0.001)$ and $F V \| I(r=0.35$, $p<0.01$ ) respectively, whereas serum cholesterol concentrations were found to correlate with $F$ VII $(r=0.27, p<0.04)$ and fibrin monomers $(r=0.29, p<0.03)$. Twelve patients $(18.5 \%)$ showed an urinary albumin excretion rate above $20 \mu \mathrm{g}$ per minute with a median level of $40 \mu \mathrm{g}$ (range 21-124 $\mu \mathrm{g}$ ) per minute. No relation between the urinary albumin excretion rate and any of the other parameters studied was found. In this group of 65 NIDDM patients we found a characteristic disadvantageous lipid profile in association with signs of an activated coagulation system. Glycometabolic contral appeared to have no major influence on the degree of activation of the coagulation system nor on the urinary albumin excretion rate in these NIDDM patients.

The results of this study may provide clues to the pathophysiological mechanisms of the cardiovascular risk factors NIDDM and hyperlipidaemia and give circumstantial support for the more aggressive approach advised in the treatment of hyperlipidaemia in diabetic patients. 


\section{Introduction}

Diabetic patients are at risk for developing sequelae of microvascular and macrovascular disease. Non-enzymatic glycosylation of tissue and plasma protein might contribute to the pathogenesis of vascular lesions (1, review). In patients with diabetes meilitus, abnormalities concerning blood coagulation and fibrinolysis have been reported such as increased platelet activation (2) and aggregation (3), elevated levels of fibrinogen, prothrombin and factors $V$, VII, VIIlc and $X(3$, review), malfunctioning tissue plasminogen activator (t-PA) (4), impaired plasminogen activation (5), increased t-PA inhibitor (6) and poorly degradable fibrin (7). The alterations reported appear to show a hypercoagulable state due to an activated coagulation system with diminished fibrinolysis, although conflicting data have been published on the latter (e.g. 8). Nonenzymatic glycosylation of factors involved in coagulation and fibrinolysis has been suggested as a possible cause for these findings $(4,5,7)$. Hypercoagulability is known to be a risk factor for the development of cardiovascular disease (9-13). Several major epidemiological studies thave shown that elevated LDL-cholesterol and triglyceride levels and decreased HDLcholesterol concentrations, which frequently occur in non-insulin-dependent diabetes mellitus (NIDDM), increase the risk for coronary heart disease in these patients (14-16). Hyperlipidaemia is also associated with hypercoagulability. Hypertriglyceridaemia has been reported to be associated with elevated levels of prothrombin, fibrinogen, clotting factors VII, VIIIc, IX, X and with increased plasminogen activator inhibitor concentrations $(10,12,17,18)$ whereas hypercholesterolaemia was associated with enhanced levels of prothrombin and factor $X(18)$.

We were interested in whether or not a disadvantageous lipid profile in NIDDM patients could contribute to a further activation of the coagulation system. In this paper we report the correlations between glycometabolic control $\left(\mathrm{HbA}_{1 \mathrm{c}}\right)$, lipids (Quetelet index, cholesterol, LDL-cholesteral, HDL-cholesterol, lipoprotein(a) and triglycerides) and signs of diabetic microangiopathy as indicated by the urinary albumin excretion rate with coagulation parameters (fibrinogen, $F$ VII, $F$ VIII, fibrin monomers and thrombin-antithrombin III) in sixty-five non-insulindependent diabetic patients.

\section{Patients, materials and methods}

\section{Patients}

Sixty-five diabetic patients ( 41 females, 24 males) were included in the study. The median age was 66 years (age range 43 to 86 years) and the median established duration of diabetes mellitus was 8 years (range 0.5 to 40 years). All the patients used oral hypoglycaemic agents and did not take anticoagulant 
drugs or any other drugs known to interfere with the coagulation system. The patients did not have intercurrent illnesses, hypertension, liver, renal or other endocrine diseases. Patients with macroalbuminuria (i.e. an urinary albumin excretion exceeding $200 \mu \mathrm{g}$ per min.) were excluded from the study. The blood samples were collected when the patients attended for their routine diabetes control.

\section{Reference group}

An age and sex matched control group ( 41 females and 24 males) was selected out of a group of healthy volunteers for assessment of the blood lipid parameters. The laboratory reference group which consisted of 50 healthy nonsmoking individuals ( 25 males, 25 females) aged 24-50 years (mean. age 40 years) was used as a reference group for the haemostasis parameters.

\section{Samples}

Venous blood samples were collected between 8.30-9.00 a.m. and citrated plasma was prepared by centrifugation of nine volumes of freshly drawn blood with one volume of trisodium citrate $(0.11 \mathrm{~mol} / \mathrm{l})$ for $30 \mathrm{~min}$. at $25^{\circ} \mathrm{C}(1600 \mathrm{~g})$. The plasma was used immediately or stored at $-70^{\circ} \mathrm{C}$ in plastic tubes and thawed with tap water for $5 \mathrm{~min}$. before use. For the glycometabolic determinations washed red cells were haemolysed and the haemolysate as such was used for the chromatographic separation of $\mathrm{HbA}_{4 \mathrm{c}}$. The urine samples for the urinary albumin determination were obtained from a morning portion. If urine was passed during the night, this sample was also saved and the entire collection period was registered. The urine samples did not show leucocyturia when tested by dipsticks.

\section{Methods}

- Fibrinogen:

turbidimetric method, using the CTS-fibrinogen reagent on the Chromotime System (Behring).

- Factor VII:

chromogenic substrate COA-set of Kabi Vitrum Diagnostica, Sweden.

- Factor Villc:

APTT one stage clotting assay employing a deficiënt plasma (Behring, Marburg, Germany).

- Fibrin monomers:

chromogenic COA-set FM test Kabi Vitrum Diagnostica.

- Thrombin-antithrombin III:

ELISA kit (Behring, Marburg, Germany.) 
- Antithrombin III:

chromogenic substrate Berichrom-antithrombin III (Behring: Marburg, Germany.)

- Lipoprotein(a):

Sandwich ELISA test kit (Biopool, Sweden)

- $\mathrm{HbA}_{1 \mathrm{c}}$ in haemolysate:

Bio Rad ion exchange column chromatography, product No 192-8001

- Urinary microalbumin:

immunoturbidimetric test of Orion Diagnostica Corporation, product No 67352

The serum samples were analysed with a Cobas Bio centrifugal fast analyzer and commercial test kits were used according to the manufacturer's instructions for determination of serum triglycerides, total cholesterol, HDL-cholesterol and LDL-cholesterol as described in chapter 3.

\section{Statistics}

The various parameters were correlated with each other with the Spearman rank test. The significance of differences was assessed by the Mann-WhitneyWilcoxon test.

\section{Results}

The basic $\mathrm{HbA}_{1 \mathrm{c}}$ and lipid characteristics of this group of 65 non-insulin dependent diabetic patients in comparison with a healthy control group are shown in table 1 . The median $\mathrm{HbA}_{1 \mathrm{c}}$ percentage (interquartile range) was 8.5 (1.7)\% whereas $35.6 \%$ of the patients showed $\mathrm{HbA}_{10}$ values above $9.0 \%$ and $18.5 \%$ yieled $\mathrm{HbA}_{1 \mathrm{c}}$ percentages above $10 \%$. Median values for serum lipid parameters were elevated for triglycerides 2.1 (1.3) mmol/l versus $1.6(0.7)$ $\mathrm{mmol} / \mathrm{l}(\mathrm{p}<0.0001)$ in the control group. HDL-cholesterol concentrations were slightly decreased in the NIDDM patients $1.2(0.3) \mathrm{mmol} / \mathrm{l}$ versus $1.3(0.4)$ $\mathrm{mmol} / \mathrm{l}(\mathrm{p}<0.02)$. The median lipoprotein(a) value in the NIDDM patients was 65 (157) $\mathrm{mg} / \mathrm{l}$ versus $44(114) \mathrm{mg} / \mathrm{l}$ in the controls (not significantly different). The median Quetelet-index was 27 (6) $\mathrm{kg} / \mathrm{m} 2$ in the NIDDM patient group.

The basic coagulation data of the diabetic patients in comparison with the reference group are shown in table 2 . We found enhanced median concentrations (interquartile range) for fibrinogen: $4.6(1.2) \mathrm{g} / \mathrm{l}$ versus $2.5(2.6) \mathrm{g} / \mathrm{l}$ in the reference group $(p<0.0001)$, tibrin monomers: $13.7(7.1) \mathrm{nmol} / /$ as against 10.5 (1.9) nmol// $(p<0.0001)$, thrombin-antithrombin III complex: $3.4(4.6) \mu \mathrm{g} / \mathrm{l}$ as compared with $2.4(2.5) \mu g / l(p<0.001)$. F VIII: 149 (49) \% versus 90 (48) \% $(p<0.0001)$ and antithrombin III: $107(18) \%$ versus $98(8) \%(p<0.001)$ (table 2$)$. 


\begin{tabular}{|c|c|c|c|c|c|}
\hline \multirow[b]{2}{*}{ Parameters (ref. range) } & \multicolumn{3}{|c|}{ NIDDM patients } & \multirow{2}{*}{$\begin{array}{l}\text { Controls } \\
\text { Median }\end{array}$} & \multirow{2}{*}{$\begin{array}{c}\text { Significantes } \\
\text { pavalue }\end{array}$} \\
\hline & Madian & $\begin{array}{l}\text { Lower } \\
\text { quartille }\end{array}$ & $\begin{array}{c}\text { Upper } \\
\text { quartile }\end{array}$ & & \\
\hline$H \mathrm{HA}_{1 c}(4 \%)$ & 8.5 & 7.6 & 9.3 & 5.7 & $<0,0001$ \\
\hline Serum cholesterol $(4.0-7.5$ mmolll) & 6.8 & 5.7 & 7.7 & 6.6 & N.S. \\
\hline LDL-cholesteroll $(3.0 .5 .0 \mathrm{mmol} / 1)$ & 4.5 & 3.9 & 5.6 & 4.3 & N.S. \\
\hline HDL-cholesterol $(0.9-1.7$ mrnol/1) & 1.2 & 1.0 & 1.3 & 1.3 & $<0.02$ \\
\hline Triglycerides $(0.8-2.0 \mathrm{mmol} / \mathrm{l})$ & 2.1 & 1.4 & 2.7 & 1.6 & $<0.001$ \\
\hline Lipoprotein(a) (<300 mg/l) & 65 & 12 & 169 & 44 & N.S. \\
\hline
\end{tabular}

\section{Table1}

Basic HbA $f_{c}$ and lipid data in 65 NIDDM patients and percentages beneath the lower and above the upper reference range limits in comparison with a healthy control group $(n=65)$.

\begin{tabular}{|c|c|c|c|c|c|}
\hline \multirow[b]{2}{*}{$\begin{array}{l}\text { Parameters } \\
\text { (rref. range) }\end{array}$} & \multicolumn{3}{|c|}{ NIDDM patients } & \multirow{2}{*}{$\begin{array}{l}\text { Controls } \\
\text { Median }\end{array}$} & \multirow{2}{*}{$\begin{array}{c}\text { Significance* } \\
\text { p-xalue }\end{array}$} \\
\hline & Median & $\begin{array}{l}\text { Lower } \\
\text { quartille }\end{array}$ & $\begin{array}{l}\text { Upper } \\
\text { quartilie }\end{array}$ & & \\
\hline Fibrinogem $(1.7-4.0 \mathrm{~g} / \mathrm{l})$ & 4,6 & 3.8 & 5.0 & 2.5 & $<0.0001$ \\
\hline F VIIIC $(61-176 \%)$ & 149 & 129 & 178 & 90 & $<0.0001$ \\
\hline FVII & & & & & \\
\hline Males (54-138\%) & 139 & 116 & 159 & 94 & $<0,0001$ \\
\hline Fomales (56-200\%) & 143 & 122 & 164 & 131 & $<0.1$ \\
\hline Fibrin monomers $(8.4 \mathrm{~m} 13.2 \mathrm{nmol} / \mathrm{l})$ & 13.7 & 10.8 & 17.9 & 10.5 & $<0.0001$ \\
\hline $\begin{array}{l}\text { Thrombin-antithrombin III } \\
(1.0-4.1 \mu \mathrm{g} / 1)\end{array}$ & 3.4 & 2.2 & 6.8 & 2.4 & $<0,001$ \\
\hline $\begin{array}{l}\text { Antithombin III } \\
(80-120 \%)\end{array}$ & 107 & 99 & 197 & 98 & $<0.001$ \\
\hline
\end{tabular}

Table 2

Basic coagulation parameters in 65 NIDDM patients and percentages beneath the lower and above the upper reference range limits in comparison with a healthy control group $(n=50)$. 


\begin{tabular}{|c|c|c|c|c|c|}
\hline \multirow{2}{*}{$\begin{array}{l}\text { Parameters } \\
\text { (Ref, range) }\end{array}$} & \multicolumn{4}{|c|}{ NIDOM Patients } & \multirow{2}{*}{ * Significance } \\
\hline & $\mathrm{AER}$ & $\mathrm{g} / \mathrm{min}$ & $\mathrm{AER} 20$ & $g / m n$ & \\
\hline Age years & 65 & (13) & 67 & $(13)$ & N.S. \\
\hline Known duration of diabeles (years) & 5 & $(10)$ & 4 & (6) & N.S. \\
\hline $\mathrm{AEP}(<20 \mathrm{\mu g} / \mathrm{min})$ & 5 & $(7)$ & 40 & $(37)$ & $<0,00001$ \\
\hline$H b A_{c c}(4-7 \%)$ & 8.5 & (18) & 81 & (2.4) & NS. \\
\hline Lipoprotein (a) ( $300 \mathrm{mg} /$ ) & 81 & (166) & 51 & $(71)$ & NS. \\
\hline
\end{tabular}

Table 3:

Median values (and interquartile ranges) of age, known duration of diabetes, urinary albumin excretion (AER), HbA , and lipoprotein (a) values in 65 NIDDM patients divided in normaalbuminuric and microalbuminuric subgroups

Median F VII concentrations were significantly elevated in the male diabetic patients: 139 (43) \% as compared with 94 (31) \% in the male controls ( $p<$ $0.0001)$. In the females the corresponding values were: $143(42) \%$ versus 131 (56) in the reference group $(\mathrm{p}<0.10)$. $\mathrm{HbA}_{10}$ values showed a tendency towards a correlation with lipoprotein(a) concentrations $(r=0.23, p=0.07)$, whereas antithrombin III represented the only parameter studied which correlated with $\mathrm{HbA}_{1 \mathrm{c}}(r=0.27, \mathrm{p}<0.03)$.

Triglycerides were correlated with the Quetelet-index $(r=0.27, p<0.03), H D L-$ cholesterol $(r=-0.41, p=0.001)$ and $F$ VII concentrations $(r=0.35, p<0.01)$, whereas serum cholesterol levels correlated with $F$ VII $(r=0.27, p<0.04)$ and with fibrin monomers $(r=0.29, p<0.03)$.

Of the 65 NIDDM patients $12(18.5 \%)$ showed a urinary albumin excretion rate above $20 \mu \mathrm{g}$ per minute with a median level of $40 \mu \mathrm{g}$ (range $21-124 \mu \mathrm{g}$ ) per min. The urinary albumin excretion rate was not correlated with $\mathrm{HbA}_{10}$ values or with any of the other lipid or haemostasis parameters studied. Several clinical characteristics of the microalbuminuric patients in comparison with the normalbuminuric NIDDM patient group are shown in table 3.

\section{Discussion}

With a median $\mathrm{HbA}_{1 \mathrm{c}}$ value of $8.5 \%$ and with $18.5 \%$ of the $\mathrm{HbA}_{1 \mathrm{c}}$ values above $10 \%$, this group of 65 NIDDM patients showed a moderate glycometabolic control. A median Quetelet index of $27 \mathrm{~kg} / \mathrm{m} 2$ (normal $18-27 \mathrm{~kg} / \mathrm{m} 2$ ) together with a median serum triglyceride level of $2.1 \mathrm{mmol} / \mathrm{l}$ (normal $0.8-2.0 \mathrm{mmol} / \mathrm{ll})$ and a slightly decreased median HDL-cholesterol of $1.2 \mathrm{mmol} / 1$ (normal $0.9-1.7$ ) are 
signs of a disadvantageous lipid spectrum in an overweight population and are frequently encountered in NIDDM patients. Insulin resistance is a characteristic feature of NIDDM and it gives rise to enhanced pancreatic insulin secretion (20). The resultant hyperinsulinaemia increases hepatic VLDL synthesis (21-23). In epidemiological studies the association between plasma insulin levels and triglyceride levels has also been demonstrated in healthy normal-weight subjects (24-26). In addition to hyperinsulinaemia in NIDDM patients, elevated glucose and plasma free fatty acid concentrations (especially in obese patients) provide abundant substrate for promoting VLDL synthesis in the liver (20-23), whereas a diminished VLDL clearance due to disturbed lipoprotein lipase activity has been reported to contribute to hypertriglyceridaemia in diabetes mellitus (27). In this group of NIDDM patients we did not find any correlation of $\mathrm{HbA}_{1 c}$ percentages with the lipid parameters measured (Spearman rank test, data not shown) and hereby we confirmed the weak association between these parameters in insulin and non-insulin-dependent diabetes mellitus reported by others (28-30).

Recently several studies on the association between glycaemic control and plasma lipoprotein(a) (LP(a)) concentrations in insulin-dependent diabetes mellitus (IDDM) have been published. Bruckert et al. (31) reported a fall in $L p(a)$ values (mean $\pm \mathrm{SD}$ ) from $46.1 \pm 6.3 \mathrm{mg} / \mathrm{dl}$ to $29.3 \pm 5.2 \mathrm{mg} / \mathrm{dl}$ in 10 poorly controlled IDDM patients after achieving good glycaemic control. Haffner et al. (32) investigated 12 IDDM patients before and after 21 days of tight metabolic control and found a small but significant decrease in $L p(a)$ concentrations from $29.7 \mathrm{mg} / \mathrm{dl}$ to $27.1 \mathrm{mg} / \mathrm{dl}$ whereas the other lipid parameters did not change significantly. In comparison with the findings in non-diabetic subjects, $L p(a)$ levels were significantly higher in the IDDM patients. Levitsky et al. (33) found that Lp(a) protein levels were directly correlated with the level of glycosylated haemoglobin in 36 white IDDM children ( $r=0.46, p<0.01)$, but not in 16 black IDDM children. Lp(a) protein levels in IDDM and healthy black children were significantly higher than those in diabetic and healthy white children. Kapelrud et al. (34) demonstrated a correlation between $\mathrm{HbA}_{116}$ values and $\mathrm{Lp}(\mathrm{a})$ concentrations in 35 normoalbuminuric IDDM patients $(r=0.50, p=<0.001)$, but not in 41 IDDM patients with microalbuminuria $(r=0.20, p=0.11)$. In our group of 65 NIDDM patients we found a tendency towards a correlation between $\mathrm{HbA}_{\text {tc }}$ levels and $L p(a)$ concentrations $(r=0.23, p=0.07)$. $L p(a)$ values in the subgroup of patients with $\mathrm{HbA}_{10}$ levels above $10 \%$ did not differ significantly from those with $\mathrm{HbA}_{10}$ percentages below $10 \%$ (data not shown). To our knowledge, studies on the correlation of LP(a) concentrations with glycaemic control in NIDDM patients have not been published previously.

Investigating the relationship between the presence of microalbuminuria (an urinary albumin excretion rate between 20 and $200 \mu \mathrm{g}$ per min) and $L p(a)$ concentrations, Kapelrud et al. (34) found median serum concentrations of $L p(a)$ to be twice as high in IDDM patients with microalbuminuria as those in normoalbuminuric IDDM patients. In 107 IDDM patients Jenkins et al. (35) reported normal apo(a) levels in normoalbuminuric patients but noted grossly elevated apo(a) values, simillar to the values found in patients with proven 
coronary artery disease, in the IDDM patients who had albuminuria or microalbuminuria. In our NIDDM patient group we did not find a correlation between microalbuminuria and $L p(a)$ values $(r=-0.11, p=0.40)$. The median $L p(a)$ concentration (interquartile range) in the microalbuminuric group (12 patients) was $51(71) \mathrm{mg} / \mathrm{l}$ (range $1-764 \mathrm{mg} / \mathrm{l}$ ) versus $86(166) \mathrm{mg} / \mathrm{l}$ (range 1 -854 $\mathrm{mg} / \mathrm{l}$ ) in the normoalbuminuric group (53 patients). These results were not significantly different. In both subgroups $L p(a)$ was not correlated with $\mathrm{HbA}_{1 \mathrm{c}}$ values or microalbuminuria, nor did the other lipid and coagulation parameters measured differ significantly between the normoalbuminuric and microalbuminuric patients. These data are in line with the results obtained in 35 NIDDM patients by Schmitz et al. (36), who found no significant differences between normoalbuminuric and microalbuminuric NIDDM patients with respect to factor VIII, von Willebrand factor and fibrinogen concentrations.

With the exception of F VII in the female patients $(p<0.10)$ all the other coagulation parameters measured were significantly elevated in the NIDDM patient group. The median fibrinogen concentration was almost doubled in comparison with the reference group whereas two thirds of the patient group showed values above the normal reference range. Fibrinogen has emerged as a strong independent risk factor for cardiovascular disease in spite of its positive correlation with the other risk factors: age, hypertension, hyperlipidaemia, diabetes mellitus, body mass index, smoking and lack of physical activity ( 37 , review). Substantiaily elevated plasma fibrin monomers and TATIII concentrations, confirm the presence of an activated coagulation system in this group of NIDDM patients.

In diabetes mellitus predominantly normal ATIII values (38-40) have been found, although elevated $(40,41)$ or decreased $(42)$ ATIII concentrations have also been demonstrated. ATIII activity has been variously assessed as decreased $(38,43,44)$ or normal $(39)$. The correlation between $\mathrm{HbA}_{1 \mathrm{c}}$ and ATIII activity has been reported as positive (42), or negative (43-45), or no correlation at all could be found (39).

Induced hyperglycaemia in diabetic and normal subjects appeared to decrease ATIII activity at stable ATIII concentrations $(43,44)$, whereas insulin-induced euglycaemia restored ATIII activity (44). In our NIDDM patient group we found elevated median ATIII values: $107(18) \%$ in comparison with the reference group: $98(8) \%(p<0.001)$. A positive correlation between ATIll concentrations and $\mathrm{HbA}_{1 \mathrm{c}}$ values $(r=0.27, \mathrm{p}<0.03)$ was found, thus confirming the results of Grignani et al. (42) which were also obtained in NIDDM patients.

The correlations found between $F$ VII and triglycerides $(r=0.35, p<0.01)$ and cholesterol concentrations $(r=0.27, p<0.04)$ have also been reported in nondiabetic subjects in epidemiological $(10,46)$ and other human studies $(18,19,47,48)$. Furthermore, serum cholesterol concentrations were found to correlate well with fibrin monomers $(r=0.29, p<0.04)$ which also suggests an association between activation of the coagulation system and hyperlipidaemia in these patients.

In conclusion, in this group of 65 NIDDM patients with moderate glycometabolic control we found a disadvantageous lipid spectrum expressed by an elevated 
Quetelet-index, elevated triglycerides and decreased HDL-cholesterol, together with and partly correlated with signs of an activated coagulation system (fibrinogen, $F$ VIIIC, F VII, fibrin monomers, antithrombin Ill, thrombinantithrombin III complex). Glycaemic controll $\left(\mathrm{HbA}_{\text {tc }}\right)$ was not correlated with the urinary albumin excretion rate or with any of the lipid or coagulation parameters measured (except for ATIII). Thus, glycometabolic control appeared to have no substantial influence on the extent of activation of the coagulation system nor on the presence or magnitude of microalbuminuria in these NIDDM patients. The influence of glycometabolic control on $L p(a)$ concentrations remains unclear. The results of this study may provide clues to the pathophysiological mechanisms of the cardiovascular risk factors NIDDM and hyperlipidaemia, and give circumstantial support for more stringent control measures in the treatment of hyperlipidaemia in patients with diabetes mellitus (49).

\section{References}

1. Brownlee $M$, Cerami A, Vlassara $H$.

Advanced glycosylation end products in tissue and the biochemical basis of diabetic complications.

N Engl J Med 1988; 318: 1315-21.

2. Tschoepe D, Ostermann $H$, Huebinger A, Ziegler D, Wiefels $K$, Gries FA.

Elevated platelet activation in type I diabetics with chronic complications under long-term near-normoglycemic control.

Haemostasis 1990; 20: 93-8.

3. Ostermann $\mathrm{H}$, van de Loo J.

Factors of the hemostatic system in diabetic patients. A survey of controlled studies. Haemostasis 1986; 16: 386-416.

4. Geiger $\mathrm{M}_{\text {s }}$ Binder $\mathrm{BA}$.

Plasminogen activation in diabetes melitus. Kinetic analysis of plasmin formation using components isolated from the plasma of diabetic donors.

J Biol Chem 1984; 259: 2976-81.

5. Geiger M, Binder BR.

Non-enzymatic glycosylation as a contributing factor to defective fibrinolysis in diabetes mellitus.

Heemostasis 1986; 16: $439-46$.

6. Small M, Kluft C, MacCuish AC, Lowe GD.

Tissue plasminogen activator inhibition in diabetes mellitus.

Diabetes Care 1989; 12: 655-8.

7. Mirshahi M, Soria J, Soria C. Bertrand O, Mirshahi M, Basdevant A.

Glycosylation of human fibrinogen and fibrin in vitro. Its consequences on the properties of fibrin(ogen).

Thromb Res 1987; 48: $279-89$. 
8. Lütjens A, Jonkhoff-Slok TW, Sandkuijl C. vd Veen EA, vd Meer J.

Polymerisation and crosslinking of fibrin monomers in diabetes mellitus.

Diabetologia 1988; 31: 825-30.

9. Chakrabarti R, Hocking ED, Feamley GR, Mann RD, Attwell TN, Jackson D.

Fibrinolytic activity and coronary artery disease.

Lancet 1968; i: 987-90.

10. Meade TW, North WR, Chakrabarti R, Stirling $Y$, Haines AP, Thompson SG,Brozovic M. Haemostatic function and cardiovascular death: early results of a prospective study. Lancet $1980^{;}$i: 1050-4.

11. Dalaker K, Hjermann I, Prydz H.

A novel form of factor VII in plasma from men at risk for cardiovascular disease.

Br J Haematol 1985; 61: 315-22.

12. Hamsten $A$, Wiman $B$, de Faire $U_{v}$ Blombäck $M$.

Increased plasma levels of a rapid inhibitor of tissue plasminogen activator in young survivors of myocardial infarction.

N Engl J Med 1985; 313: 1557-63.

13. Trip MD, Cats VM, van Capelle FJ, Vreeken J.

Platelet hyperreactivity and prognosis in survivors of myocardial infarction.

N Engl J Med 1990; 322: 1549-54.

14. Pyorala K, Laakso M, Uusitupa M.

Diabetes and atherosclerosis: an epidemiologic view.

Diabetes Metab Rev 1987; 3: 463-524.

15. Fontbonne A, Eschwege E, Cambien F, Fichard JL, Ducimetiere P, Thibult N, Warnet JM, Claude JR, Rosselin GE.

Hypertriglyceridaemia as a risk factor of coronary heart disease mortality in subjects with impaired glucose tolerance or diabetes.

Diabetologia 1989; 32: 300-4.

16. Rosengren $A$, Welin $L, T$ sipogianni $A$, Wilhelmsen $L$.

Impact of cardiovascular risk factors on coronary heart disease and mortality among middle aged diabetic men: a general population study.

Br Med J 1989; 299: 1127-31.

17. Simpson HC, Mann Jl, Meade TW, Chakrabarti $\mathbb{R}$, Stiring $Y$, Woolf $L$. Hypertriglyceridaemia and hypercoagulability.

Lancet $1983 ;$ i: $786-90$.

18. Constantino M, Merskey L, Kudzma DJ Zucker MB.

Increased activity of vitamin K-dependent clotting factors in human hyperlipo-

proteinaemia-association with cholesterol and triglyceride levels.

Thromb Haemost 1977; 38: 465-74.

19. Krone W, Nägele $H$.

Effects of antihypertensives on plasma lipids and lipoprotein metabolism.

Am Heart J 1988; 116: 1729-34.

20. Defronzo RA.

Lilly Lecture 1987. The triumvirate: $\beta$ cell, muscle, liver. A collusion responsible for NIDDM.

Diabetes 1988; $37: 667-87$.

21. Reaven GM.

Banting lecture 1988. Role of insulin resistance in human disease

Diabetes 1988; 37: 1595-607. 
22. Reaven GM.

Non-insulin-dependent diabetes mellitus, abnormal lipoprotein metabolism, and atherosclerosis.

Metabolism 1987; 36 (2 suppl. 1): 1-8.

23. Kissebah AH, Adams PW, Wynn V.

Interrelationship between insulin secretion and plasma free fatty acid and triglyceride transport kinetics in maturity onset diabetes and the effect of phenethylbiguanide (Phenformin).

Diabetología 1974; 10: 119-30.

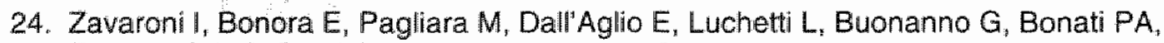
Bergonzani M, Ginudi L, Passeri M, Reaven $G$.

Risk factors for coronary artery disease in healthy persons with hyperinsulinemia and normal glucose tolerance.

N Engl J Med 1989; 320: 702-6.

25. Orchard TJ, Becker Dل, Bates M, Kuller LH, Drash AL.

Plasma insulin and lipoprotein concentrations: an atherogenic association?

Am J Epidemioll 1983; 118: 326-37.

26. Haffner $S M_{i}$ Fong $D$, Hazuda HP, Pugh لA, Patterson JK.

Hyperinsulinemia, upper body adiposity, and cardiovascular risk factors in non-diabetics.

Metabolism 1988; 37: 338-45.

27. Brunzell JD, Porte Dur, Bierman EL.

Abnormal lipoprotein lipase mediated plasma triglyceride removal in untreated diabetes mellitus associated with hypertriglyceridemia.

Metabolism 1979; 28: 901-7.

28. Dornan TL, Carter RD, Bron AJ, Turner RC, Mann Jl.

Law density lipoprotein cholesterol: an association with the severity of diabetic retinopathy.

Diabetologia 1982; $22: 167-70$.

29. Paterson JR, Pettigrew AR, Dominiczak $M H_{3}$, Small $M$.

Screening for hyperlipidaemia in diabetes mellitus. Relationship to glycaemic control.

Ann Clin Biochem 1991; 28: 354-8.

30. Ikeda $T$, Ochi $H$, Ohtani I, Fuilyama $K$, Hoshino $T$, Tanaka $Y$, Takeuchi $T$, MashibaH. Serum lipid and apolipoprotein levels in non-hypertensive lean NIDDM patients.

J Intern Med 1991; 230: 131-4.

31. Bruckert $E$, Davidoff $P$, Grimaldi $A$, Truffert J, Giral $P$, Doumith $R$, Thervet $F$, De Gennes JL. Increased serum levels of lipoprotein(a) in diabetes mellitus and their reduction with glycemic control.

J Am Med Assn 1990; 263: 35-6.

32. Haffiner $S M$, Tuttle KA, Rainwater DL.

Decrease of lipoprotein(a) with improved glycemic control in IDDM subjects.

Diabetes Care 1991; 14: 302-7.

33. Levitsky LL, Scanu AM, Gould SH.

Lipoprotein(a) levels in black and white children and adolescents with IDDM.

Diabetes Care 1991; 14: 283-7.

34. Kapelrud $H_{1}$ Bangstad $H-J$, Dahl-JØrgensen K, Berg K, Hanssen KF.

Serum $L p(a)$ lipoprotein concentrations in insulin dependent diabetic patients with microalbuminuria.

Br Med J 1991; 303: 675-8. 
35. Jenkins Ad, Steele JS, Janus ED, Best JD.

Increased plasma apolipoprotein(a) leveis in IDDM patients with microalbuminuria.

Diabetes 1991: 40: 787-90.

36. Schmitz $A_{1}$ Ingerslev J.

Haemostatic measures in type 2 diabetic patients with microalbuminuria.

Diabetic Med 1990; 7:521-5.

37. Emst E.

Plasma fibrinogen, an independent cardiovascullar risk factor.

$J$ Intern Med 1990; 227: 365-72.

38. Ceriello A, Dello Russo P, Zucotti C. Florio A, Nazarro S, Pietrantuono C, Rosato GB.

Decreased antithrombin III activity in diabetes may be due to non-enzymatic glycosylation.

Thromb Haemost $1981 ; 46 ; 648-51$.

39. Christe M, Fritschi J, Lämmle B, Tran TH, Marbet GA, Berger W, Duckert F.

Fifteen coagulation and fibrinolysis parameters in diabetes melitus and in patients with vascullopathy.

Thromb Haemost $1984 ; 52: 138-43$.

40. Marongiu F, Conti M, Mameli G, Sorano GG, Cossu E, Cirillo R, Balestrieri A. Is the imbalance between thrombin and plasmin activity in diabeles related to the behaviour of antiplasmin activity?

Thromb Res 1990; 58: 91-9.

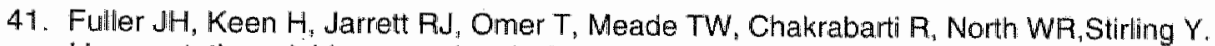
Haemostatic variables associated with diabetes and its complications.

Br Med J 1979; 2: 964-6.

42. Grignani $G$, Gamba G, Geroldi D, Pacchiarini L, Solerte B, Ferrari E, Ascari E.

Enhanced antithrombotic mechanisms in patients with maturity onset diabetes mellitus withou thromboembolic complications.

Thromb Haemost 1981; 46: 648-51.

43. Ceriello A, Giugliano D, Quatraro A, Stante A, Dello Russo P, Torella R.

Increased alpha 2-macroglobulin in diabetes: a hyperglycemia relatted phenomenon associated with reduced antithrombin III activity.

Acta Diabetol Lat 1989; 26: 147-54.

44. Ceriello A, Giugliano D, Quatraro A, Marchi E, Barbanti Mi, Lefebure P.

Evidence for a hyperglycaemia-dependent decrease of antithrombin III thrombin complex formation in humans.

Diabetologia 1990; 33 : 163-7.

45. Sowers JR, Tuck ML, Sowers DK.

Plasma antithrombin III and thrombin generation time: correlation with hemoglobin $A 1$ and fasting serum glucose in young diabetic women.

Diabetes Care 1980; 3: 655-8.

46. Meade TW, Mellows S, Brozovic M Miller GJ, Chakrabarti RF, North WR, HainesAP, Stirling $Y$, Imeson JD, Thompson SG.

Haemostatic function and ischaemic heart disease: principal results of the Northwick Park Heart Study.

Lancet 1986; ii: 533-7.

47. Carvalho de Sousa J, Bruckert E, Giral P, Soria C, Chapman J, Truffert J, Dairou F, De Gennes JL, Caen JP.

Coagulation factor VIl and plasma triglycerides. Decreased catabolism as a possible mechanism of factor VI! hyperactivity

Haemostasis 1989; 19: 125-30. 
48. NordOy $A_{\text {s }}$ llingworth DP, Connor WE Goodnight $S$ Jr. Increased activity of factor VII and factor VII-phospholipid complex measured using a Normotest system in subjects with hyperlipidemia.

Haemostasis 1990; 20: 65-72.

49. American Diabetes Association.

Role of cardiovascular risk factors in prevention and treatment of macrovascular disease in diabetes.

Diabetes Care $1989 ; 12: 573-9$. 


\section{Chapter 7}

\section{Microalbuminuria in insulin-regulated diabetic patients: relationship to lipid, glycometabolic, coagulation and fibrinolysis parameters}

J.W.J. van Wersch, S.H.J. Donders, L.W.J.J.M. Westerhuis, W.J.R.R.Venekamp Eur J Clin Chem Clin Biochem 1991;29:493-498 


\section{Summary}

One hundred and sixteen insulin-treated diabetic patients were evaluated for the relationship between the presence of microalbuminuria and several lipid, glycometabolic, coagulation and fibrinolysis factors. There were significant correlations only between microalbuminuria and $\mathrm{HbA}_{1 c}(r=0.23, p=0.008)$ or $D$ dimer $(r=0.28, p=0.002)$ levels. After the subdivision of the patients into a normoalbuminuric group $(n=85)$ and a group with microalbuminuria $(n=31)$, significant differences were found between these two groups with regard to the HDL- cholesterol $(p<0.05)$ and $\mathrm{HbA}_{1 c}$ levels $(p<0.01)$ as well as for D-dimer concentrations $(p<0.01$ ). Comparison of the patient groups without and with microalbuminuria separately with a group of healthy volunteers with normoalbuminuria resulted in significant differences for HDL-cholesterol, triglycerides, $\mathrm{HbA}_{1 \mathrm{c}}$, fructosamine, fibrin monomer and $\mathrm{D}$-dimer, whereas fibrinogen also was significantly different between the normoalbuminuric diabetic group and the healthy volunteer group. Several factors predisposing to atherosclerosis (decrease of HDL-cholesterol, increase of triglycerides, coagulation activation with relatively insufficient fibrinolysis) were noticed in the two diabetic groups without or with micro-albuminuria, but were more pronounced in the latter group. The application of a Receiver Operating Characteristic (ROC) curve for $\mathrm{HbA}_{10}$ against microalbuminuria (cut-off level 20 $\mu \mathrm{g} / \mathrm{min}$ ) reconfirmed the association between adequate glycaemic control in diabetics and the absence of microalbuminuria.

In summary, the results of this study showed a significantly poorer glycaemic control in insulin-treated diabetics with microalbuminuria than in those with normoalbuminuria. The presence of lower HDL-cholesterol and the elevation of D-dimers was more pronounced in the microalbuminuria group. No direct correlation could, however, be found between the coagulation and fibrinolysis factors and the extent of microalbuminuria in the diabetic patient groups.

\section{Introduction}

The occurrence of microalbuminuria is accepted as being an early indicator of micro-angiopathy in diabetes mellitus i.e. diabetic nephropathy (1). The onset of the clinical symptoms of diabetic nephropathy can be preceeded by a silent period of variable duration during which diabetic patients show only microalbuminuria (2).

This stage can be defined as the duration of time in which the mean urinary albumin excretion rate is significantly higher $(20-200 \mu \mathrm{g} / \mathrm{min})$ than that in reference subjects (3). The clinical syndrome of diabetic nephropathy is 
characterised by persistent proteinuria (4), accompanied by increased morbidity and mortality (5-11). At the stage of clinical proteinuria and progressive renal failure, changes in plasma lipoprotein concentrations (12-14) have been thought to contribute to the increased cardiovascular risk. Recently, in a case-control study the concentrations of lipoproteins, apolipoproteins, fibrinogen and factor VII were compared in insulin-dependent diabetic patients with $(n=20)$ or without $(n=20)$ microalbuminuria under similar glycometabolic control $\left(\mathrm{HbA}_{1}\right)(15)$.

In this study we have investigated the correlations between microalbuminuria and several lipid fractions (cholesterol, HDL-cholesterol, LDL-cholesterol, triglycerides) as well as parameters for glycometabolic control ( $\mathrm{HbA}_{1 \mathrm{c}}$ and fructosamine) $(16,17)$. Furthermore, fibrinogen was measured, as were sensitive indicators of clotting activation such as fibrin monomers and the thrombinantithrombin III complex (18). In addition, the fibrinolysis variables plasminogen activator inhibitor-1 $(19,20)$ and D-Dimers, as a sensitive indicator of the onset of reactive fibrinolysis (21), were also measured.

The aim of the study was to see if, besides the urinary microalbumin excretion rates, other biochemical parameters were associated with the occurrence of diabetic microangiopathy.

\section{Materials, patients and methods}

\section{Methods}

The serum samples were analysed with a Cobas Bio centrifugal fast analyzer and commercial test kits were used according to the manufacturers' instructions for determination of serum triglycerides, total serum cholesterol, HDL-cholesterol and LDL-cholesterol as described in chapter 3.

- $\mathrm{HbA}_{1 \mathrm{c}}$ in haemolysate:

Bio Radi ion exchange column chromatography, product N¹92-8001.

- Serum fructosamine:

Hoffmann La Roche, Basle, Switzerland, product No. 0711217.

The test was performed according to the method of Johnson, Metcalf and Baker (17) on a Cobas Bio centrifugal analyser.

- Plasma D-Dimer:

for the ELISA D-dimer determinations the test kit of Boehringer Mannheim, product No 998117 was used. The measurements were carried out on the Bio Rad microtitre reader system. The reactions were performed in polystyrene microtitre plates of the Nunc Corporation.

- Plasma plasminogen:

The test kit of Kabi Vitrum COA-SET PAI activator inhibitor-1 with chromogenic substrate S-2251 was employed. 
- Plasma Thrombin-antithrombin III:

ELISA test kit Enzygnost-TAT, Behring, Hoechst, Marburg (Germany), product No OURC $10 / 11$

- Fibrinogen:

turbidimetric method of Behring, using the CTS-fibrinogen reagent on the Chromotime System (Behring).

- Fibrin monomers:

chromogenic COA-set FM test Kabi Vitrum Diagnostica.

- Urinary microalbumin:

immunoturbidimetric test of Orion Diagnostica Corporation, product No 67352.

\section{Patients}

One hundred and sixteen insulin-treated diabetic patients, consisting of 47 males (mean age 55.3 years, range 20-80) and 69 females (mean age 60.1 years, range 30-82) were included in the study. The percentage of patients with microalbuminuria (i.e. $20-200 \mu \mathrm{g}$ urinary albumin excretion per min) was $26.7 \%$. Patients with urinary albumin excretion exceeding $200 \mu \mathrm{g}$ per min were excluded from the study. The co-medication of the patients consisted mainly of oral anticoagulants or acetylsalicylic acid. Patients treated with antihypertensive drugs or corticosteroilds were excluded. The number of true type 1 subjects amounted to 62 , equally subdivided over the two albumin excretion groups. The general characteristics of the patients are given in table 1 . The diagnosis of

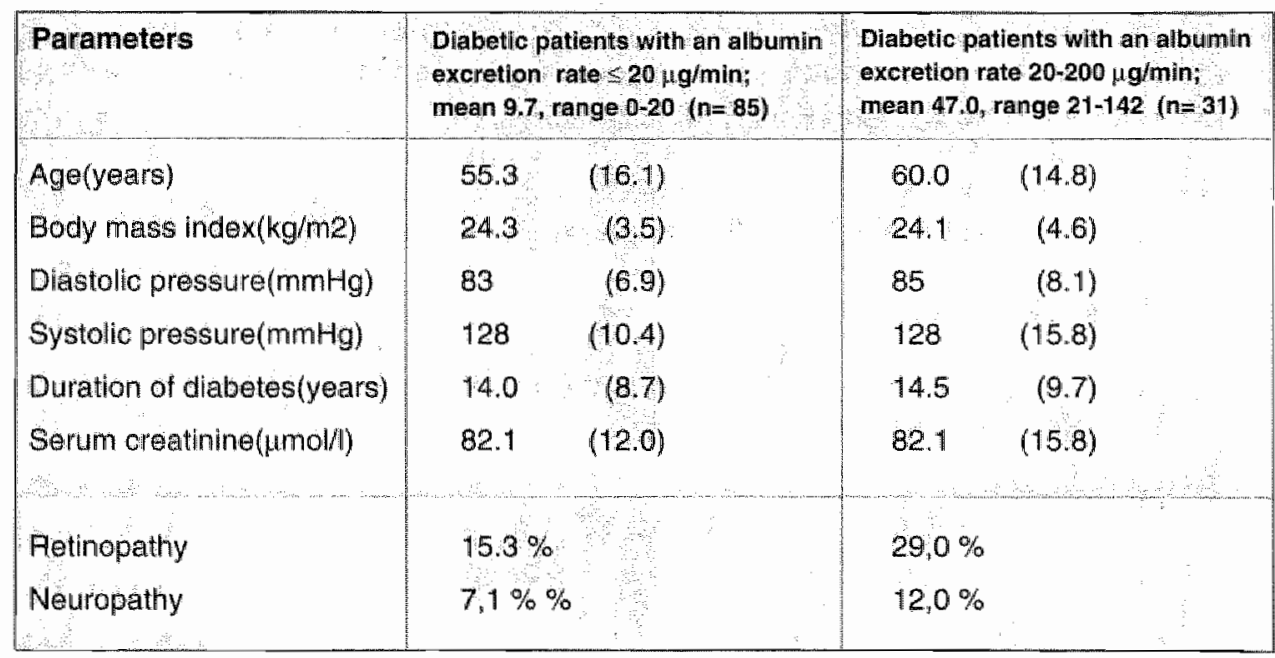

Table 1:

General characteristics of the patients according to the albumin excretion rate. Values are means (SD). The proportions of the patients with retinopathy or neuropathy are given as percentages. 
retinopathy was assessed by fundoscopy and fluorescence angiography. The neuropathy was diagnosed by measurement of the vibration sense and the presence of sensory disturbance in the extremities. The blood samples were collected when the patients attended the hospital (St. Gregorius hospital, Brunssum, The Netherlands) for their routine diabetes control in the Department of Internal Medicine. The reference values were obtained from 50 subjectively healthy individuals, ranging in age from 24 to 50 years. The reference ranges were defined as the mean values $\pm 2 \mathrm{SD}$.

\section{Samples}

Venous blood samples were collected between 8.30 and 9.00 a.m. and citrated plasma was prepared by centrifugation of nine volumes of freshly drawn blood with one volume of trisodium citrate $(0.11 \mathrm{~mol} / \mathrm{l})$ for $30 \mathrm{~min}$. at $25^{\circ} \mathrm{C}(1600 \mathrm{~g})$. The plasma was used immediately or stored at $-70^{\circ} \mathrm{C}$ in plastic tubes and thawed under tap water for $5 \mathrm{~min}$. before use. For the glycometabolic determinations, washed red cells were haemolysed and the haemolysate was used for the chromatographic separation of $\mathrm{HbA}_{1 \mathrm{c}}$. The urine samples for the urinary albumin determinations were obtained from a morning portion after overnight collection and with registration of the collection period.

\section{Statistics}

The different parameters were correlated with each other with the Spearman rank test. The significance of the differences was assessed by the MannWhitney-Wilcoxon test. The sensitivity and specificity of $\mathrm{HbA}_{1 \mathrm{c}}$ and $\mathrm{D}$-dimer were calculated according to the presence or absence of microalbuminuria as decision standard (cut-off level $20 \mu \mathrm{g} / \mathrm{min}$ ). Receiver Operating Characteristic (ROC) curves for assessing the power of the tests were constructed as described earlier (22).

\section{Results}

The Spearman rank correlation is given between urinary microalbumin concentrations and several biochemical parameters in table 2. Only for $\mathrm{HbA}_{1 \mathrm{c}}$ and D-dimer a significant correlation with microalbuminuria was found, with $r$ values of $0.232(p=0.008)$ and $0.278(p=0.002)$ respectively. In tabie 3 the diabetic patient groups without $(\leq 20 \mu \mathrm{g} / \mathrm{min})$ and with $(>20 \mu \mathrm{g} / \mathrm{min})$ microalbuminuria are compared with a healthy volunteer group without microalbuminuria. No significant differences for both diabetic groups were estimated for cholesterol, cholesterol/HDL-cholesterol ratio, LDL-cholesterol, TATIII and PAI. Additionally, no significant difference was found in the high albumin excretion rate group for fibrinogen. The other parameters showed highly 


\begin{tabular}{|l|l|l|}
\hline Microalbuminuria versus parameter & r-vallues & p-values \\
CHOL & 0.04 & 0.65 \\
CHOLHDL & 0.01 & 0.26 \\
HDLCHOL & 0.14 & 0.11 \\
LDLCHOL & 0.03 & 0.79 \\
Triglycerides & 0.13 & 0.14 \\
HbA & 0.23 & 0.008 \\
Fructosamine & 0.07 & 0.42 \\
Fibrinogen & 0.18 & 0.06 \\
Fibrin monomers & 0.13 & 0.17 \\
Thrombin-antithrombin Ill & 0.11 & 0.23 \\
Plasminogen activator inhibitor-1 & 0.05 & 0.60 \\
D-dimer & 0.28 & 0.002 \\
\hline
\end{tabular}

Table 2."

Spearman rank correlations between winary microalbumin and several biochemical parameters in diabetic patients.

\begin{tabular}{|c|c|c|c|c|c|}
\hline \multirow{4}{*}{ Variables } & \multicolumn{3}{|c|}{ Albumin excretion rate } & & \\
\hline & \multirow{2}{*}{$\begin{array}{c}\leq 20 \mathrm{\mu g} / \mathrm{min} \\
\text { Group of healthy } \\
\text { volunteers } \\
\text { Group } 1 \\
(\mathrm{~m}=50)\end{array}$} & \multirow{2}{*}{$\begin{array}{c}\leq 20 \mu \mathrm{g} / \mathrm{min} \\
\text { Diabetics } \\
\text { Group } 2 \\
(\mathrm{n}=85)\end{array}$} & \multirow{2}{*}{$\begin{array}{c}20-200 \mu \mathrm{g} / \mathrm{min} \\
\text { Diabetics } \\
\text { Group 3 } \\
(\mathrm{n}=31)\end{array}$} & \multirow{2}{*}{\multicolumn{2}{|c|}{$\begin{array}{c}\text { Significance level } \\
\mathrm{p} \text {-value }\end{array}$}} \\
\hline & & & & & \\
\hline & Mean (SD) & Mean (SD) & Mean (SD) & G2/G1 & G3/G1 \\
\hline Cholesterol(mmo:/l) & $5.8 \quad(0.9)$ & $6.2 \quad(1.5)$ & $6.0 \quad(1.4)$ & n.s. & n.s. \\
\hline CHOL/HDL-CHOL ratio & $5.3(0.9)$ & $5.2 \quad(2.0)$ & $6.0 \quad(2.7)$ & n.s. & n.s. \\
\hline HDL-CHOL (mmol/l) & $1.5(0.13)$ & $1.27(0.44)$ & $1.1 \quad(0.3)$ & $<0.001$ & $<0.0001$ \\
\hline $\mathrm{LDL}-\mathrm{CHOL}(\mathrm{mmol} / /)$ & $4.0(0.5)$ & $3.9(1.2)$ & $3.9 \quad(1.1)$ & n.s. & n.s. \\
\hline Triglycerides(mmol/l) & $1.4 \quad(0.3)$ & $2.49(2.80)$ & $2.24(1.31)$ & $<0.01$ & $<0.0001$ \\
\hline $\mathrm{HbA}_{1 \mathrm{C}}(\%)$ & $5.5(0.75)$ & $7.9(1.6)$ & $8.8 \quad(1.9)$ & $<0.0001$ & $<0.0001$ \\
\hline Fructosamine (mmol/) & $2.9(0.3)$ & $3.3(0.6)$ & $3.5 \quad(0.8)$ & $<0.0001$ & $<0.0001$ \\
\hline Fibrinogen $(g / l)$ & $3.8(0.3)$ & $3.4(0.8)$ & $3.7(1.2)$ & $<0.001$ & n.s. \\
\hline $\begin{array}{l}\text { Fibrin monomers } \\
\text { (nmol/l) }\end{array}$ & $10.8(1.2)$ & $13.9(4.0)$ & $13.7(5.2)$ & $<0.0001$ & $<0.0001$ \\
\hline $\begin{array}{l}\text { Thrombin- } \\
\text { antithrombin } \| 1(\mu \mathrm{g} /)\end{array}$ & $2.6(0.8)$ & $4.4(11.8)$ & $5.6(10.8)$ & n.s. & n.s. \\
\hline $\begin{array}{c}\text { Plasminogen activator } \\
\text { inhibitor-1(AU/m) }\end{array}$ & $12.7(6.3)$ & $14.8(11.1)$ & $18.3(11.4)$ & n.s. & nis. \\
\hline D.dimer $(\mu g /)$ & $238(100)$ & $412(356)$ & $567(468)$ & $<0.0001$ & $<0.0001$ \\
\hline
\end{tabular}

Table 3.

Comparison of the healthy volunteers (group 1) with the two diabetic groups with (group 3) or without (group 2) microalbuminuria (Mann-Whitney-Wilcoxon test). 


\begin{tabular}{|c|c|c|c|c|}
\hline \multirow[t]{2}{*}{ Dlabetics } & \multicolumn{3}{|c|}{ Albumin excretion rate } & \multirow[b]{3}{*}{$\begin{array}{c}\text { Significance level } \\
\text { p-value }\end{array}$} \\
\hline & \multicolumn{2}{|c|}{$\leq 20 \mu \mathrm{g} / \mathrm{min}$} & $20-200 \mu \mathrm{g} / \mathrm{min}$ & \\
\hline Variables & Mean & $\begin{array}{l}2 \\
(S D)\end{array}$ & $\begin{array}{l}\text { Group } 3 \\
\text { Mean } \\
(\mathrm{SD})\end{array}$ & \\
\hline Cholesterol(mmolm) & 6.2 & $(1.5)$ & $6.0 \quad(1.4)$ & n,s. \\
\hline CHOL/HDL-CHOLratio & 5.2 & $(2.0)$ & $60,(2,7)$ & n.s. \\
\hline HDL-CHOL (mmoll) & 127 & $(0.44)$ & $1.1(0.3)$ & $<0.05$ \\
\hline LDL-CHOL (mmol/) & 39 & $(12)$ & $3.9(1,1)$ & ns: \\
\hline Triglycerides(mmoll) & 2,49 & $(2.00)$ & $2.24(1.31)$ & n.s, \\
\hline $\mathrm{HbA}_{\mathrm{TC}}(\%)$ & 79 & $(16)$ & $88(19)$ & $<0.01$ \\
\hline Fructosamine(mmol/) & 3.3 & $(0.6)$ & $(0,8)$ & nss \\
\hline Fibrinogen $(g /)$ & 3.4 & $(0.8)$ & $37(1,2)$ & ,.$s$. \\
\hline $\begin{array}{c}\text { Fibrin monomers } \\
\text { (nmol/l) }\end{array}$ & 13.9 & $(4,0)$ & $137(62)$ & ns \\
\hline $\begin{array}{l}\text { Thrombin- } \\
\text { antithrombin }(\mathrm{l}(\mu \mathrm{g} / \mathrm{l})\end{array}$ & 4.4 & $(118)$ & $56(10,8)$ & 10.s, \\
\hline $\begin{array}{l}\text { Plasminogen activator } \\
\text { Inhibitor } 1 \text { (AU/m) }\end{array}$ & 14.8 & $(111)$ & $18.3(11.4)$ & n.s. \\
\hline D-dimein (1)g/) & 412 & $(356)$ & $567(468)$ & 80.01 \\
\hline
\end{tabular}

Table 4:

Mutual comparison of the diabetic groups without (group 2) or with (group 3) microalbuminuria (Mann-Whitney-Wilcoxon test).

significant differences between the two patient groups and the volunteer group. Mutual comparison of the two patient groups as given in table 4 showed a significant decrease for HDL-cholesterol $(p<0.05)$, and significant increases for $\mathrm{HbA}_{1 \mathrm{c}}(\mathrm{p}<0.01)$ and $\mathrm{D}$-dimer $(\mathrm{p}<0.01)$ values. For a proper judgement of the power of the $\mathrm{HbA}_{10}$ in relation to the microalbuminuria, a ROC-curve (fig 1) has been calculated at different cut-off levels of the test against microalbuminuria as the reference parameter at the cult-off decision level $20 \mu \mathrm{g} / \mathrm{min}$. For the $\mathrm{HbA}_{\text {ic }}$ range from $6 \%$ to $12 \%$ the sensitivity ranged from $38 \%$ to $100 \%$, the specificity from $85 \%$ to $65 \%$. 


\section{Discussion}

The general characteristics of the diabetic population studied as shown in table 1 contain some data which need further clarification. The reported mean values for blood pressure and urinary albumin excretion in patients with a mean duration of diabetes mellitus of 14 years indicate, as mentioned in the patients section, that patients with hypertension and "macroalbuminuria" (an urinary albumin excretion rate exceeding $200 \mu \mathrm{g}$ per min) were excluded from the study. Possibly this is why no differences were found in mean systolic and diastolic blood pressure between the diabetic patients with and those without microalbuminuria. The correlation between microalbuminuria and several biochemical parameters was shown to be only significant for $\mathrm{HbA}_{1 \mathrm{c}}$ and $\mathrm{D}$-dimer (table 2). These results suggest an increased prevalence of microalbuminuria associated with poorer glycaemic control and augmented reactive fibrinolysis (probably after preceding coagulation activation).

Recently we have described an increase of coagulation activation in poor glycometabolic control states (23) and a relative failure of the reactive fibrinolysis to keep up with the rise in coagulation activity (24) in a large population of insulin-regulated diabetic patients. From this point of view the D-dimer level indirectly might be an indicator of long term sequelae of diabetes mellitus such as microalbuminuria. Comparison of the insulin-regulated diabetics with or without microalbuminuria with a group of healthy individuals showed significant alterations in some lipid parameters (HDL-cholesteral, triglycerides) and in some coagulation and fibrinolysis parameters (FM, D-dimer). Several factors might be responsible for the differences between the three groups, but most probable is the influence of the level of glycaemic control. In young insulin-dependent diabetics the glycometabolic control state has been shown to influence the lipoprotein serum concentrations $(25-27)$ as well as the prevalence of microalbuminuria, whereas in diabetics with microalbuminuria and with poor gllycaemic control changes in the lipid fractions have been described (13). Recently the triglycerides have been described as enhancing the activation of coagulation factor VII (28), leading to thrombin formation and hence to fibrin monomer formation and reactive fibrinolysis (D-dimers). Because serum triglycerides correlate with plasminogen activator inhibitor, fibrinolysis might be impaired on behalf of the elevated triglyceride levels (29). Moreover increased serum triglycerides as well as elevated plasminogen activator inhibitor- 1 levels have been observed to be strongly related to an enhanced risk of ischaemic heart disease (30-34). The two diabetic groups of this study show relevant differences with the reference group for those parameters which are known to be correlated with an enhanced risk of cardiovascular disease. In the mutual comparison of the two diabetic patient groups with and without microalbuminuria (table 4) the HDL-cholesterol concentration, a known risk factor for cardiovascular disease, was significantly decreased in the microalbuminuria group. Moreover there appeared to be an enhanced clotting activation (fibrin monomers) with reactive fibrinolysis (D-dimer) in both diabetic groups, whereas 
the $\mathrm{HbA}_{10}$ was higher in the microalbuminuria group, ndicating a poorer glycaemic control. The relative decrease of the fibrinolysis level with increasing $\mathrm{HbA}_{10}$ as we reported earlier (24), however, might show insufficient reactive fibrinolysis for the extent of the signalized coagulation activation. For the testing of the power of $\mathrm{HbA}_{1 \mathrm{c}}$ analyte as a parameter predictive for microalbuminuria we constructed a ROC curve for $\mathrm{HbA}_{1 c}$ at different cut-off levels. With the aid of the ROC curve we could demonstrate that at a cut-off level of $12 \% \mathrm{HbA}_{10}$ a sensitivity for the prediction of microalbuminuria (> $20 \mu \mathrm{g} / \mathrm{min})$ of $100 \%$ could be achieved. Moreover it has to be noted that there is a jump in the sensitivity between $11 \%$ or $12 \% \mathrm{HbA}_{1 \mathrm{c}}$ from 66.7 to $100 \%$, which might be another indication for an aim of glycaemic control at least under the value of $11 \% \mathrm{HbA}_{1 \mathrm{c}}$. Nevertheless it seems worthwhile from the course of the ROC curve to strive for a normoglycaemia, because in that range a decrease of the sensitivity is achievable from $66.7 \%$ (at a $\mathrm{HbA}_{1 \mathrm{c}}$ level of $11 \%$ ) to $37.8 \%$ (at a $\mathrm{HbA}_{1 \mathrm{c}}$ level at $6 \%$ ). This finding is in agreement with the results reported by Klein et al. (35), who were able to demonstrate a strong and consistent relation between hyperglycaemia and the incidence and progression of retinopathy. They emphasized the importance of normoglycaemia in diabetics.

In summary, the results of this study show a significantly poorer glycaemic control in insulin-treated diabetics with microalbuminuria than in those with normoalbuminuria. Several abnormalities are significantly more obvious in the microalbuminuria group than in the normoalbuminuria group. In both subgroups

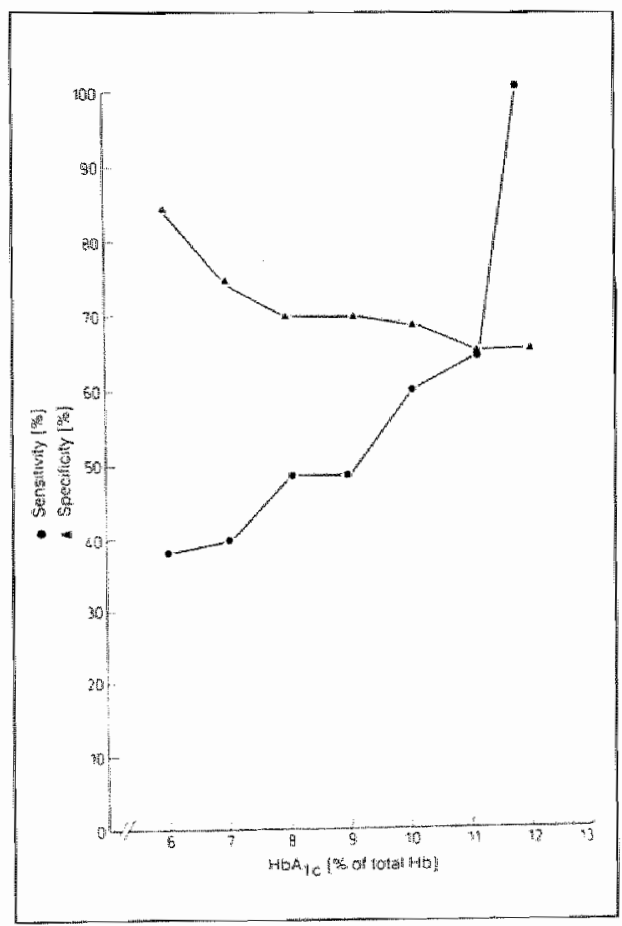

fig. 1 Sensitivity $(\cdot)$ and specificity $(\Delta)$ at different $\mathrm{Hb} \mathrm{A}_{1 \mathrm{C}}$ decision levels (reference cut-off parameter: urinary microalbumin $20 \mu \mathrm{g} / \mathrm{min}$ ) 
lower HDL-cholesterol values and higher triglyceride levels are present, which are prerequisites for the development of atherosclerosis. From the coagulation and fibrinolysis parameters the elevations of fibrin monomer and D-dimer concentrations should be noticed, because they point in the direction of coagulation activation with possibly relatively insufficient reactive fibrinolysis in poor glycaemic control, which might be risk factors for coronary heart disease as well. However, no direct correlation was seen between coagulation and fibrinolysis and the urinary albumin excretion rate in these insulin-regulated diabetic patient groups.

\section{References}

1. Viberti $\mathrm{GC}_{1}$ Jarret $R$ J, Mahmud $\mathrm{U}_{1}$ Hill RD, Argyropoulus $\mathrm{A}_{\text {, Keen }} \mathrm{H}$. Microalbuminuria as a predictor of clinical nephropathy in insulin dependent diabetes mellitus.

Lancet 1982; i: 1430-2.

2. Feldt-Rasmussen B, Mathiesen ER.

Variability of urinary albumin excretion in incipient diabetic nephropathy.

Diabetic nephropathy 1984; 3 : 101-3.

3. Mogensen CE, Christensen CK, Vitinghus $E$

The stages in diabetic renal disease with emphasis on the stage of incipient diabetic nephropathy.

Diabetes 1983; 32 (suppl.2): 64-78.

4. Borch-Johnsen $K_{\text {, Kreiner } S \text {. }}$

Proteinuria: value as predictor of cardiovascular mortality in insulin dependent diabetes. mellittus.

Br Med J 1987; 294: "651-1654.

5. Mc Crary RF, Pitts TO, Puschett JB.

Diabetic nephropathy. Natural course, survivorship and therapy.

Am J Nephrol 1981; 1: 206-18.

6. Andersen AR, Christiansen JS, Andersen JK, Kreiner S. Deckert T.

Diabetic nephropathy in type 1 (insulim-dependent) diabetes: an epidemiological study.

Diabetologia $1983: 2: 496-501$

7. Borch-Johnson K, Andersen PK, Deckert $T$.

The effect of proteinuria on relative mortality in type 1 (insulin-dependent) diabetes mellitus.

Diabetologia $1985 ; 28: 590-6$.

8. Krolewski AS, Kosinski EJ, Warram JH, Leland OS, Busick EJ, Asmal AC, Rand LI, Christlieb AR, Bradley RF, Kahn CR.

Magnitude and determinants of coronary artery disease in juvenile-onset, insulindependent diabetes mellitus.

Am J Cardiol 1987:59:750-5.

9. Mogensen CE.

Microalbuminuria predicts clinical proteinuria and early mortality in maturity onset diabetes.

N Engl J Med 1984; 6 : 356-60. 
10. Jarrett $\mathrm{RJ}$, Viberti $\mathrm{GC}$. Argyropoulus $\mathrm{A}$, Hill RD, Mahmud U, Murrells TJ. Microalbuminuria predicts mortality in non-insulin dependent diabetes.

Diabetic Med 1984; 1: 17-9.

11. Matlock MB, Keen H, Viberti GC, El Gohart MR, Murrells TJ, Scott GS, Wing JA, Jackson PG. Coronary heart disease and urinary albumin excretion rate in type II (non-insulin-dependent) diabetic patients.

Diabetologia $1988 ; 31: 82-7$.

12. Winocour $P H$, Durrington $P N$, Ishola $M$, Anderson $D C$, Cohen $H$.

Influence of proteinuria on vascular disease, blood pressure and lipoproteins in insulin dependent diabetes mellitus.

Br Med J 1987; 294: 1648-51.

13. Jensen $T$, Stender $S_{\text {, Deckert } T \text {. }}$.

Abnormalities in plasma concentrations of lipoproteins and fibrinogen in type I (insulindependent) diabetic patients with increased urinary albumin excretion.

Diabetologia $1988 ; 31: 142-5$.

14. Vannini $P$, Ciavarella A, Flammini M, Bargossi AM, Forlani $G$, Borgnino LC, Orsino $G$. Lipid abnormalities in insulin dependent diabetic patients with albuminuria.

Diabetes Care 1984; $7: 151-4$.

15. Jones SL, Close CF, Matlock MB, Jarrett $R J$, Keen $H$, Viberti GC.

Plasma lipid and coagulation factor concentrations in insulin dependent diabetics with microalbuminuria.

Br Med J 1989; 298: 487-90.

16. Miedema K, Casparie T.

Glycosylated haemoglobins: biochemical evaluation and clinical utility (review).

Ann Clin Biochem 1984; $21: 2-15$.

17. Johnson RN, Metcalf PA, Baker JR.

Fructosamine: a new approach to the estimation of serum glycosylation. An index of diabetic control.

Clin Chim Acta 1982; 127: 87-95.

18. Pelzer $\mathrm{H}_{3}$ Egbring $\mathbb{R}$, Seitz $R$, Blanke $H_{1}$ Heimburger $N$.

Thrombin-antithrombin III complex: a new parameter for detection of thrombotic states.

Thromb Haemost 1987; 58 (suppl): 237.

19. Hamsten A, Waldins $G$, Szamosi A, Blombäck M, De Faire U, Dahlen G, Landon C, Wiman $B$. Plasminogen activator inhibitor in plasma: risk factor for recurrent myocardial infarction. Lancell 1987 ; ii: $3-9$.

20. Wiman $B$, Liundberg B, Chmielewska $J$, Urden $G$, Blombäck M. Johnson $H$. The role of the fibrinolytic system in deep vein thrombosis.

J Lab Clin Med 1985; 105: 265-70.

21. Hunt FA, Rylatt DB, Hart AA, Bundesen $P G$.

Serum crosslinked fibrin (XDP) and fibrinogen/fibrin degradation products (FDP) in disorders associated with activation of the coagulation or fibrinolytic systems.

Br J Haem 1985; 60: 715-22.

22. Bick JR, Schultz EK.

The use of relative operating characteristic (ROC) curves in the performance evaluation. Arch Pathol Lab Med 1986; 110: 13-20.

23. van Wersch JWJ, Westerhuis LWJJM, Venekamp WJPR.

On coagulation activation in diabetes mellitus.

Haemostasis $1990 ; 20 ; 263-9$. 
24. van Wersch JWJ, Westerhuis LWJJM, Venekamp WJRR.

Glycometabolic control and tibrinolysis in diabetic patients.

Haemostasis $1990 ; 20: 241-50$.

25. Pietri $A_{1}$ Dunn $F$ L, Raskin $P$.

The effect of improved diabetic controt on plasma lipid and lipoprotein levels. A comparison of conventional therapy and continuous subcutaneous insulin imfusion.

Diabetes 1980; 29: 1001-5.

26. Tamborlane WV, Sherwin RS, Gienel $M$, Felig P.

Restoration of nomal lipid and aminoacid metabolism in diabetic patients trealed with a portable insulin-infusion pump.

Lancet 1979; i: 1258-61.

27. Lopes-Virella MF. Wohltmann HJ, Loadholt CB, Buse MG.

Plasma lipids and lipoproteins in young insulin-dependent diabetic patients: relationship with control.

Diabetologia 1981; 21: 216-23.

28. Nord Øy $A$, Illingworth DP, Connor WE, Goodnight $S$.

Increased activity of factor VII and factor VII-phospholipid complex measured using a Normotest system in subjects with hyperlipidemia.

Haemostasis $1990 ; 20: 65-72$.

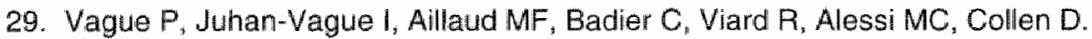

Correlation between blood fibrinolytic activity, plasminogen activator inhibitor level, plasma insulin level and relative body weight in normal and obese subjects.

Metabolism 1986; 35: 250-3.

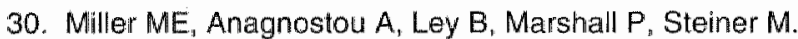

Effect of fish oil concentration on hemorrheological and hemostatic aspects of diabetes mellitus: a preliminary study.

hromb Res 1987; 47: 201-14.

31. Carlson LA, Böttiger LE.

Ischaemic heart disease in relation to factual values of plasma triglycerides and cholesterol. Lancet 1972 ; i: 865-8.

32. Aberg $H_{\text {, Lithell }} H$, Selinus I, Hedstrand $H$.

Serum triglycerides are a risk factor for myocardial infarction but not for angina pectoris.

Results from a 10-year follow-up of Uppsala primary preventive study.

Atherosclerosis $1985 ; 54: 89-97$.

33. Páramo JA, Colucci $M$, Collen D.

Plasminogen activator inhibitor in the blood of patients with coronary artery disease.

Br Med J 1985; 291: 573-4.

34. Mehta J, Menta P, Lawson D, Saldeen T.

Plasma tissue plasminogen activator inhibitor levels in coronary artery disease: correlation with age and serum triglyceride concentrations.

J Am Coll Cardiol 1987; 9:263.

35. Klein R, Klein BEK, Moss SE, Davis MD, DeMets DL.

Glycosylated hemoglobin predicts the incidence and progression of diabetic retinopathy.

J Am Med Assn 1988; 260: 2864-71. 


\section{Chapter 8}

\section{Summary and conclusions}

In this thesis, the correlations between coagulation and fibrinolysis and, among other lipid parameters, lipoprotein(a) are described in patients with hypertension and in patients with diabetes mellitus. In the diabetic patient groups these parameters have been investigated in relation to the urinary albumin excretion rate, whereas $L p(a)$ has also been studied in relation to coagulation and fibrinolysis parameters in patients with acute deep venous thrombosis.

Chapter 1 gives a review of lipoprotein(a) or $L p(a)$, which was identified as a distinct lipid fraction in 1963 by K. Berg. In the 1970's Lp(a) was determined as being identical with 'sinking' pre-beta-lipoprotein or pre-beta,-lipoprotein, and high Lp(a) plasma levels were associated with coronary artery disease. The distribution of $L p(a)$ among various populations appeared to be highly skewed, with predominantly low levels. In the 1980's Lp(a) was shown to consist of an LDL-like particle and a unique glycoprotein, apolipoprotein(a) or apo(a), attached to the apo B-100 moiety of the lipid particle by disulphide bridging. Several studies, some including coronary arteriography, confirmed $L p(a)$ as an independent risk factor for cardiovascular and cerebrovascular disease.

Whether or not $L p(a)$ has a physiological function is still unknown, but the absence of $L p(a)$ in plasma has not been reported to cause any kind of disease or noticeable deficiency state. The liver appears to be the major, if not the exclusive, production site of $L p(a)$. $L p(a)$ catabolism is reported to occur at constant rates and is not related to $L p(a)$ concentrations. However, a positive correlation thas been assessed between the serum concentration and synthesis rate of $L p(a)$. Age, gender, diet and drugs (with a few exceptions) appear to have no substantial effect on $L p(a)$ levels. A race dependency has been demonstrated by high $L p(a)$ values in a black American population.

The homology of apo(a) with plasminogen at protein and CDNA level discovered by the research groups of Eaton and McLean in 1987 is regarded as an important breakthrough in $L p(a)$ research. Plasminogen consists of a protease domain and five different sequentially repeated homologous domains called kringles. Kringles are glycopeptides containing approximately a hundred aminoacids with a pretzel-like structural appearance. Apo(a) contains one kringle domain homologous to kringle 5 and up to 37 kringle domains homologous to kringle 4. Furthermore, the serine protease domain of apo(a) is highly homologous to its counterpart in plasminogen. The apo(a) gene is localized to chromosome 6 , adjacent to the plasminogen encoding gene. Six 
apo(a) isoforms have been found according to their relative electrophoretic mobility compared with apo B-100: F (faster than apo B-100), B (similar to apo B-100) and S1, S2, S3, S4 (slower than apo B-100). Isoforms F, B, S1 and S2 have been associated with low apo(a) molecular weights and high $L p(a)$ levels, whereas isoforms $\mathrm{S3}$ and $\mathrm{S} 4$ have been associated with high apo(a) molecular weights and low $L p(a)$ values. Each individual expresses either one or two of these isoforms.

The homology of apo(a) with plasminogen, together with the established lack of fibrinolytic capacity due to one amino acid substitution at the cleavage site of the molecule, has given rise to speculations that $L p(a)$ might interfere with the profibrinolytic function of plasminagen. In vitro studies supporting this hypothesis are rapidly accumulating.

When we focus on the importance of $L p(a)$ in medical practice in 1992 we have to consider that standardization of plasma $L p(a)$ determinations has not yet been achieved and that the effects of drug-induced $L p(a)$ reduction on cardiovascular disease are unknown. Furthermore, the only eventually appropriate $L p(a)$ reducing drug, nicotinic acid, shows serious side effects. Therefore, routine plasma $L p(a)$ determinations on a large scale are not indicated at the moment. High $L p(a)$ levels should be regarded in relation to the overall risk profile of the individual patient and may be used as an additional argument for the treatment of other risk factors.

As has been mentioned above, numerous in vitro studies report an interference of $L p(a)$ with fibrinolysis but data concerning the effect of $L p(a)$ on the plasma fibrinolytic system in vivo are scarce. We therefore studied the correlations between $L p(a)$ and several haemostasis parameters in patients with acute deep venous thrombosis (DVT) and in patients with hypertension or diabetes mellitus, all known to be more or less states typified by an activated coagulation system and reactive fibrinolysis whereas hypertension and diabetes mellitus also predispose to atherogenesis.

In chapter 2 the correlations between $L p(a)$ and the haemostasis parameters fibrin monomers, thrombin-antithrombin III complexes (TAT), D-dimers, tissue plasminogen activator antigen (t-PA) and plasminogen in 31 patients with acute DVT are reported. The median time span from the onset of symptoms to the confirmation of the diagnosis by real-time B-mode ultrasonography was 2 days (range: 1-7 days). Grossly elevated values for TAT and D-dimer were found in all patients. Elevated values of fibrin monomers, t-PA and plasminogen were found in $97 \%, 32 \%$ and $48 \%$ of the patients, respectively. Strong positive correlations were found for fibrin monomers and TAT with D-dimers $(r=0.56, p=$ 0.002 and $r=0.68, p=0.0002)$, TAT and t-PA $(r=0.64, p=0.0006)$, whereas a weaker but nevertheless significant correlation between fibrin monomers and plasminogen $(r=0.38, p=0.003)$ was also found. These data indicate a normally functioning coagulation/fibrinolysis axis in patients with acute DVT. A correlation between $L p(a)$ and the coagulation and fibrinolysis variables was not found, which suggests that variations in $L p(a)$ concentrations are not accompanied by parallel changes in coagulation or fibrinolysis parameters. 
In chapter 3 the correlations of $L p(a)$ with other blood lipids (serum cholesterol, LDL-cholesterol, HDL-cholesterol and triglycerides), coagulation parameters (fibrinogen, factor VII, factor VIIllc, fibrin monomers, TAT) and fibrinolysis parameters (t-PA, plasminogen activator inhibitor-1 (PAl-1) and D-dimers) are described in 54 patients with essential hypertension, in 65 non-insulindependent diabetic patients and in 116 insulin-regulated diabetic patients. Lp(a) values in the hypertensive patients were significantly elevated with a median value of $122 \mathrm{mg} / \mathrm{l}$ compared with $44 \mathrm{mg} / / \mathrm{in}$ a healthy reference group ( $\mathrm{p}<$ 0.0001 ). In the diabetic patient groups, $L p(a)$ values did not significantly differ from those in the reference group. A weak positive correlation between Lp(a) and LDL-cholesterol was found in the hypertensive patients $(r=0.25, p=0.04)$ and in the insulin-regulated diabetic patients $(r=0.20, p=0.03)$, whereas $\operatorname{Lp}(a)$ was negatively correlated with triglycerides in the hypertensive patients ( $r=$ $-0.30, p=0.03$ ).

More or less obvious signs of an activated coagulation system and reactive fibrinolysis were encountered in all three patient groups. In the hypertensive patient group and in both diabetic patient groups no correlation could be found between $L p(a)$ values and the haemostasis parameters investigated.

Chapter 4 describes the haemostasis and lipid parameters in 43 treated and 11 untreated hypertensive patients. The treated hypertensive patients included in this study were still hypertensive despite treatment with antihypertensive drugs. Lipid values (Quetelet-index, serum cholesterol, LDL-cholesterol, HDLcholesterol, triglycerides, lipoprotein(a), coagulation parameters (fibrinogen, $F$ VIIIc, F VIII VWF, F VII, fibrin monomers, thrombin-antithrombin III complex) and fibrinolysis parameters (plasminogen, $\alpha_{2}$-antiplasmin, tissue plasminogen activator (t-PA) antigen and activity, plasminogen activator inhibitor-1 (PAl-1) and D-dimers) did not significantly differ between the treated and untreated patients. The blood lipid profile was disadvantageous with elevated values for serum triglycerides, LDL-cholesterol and lipoprotein(a) in $46 \%, 28 \%$ and $28 \%$ of the hypertensive patients, respectively.

In comparison with the values in the reference group, the coagulation parameters VII, VIIIC, fibrin monomers and thrombin-antithrombin III were significantly elevated and compatible with an activation of the coagulation system in these patients. Correlations were found between systolic blood pressure and serum cholesterol $(r=0.43, p=0.003)$, LDL-cholesterol $(r=0.34, p=$ $0.02)$ and triglycerides $(r=0.35, p=0.01)$. The Quetelet-index was correlated with fibrinogen ( $r=0.37, p=0.02)$ and thrombin-antithrombin III $(r=0.30, p=0.04)$ whereas triglycerides were correlated with $F$ VII $(r=0.34, p=0.03)$ and fibrin monomers ( $r=0.29, p=0.04$ ), respectively.

Compared with findings in the reference group the hypertensive patient group showed significantly elevated values for the fibrinolytic variables PAI-1, tissue plasminogen activator antigen, $\alpha_{2}$-antiplasmin and D-dimers. Tissue plasminogen activator activity was grossly decreased in the hypertensive patients. Triglycerides were correlated with tissue plasminogen activator antigen $(r=0.44, p=0.003)$ and with PAl-1 $(r=0.47, p=0.004)$, whereas the Quetelet- 
index was correlated with tissue plasminogen activator antigen $(r=0.32, p=0.03)$. Elevated PAll-1 levels and decreased tissue plasminogen activator activity are signs of an inhibited fibrinolysis. These data link hypertension and hyperlipidaemia with increased coagulation activity and inhibition of fibrinolysis, and may hereby contribute to the understanding why these two cardiovascular risk factors facilitate the progression of atherogenesis.

In chapter 5 the results of prothrombin fragment 1.2, factor VII, fibrin monomers and thrombin-antithrombin III (TAT) determinations in the hypertensive patient group mentioned in chapter 4 are reported. Prothrombin conversion to thrombin mediated by the prothrombinase complex (factor $\mathrm{Xa}, \mathrm{Va}$, calcium and phospholipid) is the key event in blood coagulation and produces a peptide designated prothrombin fragment 1.2 (F 1.2). The F 1.2 plasma level can be regarded as an indication of the activity of the prothrombinase complex and a recently developed ELISA method has made it possible to determine $F 1.2$ concentrations. F 1.2 levels were significantly increased in the hypertensive patients with a median vallue of $1.47 \mathrm{nmol} / \mathrm{l}$ versus $0.66 \mathrm{nmol} / \mathrm{l}$ in the reference group $(p<0.0001)$. The enhanced values of $F 1.2$ in these patients were more pronounced than the elevations in TAT or fibrin monomers and might indicate that $F 1.2$ is a more sensitive indicator of coagulation activity than the two latter parameters. Together with $F$ VII the $F 1.2$ elevation was of greater magnitude in the male patients than in the females. $F 1.2$ was correlated with fibrin monomers ( $r=0.33, p<0.03$ ) but not with other coagulation parameters, blood pressure, age or duration of hypertension. The elevated $F 1.2$ levels in this hypertensive patient group confirm the presence of an activated coagulation system in hypertension, which might be a primary or a secondary phenomenon.

In chapter 6 the correlations between glycometabolic control, lipid parameters, coagulation parameters and the urinary albumin excretion rate are reported in 65 non-insulin-dependent diabetes mellitus (NIDDM) patients. In comparison with a healthy control group, increased serum triglycerides and slightly decreased HDL-cholesterol values were found in the NIDDM patient group. The coagulation parameters showed increased values for fibrinogen, fibrin monomers, thrombinantithrombin III, F VIIIC and, in the male patients only, F VII. The $\mathrm{HbA}_{1 \mathrm{C}}$ values were only correlated with ATIII $(r=0.27, p<0.03)$, but showed a tendency towards a correlation with lipoprotein(a) levels $(r=0.23, p<0.07)$.

Triglycerides were correlated with the Quetelet-index $(r=0.27, p<0.03)$, HDLcholesterol $(r=-0.41, p<0.001)$ and $F V I I(r=0.35, p<0.01)$ whereas serum cholesterol concentrations were correlated with $F$ VII $(r=0.27, p<0.04)$ and fibrin monomers $(r=0.29, p<0.03)$. Twelve patients $(18.5 \%)$ showed microalbuminuria (a urinary albumin excretion rate between 20 and $200 \mu \mathrm{g}$ per min). The urinary albumin excretion rate was not correlated with any other parameter studied.

In this NIDDM patient group, glycometabolic control appeared to have no substantial influence on the extent of activation of the coagulation system nor on the presence or degree of microalbuminuria. These results may provide clues to the pathophysiological mechanisms of cardiovascular risk factors NIDDM and 
hyperlipidaemia and give circumstantial support for the more stringent control measures advised in the treatment of hyperlipidaemia in NIDDM patients.

Chapter 7 describes the relationship of microalbuminuria with lipid, glycometabolic, coagulation and fibrinolysis parameters in 116 insulin-treated diabetic patients. The urinary albumin excretion rate appeared to be only correlated with $\mathrm{HbA}_{1 \mathrm{c}}(r=0.23, p=0.008)$ and D-dimer concentrations $(r=0.28$, $\mathrm{p}=0.002$ ). In comparison with the normoalbuminuric diabetic patient group ( $\mathrm{n}=$ 85), $\mathrm{HbA}_{1 c}$ values and $\mathrm{D}$-dimer levels were enthanced in the microalbuminuric diabetic patients $(n=31)$ whereas HDL-cholesterol was decreased. The application of a Receiver Operating Characteristic (ROC) curve for $\mathrm{HbA}_{10}$ against microalbuminuria (cut-off level $20 \mu \mathrm{g} / \mathrm{min}$ ) reconfirmed the association of poor glycaemic control in diabetics with the presence of microalbuminuria. In conlusion, these results show a significantly poorer glycaemic control in the patients with microalbuminuria than in the normoalbuminuric diabetic patients. The presence of lower HDL-cholesterol and elevated D-dimer levels was more pronounced in the micro-albuminuric group. No direct correlation could, however, be found between the coagulation and fibrinolysis factors measured and the degree of microalbuminuria in this insulin-regulated diabetic patient group.

\section{Based on the results reported in this thesis the following conclusions can be drawn:}

- There is no evidence for an association of lipoprotein(a) concentrations with coagulation or fibrinolysis parameters in vivo in the patient groups with acute deep venous thrombosis, essential hypertension or diabetes mellitus.

- In the hypertensive patient group increased plasma prothrombin fragment 1.2 concentrations were found.

- In the patients with essential hypertension and in the diabetic patient groups the increased values of the coagulation and fibrinolysis parameters measured are indicative of an activated coagulation system and a reactive fibrinolysis.

- Plasma prothrombin fragment 1.2 concentrations might give a more sensitive indication of coagulation activity than fibrin monomers or thrombin-antithrombin IIf levels.

- The increased plasminogen activator inhibitor-1 concentrations and decreased tissue plasminagen activator activity assessed in the hypertensive patient group are signs of inhibited fibrinolysis in these patients.

- In the hypertensive patient group the correlations between blood pressure, lipid parameters, and coagulation and fibrinolysis factors agree with a multifactorial interaction of cardiovascular risk factors.

- The relation between the level of glycometabolic control, as indicated by $\mathrm{HbA}_{1 \mathrm{c}}$ values, and lipoprotein(a) concentrations in diabetic patients is still unclear. 
- The extent of activation of the coagulation system in the NIDDM patient group is not substantially affected by glycometabolic control, as indicated by $\mathrm{HbA}_{1 \mathrm{c}}$ values.

- In the NIDDM patient group the presence or degree of microalbuminuria is not related to glycometabolic control as indicated by $\mathrm{HbA}_{1 \mathrm{c}}$ values and not associated with higher $L p(a)$ concentrations.

- In the insulin-regulated diabetic patient group microalbuminuria is associated with poorer glycaemic control, lower HDL-cholesteral values and higher Ddimer concentrations. 


\section{Chapter 9}

\section{Samenvatting en conclusies}

In dit proefschrift worden de correlaties beschreven tussen verschillende stollings- en fibrinolyseparameters en de lipiden waaronder het lipoproteine(a) bij patiënten met hypertensie en bij patiënten met diabetes mellitus. Bij de laatste patiëntengroep zijn de genoemde parameters onderzocht in relatie met de albumenuitscheiding in de urine. Bij een patiëntengroep met acute diepe veneuze thrombose is de relatie tussen lipoproteine(a) en de stollings- en fibrinolyseparameters beschreven.

Hoofdstuk 1 is een overzichtsartikel over lipoproteine(a) of $L p(a)$, dat in 1963 als een aparte lipidenfractie ontdekt werd door $\mathrm{K}$. Berg. In de jaren zeventig werd vastgesteld dat Lp(a)-identiek was aan het "sinking" pre-beta-lipoproteine of thet pre-beta ${ }_{1}-$ lipoproteine en werden hoge $L p(a)$ plasmaconcentraties geassocieerd met coronaire hartziekten $(\mathrm{CHZ})$.

De verdeling van $L p(a)$-waarden onder de bevolking bleek asymmetrisch met overwegend lage concentraties. In de jaren 80 werd vastgesteld dat $L p(a)$ bestaat uit een op LDL gelijkend vetdeeltje met hieraan gekoppeld het apolipoproteïne(a) of apo(a), een uniek glycoproteine. In grote studies, waarvan sommige gedocumenteerd met coronaire angiografie, werd $L p(a)$ bevestigd als een onafhankelijke risicofactor voor $\mathrm{CHZ}$ en cerebrovasculaire aandoeningen en voor $\mathrm{CHZ}$ in grootte vergelijkbaar met LDL-cholesterol.

Een fysiologische rol van $L p(a)$ is niet bekend, maar onmeetbaar lage $L p(a)-$ concentraties gaan voor zover bekend niet gepaard met ziekte of merkbare deficiënties. De synthese van $L p(a)$ lijkt vrijwel geheel te geschieden in de lever. Het Lp(a)-katabolisme is in tegenstelling tot de synthese niet gecorreleerd met Lp(a)-plasmaconcentraties. Leeftijd, geslacht dieet en medicatie (met enkele uitzonderingen) bleken geen duidelijk effect te hebben op plasma Lp(a)concentraties. Hoge Lp(a)-waarden vastgesteld in een zwarte populatie in Houston in de V.S. duiden wel op interraciale verschillen.

De in 1987 met moleculair-biologisch onderzoek door de onderzoeksgroepen van Eaton en McLean vastgestelde homologie tussen apo(a) en plasminogeen wordt beschouwd als een belangrijke doorbraak in Lp(a)-research. Plasminogeen bestaat uit een serineprotease en 5 aaneengeschakelde verschillende 'kringles'. Kringles zijn glycopeptiden welke rond de 100 aminozuren bevatten die door interne disulfiede bruggen een krakeling-achtige ruimtelijke structuur bezitten. Apo(a) bevat 1 kringle gelijkend op kringle 5 en 14 tot 37 kringles gelijkend op kringle 4 . Het serineprotease domein van apo(a) is voor $94 \%$ homoloog aan dat van plasminogeen. Het apo(a)-gen is gelocaliseerd 
op chromosoom 6 dichtbij het gen dat codeert voor plasminogeen. Met electroforese kunnen 6 apo(a)-isovormen onderscheiden worden: $F$ ("faster' dan apo B-100), B (gelijk aan apo B-100) en S1, S2, S3, S4 ('slower' dan apo B100). Isovormen $F, B, S 1$ en $S 2$ vertonen een laag molecuulgewicht en hoge $L p(a)$ plasmaconcentraties, terwijl voor de isovormen S3 en S4 het omgekeerde geldt. Per individu worden 1 of 2 isovormen gezien.

De homologie van apo(a) met plasminogeen, tezamen met de afwezigheid van fibrinolytische capaciteit van apo(a) door een aminozuur substitutie ter plaatse van het activeringscentrum vari het molecuul, heeft aanleiding gegeven tot de suggestie van een mogelijke interferentie van $L p(a)$ met het pro-fibrinolytisch vermogen van plasminogeen. Deze hypothese vindt steun in vele recente publicaties van in vitro onderzoek.

Bij het bepalen van de relevantie van het $L p(a)$ voor de dagelijkse medische praktijk in 1992 blijkt dat er nog geen uniforme gestandaardiseerde Lp(a)bepaling ter beschikking staat, dat het effect van medicamenteus geinduceerde $\mathrm{Lp}(\mathrm{a})$-reductie op het voorkomen van $\mathrm{CHZ}$ niet bekend is en dat nicotinezuur, het enige hiervoor momenteel geschikt geachte en beschikbare medicament, ernstige en hinderlijke bijwerkingen vertoont. Op grond van deze overwegingen moet geconcludeerd worden dat $L p(a)$-bepalingen op grote schaal momenteel nog niet geïndiceerd zijn. Voor de individuele patiënt zou een hoge $L p(a)$ plasmaconcentratie bekeken moeten worden tegen de achtergrond van zijn totale cardiovasculaire risicoprofiel als een additioneel argument voor de behandeling van andere risicofactoren.

Zoals boven vermeld zijn er recent veel publicaties verschenen die een interferentie van $L p(a)$ op de fibrinolyse in in vitro melden. Over de relatie van $\mathrm{Lp}(\mathrm{a})$ met het plasma fibrinolytisch systeem in vivo is slechts sporadisch gepubliceerd. Wij hebben daarom naar correlaties gezocht tussen $L p(a)$ en verschillende haemostasis parameters bij patiënten met acute diepe veneuze thrombose (DVT), bij patiënten met essentiële hypertensie en bij patiënten met diabetes mellitus. Van deze patiëntengroepen is in meerdere of mindere mate een geactiveerd stollingssysteem met een reactief toegenomen fibrinolyse beschreven terwijl hypertensie en diabetes mellitus predisponeren voor het ontstaan van atherosclerose.

In hoofdstuk 2 worden de correlaties tussen Lp(a) en de haemostasis parameters fibrinemonomeren, thrombine-antithrombine III complex (TAT), Ddimeer, weefsel plasminogeen activator antigeen (t-PA) en plasminogeen in 31 patiënten met acute DVT beschreven. De mediane tijdsduur tussen het ontstaan van de symptomen en de bevestiging van de diagnose met real-time B-mode ultrasonografie was 2 dagen (spreiding: 1-7 dagen). Bij iedere patiënt werden sterk verhoogde TAT- en D-dimeerconcentraties gevonden. Fibrinemonomeren, I-PA en plasminogeen waren verhoogd in respectievelijk $97 \%, 32 \%$ en $48 \%$ van de patiënten. Sterke positieve correlaties werden vastgesteld voor fibrinemonomeren en TAT met D-dimeer $(r=0,56, p=0,002$ en $r=0,68, p=$ $0,0002)$ en TAT met $t-P A(r=0,64, p=0,0006)$. Een zwakkere correlatie bestond tussen fibrinemonomeren en plasminogeen $(r=0,38, p=0,003)$. Deze gegevens 
wijzen op een adequaat functionerende stollings- en fibrinolyse-as in patienten met acute DVT. Er werd geen correlatie tussen $L p(a)$ en de onderzochte haemostasisparameters gevonden. Aanwijzingen voor een relatie van $\mathrm{LP}(\mathrm{a})-$ concentraties met het fibrinolytisch systeem werden in dit onderzoek niet waargenomen.

In hoofstuk 3 worden de correlaties beschreven tussen Lp(a) en overige bloedvetten (serum cholesterol, LDL-cholesterol, HDL-cholesterol en triglyceriden), stollingsparameters (fibrinogeen, factor VII, factor VIIlc, fibrinemonomeren en TAT) en fibrinolytische parameters ( $t$-PA antigeen, plasminogeen-activator-inhibitor-1 (PAl-1) en D-dimeer) bij 54 patiënten met essentiële hypertensie, bij 65 niet-insuline-afhankelijke diabetes mellitus (NIDDM) patiënten en bij 116 met insuline behandelde patiënten met diabetes mellitus. In vergelijking met een controlegroep bestaande uit 50 gezonde vrijwilligers werden verhoogde $L p(a)$-plasmaconcentraties vastgesteld in de hypertensiegroep met een mediane waarde van $122 \mathrm{mg} / \mathrm{l}$ tegen $44 \mathrm{mg} / \mathrm{l}$ in de controlegroep ( $p<0,0001)$. De $L p(a)$-waarden in beide patiëntengroepen met diabetes mellitus waren niet significant verschillend van die van de controlegroep. In de patiëntengroepen met hypertensie en insuline gereguleerde diabetes mellitus werden zwakke correlaties gevonden tussen $L p(a)$ en LDLcholesterol $(r=0,25, p=0,04$ en $r=0,20, p=0,03)$. In de groep hypertensiepatiënten werd voorts een zwakke negatieve correlatie tussen Lp(a) en triglyceriden vastgesteld $(r=-0,30, p=0,03)$. In alle patiëntengroepen werden in meerdere of mindere mate aanwijzingen gevonden voor een geactiveerd stollingssysteem met reactieve fibrinolyse. In geen van de beschreven patiëntengroepen werd een correlatie tussen $\mathrm{Lp}(\mathrm{a})$ en de onderzochte haemostasisparameters gevonden. Deze resultaten leveren geen aanwijzingen voor het bestaan van een verband tussen $L p(a)$-concentraties en stollings- en/of fibrinolyseparameters. Zij bevestigen de aanwezigheid van een geactiveerd stollingssysteem in patienten met hypertensie of diabetes mellitus.

Hoofdstuk 4 beschrijft vetstofwisselings-, stollings- en fibrinolyseparameters bij 43 medicamenteus behandelde en 11 onbehandelde patiënten met essentiële hypertensie. De met antihypertensiva behandelde patiënten waren ondanks de medicatie hypertensief ten tijde van het onderzoek. Lipiden (Quetelet-index, serum cholesterol, LDL-cholesterol, HDL-cholesterol, triglyceriden en lipoproteine(a)), stollingsparameters (fibrinogeen, F VIIIc, F VIII VWF, F VII, fibrinemonomeren, thrombine-antithrombine lll-complex) en fibrinolyseparameters (plasminogeen, $\alpha_{2}$-antiplasmine, weefsel-plasminogeen-activator (t-PA)-antigeen en activiteit, plasminogeen-activator-inhibitor-1 (PAI-1) en $D$-dimeer) waren in de behandelde en niet behandelde patiënten niet significant verschillend. De hypertensiepatiënten vertoonden een lipidenspectrum met verhoogde waarden voor triglyceriden, LDL-cholesterol en lipoproteine(a) in respectievelijk $46 \%, 28 \%$ en $28 \%$ van de patiënten. Bij de hypertensiepatiënten werden in vergelijking met de referentiegroep voor de stollingsfactoren $F$ VII, $F$ VIllc, fibrinemonomeren en TAT significant verhoogde waarden gemeten 
passend bij een geactiveerd stollingssysteem. Correlaties werden gevonden tussen systolische bloeddruk en respectievelijk het serumcholesterol $(r=0,43$, $p=0,0003)$, LDL-cholesterol $(r=0,34, p=0,02)$ en triglyceriden $(r=0,35, p=0,01)$. De Quetelet-index correleerde met fibrinogeen $(r=0,37, p=0,02)$ en met TAT $(r=0,30, p=0,04)$. Voorts bestond er een correlatie tussen serumtriglyceriden met $F$ VII $(r=0,34, p=0,03)$ en met fibrinemonomeren $(r=0,29, p=0,04)$.

In vergelijking met de referentiegroep werden bij de hypertensiepatiënten verhoogde concentraties gemeten voor de fibrinolyse parameters PAl-1, t-PA antigeen $\alpha_{i}$-antiplasmine en D-dimeer terwijl de t-PA-activiteit sterk verlaagd was. Correlaties werden gevonden tussen triglyceriden en respectievelijk t-PA antigeen $(r=0,44, p=0,003)$ en PAl- $1(r=0,47, p=0,004)$ en tussen de Queteletindex en t-PA-antigeen $(r=0,32, p=0,03)$. Verhoogde PAl-1-concentraties en verlaagde $t-P A$-activiteit wijzen op een overheersende remming van het plasmatisch fibrinolytisch systeem.

De resultaten van deze studie wijzen op een associatie van hypertensie met hyperlipidemie, met een activatie van het stollingssysteem en met een remming van de fibrinolyse. Deze toestand van zogenaamde 'hypercoagulabiliteit' zou een bijdrage kunnen leveren aan het atherogene mechanisme van deze cardiovasculaire risicofactoren.

In hoofdstuk 5 worden in dezelfde groep hypertensiepatiënten de stollingsparameters prothrombine fragment 1.2, factor VII, fibrinemonomeren en TAT beschreven. Bij de conversie van prothrombine naar het actieve thrombine onder invloed van het prothrombinase complex (factor $\mathrm{Xa}, \mathrm{Va}$, calcium en fosfolipiden) komt het peptide prothrombine fragment 1.2 (F 1.2) vrij. De $F 1.2$ plasmaconcentratie, welke bepaald kan worden met een recent ontwikkelde ELISA methode, kan beschouwd worden als een indicator van de activiteit van het prothrombinase complex. De F 1.2 concentraties waren significant verhoogd in de groep van hypertensiepatiënten met een mediane waarde van $1,47 \mathrm{nmol} / \mathrm{l}$ tegenover $0,66 \mathrm{nmol} / \mathrm{l}$ in de controlegroep $(p<0,0001)$. De F1.2 concentraties waren, in vergelijking met de waarden gemeten voor TAT en fibrinemonomeren, bij deze patiënten in sterkere mate verhoogd, hetgeen zou kunnen betekenen dat $F 1.2$ een gevoeliger indicator is voor stollingsactiviteit dan beide andere parameters. In vergelijking met de vrouwelijke patiënten werden bij de mannelijke hypertensiepatiënten hogere concentraties voor $F$ VII en $F 1.2$ concentraties gezien. Er bestond een correlatie tussen $F 1.2$ concentraties en fibrinemonomeren $(r=0,33, p<0,03)$ maar niet met de andere onderzochte stollingsparameters, bloeddruk, leeftijd of bekende duur van de hypertensie. De verhoogde $F 1.2$ concentraties in deze groep hypertensiepatiënten is een bevestiging van de aanwezigheid van een geactiveerd stollingssysteem in hypertensiepatiënten. Het is momenteel nog niet duidelijk of dit een primair dan wel een secundair fenomeen is.

In hoofdstuk 6 worden de correlaties tussen glycometabole controle, lipiden, stollingsparameters en de albumenexcretie in de urine bij 65 patiënten met nietinsuline-afhankelijke diabetes mellitus (NIDDM) beschreven. Alle patiënten werden behandeld met dieet en orale antidiabetica. In vergelijking met de 
controlegroep werden verhoogde triglyceriden en licht verlaagde HDL. cholesterol concentraties gemeten. De stollingsparameters toonden verhoogde waarden voor fibrinogeen, fibrinemonomeren, thrombine-antithrombine III complex (TAT), factor VIllc en, bij de mannelijke NIDDM patiënten, ook verhoogde $F$ VII waarden. Het $H_{b A_{1}}$ bleek alleen gecorreleerd met antithrombine III $(r=0,27, p<0,03)$ en vertoonde een tendens naar een correlatie met lipoproteine(a)-concentraties $(r=0,23, p<0,07)$. Voorts werden correlaties waargenomen tussen triglyceriden en respectievelijk de Quetelet-index $(r=0,27$, $p<0,03)$, het HDL-cholesterol $(r=-0,41, p<0,001)$ en factor VII $(r=0,35, p<$ 0,01 ) en tussen serum cholesterol concentraties en respectievelijk factor VII ( $r=$ $0,27, p<0,04)$ en fibrinemonomeren $(r=0,29, p<0,03)$.

Twaalf patiënten $(18,5 \%)$ vertoonden microalbuminurie (een albumenexcretie in de urine van $20-200 \mu \mathrm{g} /$ minuut) die niet met een van de andere onderzochte parameters gecorreleerd bleek. Bij deze groep van NIDDM patiënten bleek de glycometabole controle niet gerelateerd aan de mate van stollingsactiviteit of aan de aanwezigheid en/of grootte van microalbuminurie.

Deze gegevens kunnen een bijdrage leveren aan het inzicht in de pathofysiologische mechanismen die ten grondslag liggen aan de micro- en macroangiopathie bij NIDDM tengevolge van de NIDDM zelf en door de hyperlipidemie. Indirect geven zij steun aan de aanbevolen stringente behandeling van hyperlipidemie bij patiënten met diabetes mellitus.

Hoofdstuk 7 beschrijft het verband tussen microalbuminurie en lipiden, glycometabole-, stollings- en fibrinolyseparameters in 116 met insuline behandelde patiënten met diabetes mellitus. De hoogte van de gemeten albumenexcretie in de urine bleek alleen gecorreleerd met $\mathrm{HbA}_{1 c}(r=0,23$, $p=0,008)$ en $D$-dimeerconcentraties $(r=0,28, p=0,002)$. In vergelijking met de normoalbuminurische patiënten $(n=85)$ vertoonden de microalbuminurische diabeten $(n=31)$ verhoogde $\mathrm{HbA}_{1 \mathrm{c}}$ - en $\mathrm{D}$-dimeerconcentraties en een verlaagd HDL-cholesterol. Toepassing van een Receiver Operating Characteristic (ROC) curve voor $\mathrm{HbA}_{1 \mathrm{c}}$ uitgezet tegen microalbuminurie (afkappunt $20 \mu \mathrm{g} / \mathrm{min}$ ) bevestigde de associatie van een slechte glycometabole controle met het optreden van microalbuminurie. Concluderend werden bij patiênten met microalbuminurie een slechtere glycometabole controle, lagere HDL-cholesterol waarden en hogere $\mathrm{D}$-dimeerconcentraties gemeten dan bij normoalbuminurische patiënten met diabetes mellitus. Er was echter geen sprake van een correlatie tussen de albumenexcretie in de urine en de onderzochte stollings- en fibrinolyseparameters bij deze groep van met insuline behandelde patiènten met diabetes mellitus.

\section{Op grond van de in dit proefschrift beschreven resultaten kunnen de volgende conclusies worden getrokken:}

- Er werden geen aanwijzingen gevonden voor het bestaan van een verband tussen lipoproteine(a)-concentraties en stollings- en/of fibrinolyseparameters bij patiënten met acute diepe veneuze thrombose, patiënten met essentiële hypertensie en patiënten met diabetes mellitus. 
- Patienten met essentiële hypertensie vertonen een verhoogdle prothrombine fragment 1.2 plasmaconcentratie.

- De verhoogde stollings- en fibrinolyseparameters welke gevonden werden bij patiënten met diabetes mellitus en bij hypertensiepatiënten wijzen op het voorkomen van een geactiveerd stollingssysteem met reactieve fibrinolyse bij deze patiëntengroepen.

- Het is mogelijk dat de plasma prothrombine fragment 1.2 concentratie een gevoeliger indicatie geeft van de mate van stollingsactiviteit dan fibrinemonomeren of thrombine-antithrombine III concentraties.

- De verhoogde concentratie van het plasminogeen-activator-inhibitor-1 (PAl-1) en verlaagde weefsel plasminogeen-activator (t-PA)-activiteit in het plasma van hypertensiepatiënten passen bij een overheersende remming van het plasma fibrinolytisch systeem van deze patiënten.

- De correlaties welke in de groep van de hypertensiepatiënten gevonden werden tussen bloeddruk, lipiden en stollings- en fibrinolyseparameters passen bij een multifactorieële interactie van cardiovasculaire risicofactoren.

- De relatie tussen de glycometabole contrale met als parameter het $\mathrm{HbA}_{1 \mathrm{c}}$ en plasma lipoproteine(a)-concentraties bij patiënten met diabetes mellitus is nog niet duidelijk.

- De activiteit van het stollingssysteem in de patiëntengroep met een nietinsuline-afhankelijke diabetes mellitus (NIDDM) was niet gerelateerd aan de mate van glycometabole controle met als parameter het $\mathrm{HbA}_{1 \mathrm{c}}$-percentage.

- In de NIDDM patiëntengroep was het optreden of de mate van microalbuminurie niet gerelateerd aan het niveau van de glycometabole controle met als parameter het $\mathrm{HbA}_{1 c}$-percentage en niet geassocieerd met hogere lipoproteine(a)-concentraties.

- In de groep van de met insuline behandelde patiënten met diabetes mellitus was het optreden van microalbuminurie geassocieerd met een slechtere glycometabole instelling $\left(\mathrm{HbA}_{1 \mathrm{c}}\right)$, een lager $\mathrm{HDL}$-cholesterol en met hogere $\mathrm{D}$ dimeerconcentraties. 


\section{Dankwoord}

Het in dit proefschrift beschreven onderzoek is verricht in het De WeverZlekenhuis op de afdeling Interne Geneeskunde en op het Haematologisch Laboratorium. Hierbij was de welwillende medewerking van de patiënten van cruciaal belang.

Eenieder die een bijdrage geleverd heeft aan de totstandkoming van dit proefschrift op welke wijze dan ook wil ik hartelijk danken. Dit geldt in het bijzonder voor de volgende personen.

- Prof. dr. P.J.Brombacher, mijn promotor, heeft op kritische en tegelijkertijd voortvarende en efficiënte wijze de totstandkoming van het proefschrift begeleid.

- De heldere analyse en opbouwende kritiek van mijn promotor prof. dr. J.A. Flendrig bestreek het gehele proefschrift; van de indeling in hoofdstukken tot en met de literatuurverwijzingen.

- Mijn copromotor dr. J.W.J. van Wersch heeft de voorwaarden voor het realiseren van dit proefschrift gecreëerd en de totstandkoming ervan op perfecte wijze begeleid. Beste Jan, hiervoor dank ik je en ook voor je zeer gewaardeerde vriendschap.

- De maatschap Interne Geneeskunde en Gastro-enterologie, bestaande uit dr. E. Zeppenfeldt, J.A.van der Snoek, M.M.F. Fickers, dr.R.E. Nikkels, dr. F.A.Th. Lustermans, J. Rijken en dr. M.A.G. Pannebakker, heeft mij op loyale wijze in de gelegenheid gesteld dit proefschrift te bewerken tijdens mijn chef de clinique-schap in het De Wever-Ziekenhuis. Bovendien heeft dr. Frans Lustermans een actieve bijdrage geleverd aan het onderzoek, hetgeen tot uiting komt in het mede-auteurschap van bijna alle artikelen.

- Petra Hawinkels was de enthousiaste en razendsnelle spil bij de verwerking van alle gegevens tot artikelen, proefschrift, brieven en posters. Bedankt Petra, je was in één Wo(o)rd Perfect en geen 5.1, maar een tien!

- De dames van de polikliniek en het secretariaat Interne Geneeskunde, met name Anja Houbiers, Tanja Vissers en Thea Block, hebben door hun secretariële ondersteuning en instructie van de patiënten een belangrijke bijdrage aan het onderzoek geleverd.

- De coördinatie van het laboratoriumonderzoek was in goede handen bij de heren J. Schröder en W.Hanssen. De medewerkers van het Haematologisch Laboratorium hebben vele bepalingen voor mijn onderzoek verricht, waarvan 
het leeuwedeel op conscientieuze wijze verricht is door Yvonne Habets en John Smeets. De gecomputeriseerde bewerking van de onderzoeksgegevens geschiedde met de deskundige hulp van $R$. Kohnen. De layout van de onderzoeksprotocollen is gemaakt door Th. Many, de laboratoriumprotocollen zijn gemaakt door J. Marell.

- De medewerksters van de Medische Bibliotheek, Miriam Wetzels, Romy Clignet en Edith Wierts leverden een vakkundige en enthousiaste bijdrage aan het verwerven van de literatuur. Miriam Wetzels heeft bovendien de literatuurverwijzingen in het proefschrift gecontroleerd.

- Dr. B. Davies heeft het manuscript gezuiverd van ongewenste continentale en transatlantische invloeden en het op kleurrijke wijze veranderd in een echt Engelstalig proefschrift.

- De medeauteurs van de artikelen hebben elk op eigen wijze hun bijdrage geleverd.

- Dr. A.F.H. Stalenhoef en prof. dr. A.C. Nieuwenhuijzen Kruseman hebben respectievelijk hoofdstuk 1 en hoofdstuk 6 van kritisch en deskundig commentaar voorzien.

- Mijn ouders zijn altijd trouwe supporters geweest en dit was nu niet anders.

- Tot slot, lieve Ruth, wil ik jou danken voor je steun, je inzicht en het begrip, dat mijn werk zich niet alspeelt binnen kantooruren. Aan het proefschrift zal het niet meer liggen. 


\section{Curriculum vitae}

De schrijver van dit proefschrift werd geboren op 25 mei 1958 in Geleen. Het diploma gymnasium B werd behaald aan het St. Thomascollege te Venlo, waarna in 1976 werd aangevangen met de studie Geneeskunde aan de Katholieke Universiteit Nijmegen. Het doctoraalexamen werd behaald in 1981, het artsexamen in 1984.

Het eerste deel van zijn opleiding tot internist volgde hij van 1984 tot 1986 in thet St. Elisabeth Hospitaal te Willemstad "Curaçao (opleider: Prof. Dr. A.E.C. Saleh). Aansluitend werd de specialisatie voltooid in het Catharina Ziekenhuis te Eindhoven (opleider: Dr. H.F.P. Hillen).

$\mathrm{Na}$ zijn registratie als internist bij de SRC werkt hij sinds 1 januari 1990 als chef de clinique in het De Wever-Ziekenhuis te Heerlen, alwaar dit proefschrift bewerkt is.

Hij is getrouwd met Ruth Cijntje, zij hebben drie kinderen: Jean-Luc, Carène en Marc. 
ISBN 90-9005154-6

\section{Vormgeving: Hein Berendsen}

De Wever-Ziekenhuis, Bureau Public Relations

c) 1992

Met Appie Macintosh, font Helvetica, druk Van Hooren Heerlen

Nadruk verboden/ No part of this book may be reproduced in any form by print: photoprint microfilm or any other means without permission from the author: 